


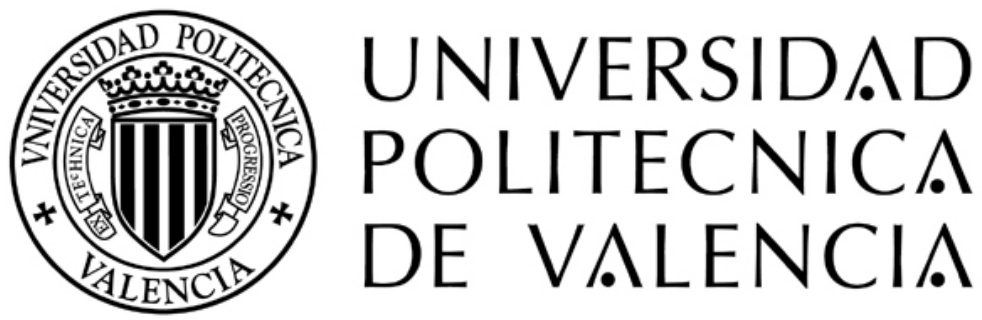

Departamento de Biotecnología
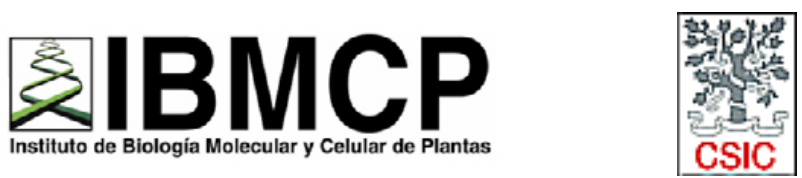

Instituto de Biología Molecular y Celular de Plantas (UPV-CSIC)

\section{Bases moleculares de la síntesis de termoespermina y sus implicaciones en el desarrollo vascular de Arabidopsis thaliana}

Trabajo presentado por Francisco Vera Sirera para optar al grado de Doctor en Biotecnología por la Universidad Politécnica de Valencia. Dirigido por Miguel Ángel Blázquez Rodríguez y Juan Carbonell Gisbert. 

El Dr. Miguel Ángel Blázquez Rodríguez, Investigador Científico del CSIC, y el Dr. Juan Carbonell Gisbert, Profesor de Investigación del CSIC, ambos pertenecientes al Instituto de Biología Molecular y Celular de Plantas (IBMCP, UPV-CSIC) de Valencia

CERTIFICAN que el Licenciado en Ingeniería Agronómica FRANCISCO VERA SIRERA ha realizado bajo su dirección en el Instituto de Biología Molecular y Celular de Plantas el trabajo que lleva por título "Bases moleculares de la síntesis de termoespermina y sus implicaciones en el desarrollo vascular de Arabidopsis thaliana", y autorizan su presentación para optar al grado de Doctor.

Y para que así conste, expiden y firman el presente certificado en Valencia, a 7 de marzo de 2011.
Dr. Miguel Ángel
Dr. Juan
Blázquez Rodríguez
Carbonell Gisbert 

El éxito es aprender a ir de fracaso en fracaso sin desesperarse.

Winston Churchill 

El hecho de escribir los agradecimientos de mi tesis ha resultado una tarea mucho más difícil de lo que me esperaba; en primer lugar, por el pánico a olvidarme de alguien, algo que sin duda haré, por lo que pido al lector que no encuentre su nombre entre estas líneas que por favor no sea muy duro conmigo, en segundo lugar, por el miedo a no saber expresar la gratitud que cada uno de los aquí citados merece, nunca se me ha dado bien traducir en letras los pensamientos que surgen por mi mente; y en tercer lugar, porque estas son las últimas líneas que escribo de esta tesis, y estoy deseando acabar ya con una guinda que, quería que fuese perfecta y que por fin he comprendido que no lo será. Así pues quisiera dar las gracias a:

- a Miguel, por haberme dado la oportunidad de realizar esta tesis, y por haberme ayudado a ver la luz cuando yo solo veía oscuridad. A Juan, por haber creído en mi, más que yo mismo. A Eugenio por haberme enseñado prácticamente todo lo que sé del laboratorio. Sin vuestro triunvirato esta tesis no habría sido posible.

- a todos los miembros pasados y presentes del L20, luego llamado $3.07 \mathrm{y}$ por último 2.07. A los Marta, Leo, David, Laura, Loli, Javi, Berta, Isabella, Andries, Jon Anders, Vero, Antonella, Espe, Nora, Iva, Juan Camilo y Mou; muchas gracias, habéis sido unos compañeros maravillosos.

- a todos aquellos miembros pertenecientes a esa categoría indefinida e indefinible llamada "4labos": Toni, Begoña, Cristina Martí, Cristina Úrbez, Carlos, José Luis, Miguel Ángel Pérez, María Jesús, Dolo, Clara, Carol, Yolanda, Eavan, Pablo, Raquel, Leandro, Sophie, Diego, Hugo, Asun, Sara, Paco Timoner, Lucas, Silvia, Vicente, Teresa, MD, Sonia, Amparo, Clara Fuster, Raquel, Carolina, Álex, José Manuel, Patricia , Paloma y alguno más que me olvidaré. No puedo cerrar este grupo sin citar a María Ángeles, la cual merecería todos mis elogios, pero de la que solo diré que es un ejemplo a seguir por mí y todos los demás. .

- a las que fueron nuestras vecinas de poyata durante los inicios del L20 "las chicas de Carmen", Pachi, Aurora, Pili, Sandra, Olga, y Leti. 
- $\quad$ al resto de miembros de los laboratorios y servicios del IBMCP.

- a aquellos que me han abierto sus laboratorios durante mis épocas de exilio voluntario, a Alberto Marina y toda la gente del Instituto de Biomedicina de Valencia (Patricia, Ana, Pepe, Isa, Marisa, Celso y Rebeca). y a Hannele Tuominen y los compañeros del Umeå Plant Science Center (Luis y Edouard).

- a todos aquellos laboratorios externos al IBMCP que nos han prestado materiales o servicios de los que nosotros no disponíamos como el Servicio de Cartografía Génica de la Universidad Miguel Hernandez de Elche, la Dra. Birgit Dräger, el Dr. François Parcy y el Dr. Keijiro Samejima.

- a Pedro y Emilio, esos dos científicos manchegos, compañeros de compras en Mercadona, limpiezas de baños y demás aventuras que surgen al compartir piso.

- a toda mi familia, tanto la de Elda con todos mis tíos y primos, como a mi nueva familia oreana, y especialmente a Antonio y Mónica, por haberme acogido como a uno más.

- a Mónica y Javi, porque sé que siempre estarán ahí cuando los necesite.

- a mi hermana Beatriz, porque aunque parezca imposible es la persona más parecida a mi del mundo.

- a mi abuelos Carmen y Santiago.

- a mis padres, Paco e Isabel, por haberme hecho lo que soy.

- a Aurora, por haber decidido compartir las alegrías y las miserias de esta vida conmigo. 
Dedicado a mi abuela Carmen, por todo lo pasado, jamás podré olvidarte; y dedicado mi hijo, por todo lo futuro, espero que nunca me olvides. 



\section{RESÚMENES}



Las poliaminas son pequeñas moléculas orgánicas policatiónicas presentes en todos los seres vivos. En las plantas regulan diversos procesos de desarrollo, como la floración, el crecimiento del tallo, la fructificación y la senescencia. La termoespermina es una tetraamina exclusiva de las plantas y procariotas cuya deficiencia, por la mutación del único gen responsable de su síntesis, ACL5, provoca un fenotipo enano en Arabidopsis thaliana, acompañado de graves defectos en la diferenciación de las células del metaxilema y una severa alteración en el patrón de formación de pared secundaria de los vasos.

Las aminopropil transferasas catalizan la síntesis de tri- y tetraaminas mediante la incorporación de un grupo aminopropilo a una di- o triamina, respectivamente. Estas aminopropil transferasas presentan un alto grado de similitud de secuencia entre sí, compartido además con las putrescina-Nmetiltransferasas, otro grupo de enzimas presentes exclusivamente en las solanáceas. Estudios filogenéticos han mostrado que las aminopropil transferasas y las putrescina-N-metil transferasas están emparentadas evolutivamente.

Los objetivos que nos planteamos en esta tesis fueron:

- establecer el mecanismo por el que la termoespermina controla la correcta formación del xilema; y

- determinar las diferencias estructurales entre las diversas aminopropil transferasas y putrescina-N-metiltransferasas, responsables de su especificidad.

El primer objetivo lo abordamos mediante la búsqueda de supresores extragénicos de acl5. De los 40 supresores dominantes aislados, 11 de ellos presentan mutaciones en la región 5 '-UTR de tres genes $b H L H$, a los que denominamos $A J A X$. Las mutaciones se localizan en una secuencia que codifica un pequeño péptido cuyo papel es reprimir la traducción de la ORF principal. Nuestros estudios in vitro indican que la supresión se consigue interfiriendo con la síntesis o la actividad de dicho pequeño péptido y permitiendo la síntesis de las proteínas AJAX. El papel de estos factores de transcripción en la regulación de la expresión génica durante el desarrollo del xilema solapa en parte con el de la termoespermina, pero no completamente, según indican los análisis transcriptómicos efectuados en plantas superproductoras de AJAX2.

El segundo objetivo se abordó mediante la comparación de los centros activos de las aminopropil transferasas y las putrescina-N-metil transferasas, y la identificación de aminoácidos potencialmente clave para sus actividades diferenciales. Se produjeron las correspondientes aminopropil transferasas recombinantes de Arabidopsis en sus versiones nativa y con los residuos clave mutados como en una putrescina-N-metil transferasa, y se compararon los parámetros cinéticos de ambas versiones. En ninguno de los casos fue posible convertir una actividad específica en otra, pero se confirmó la importancia de dichos residuos para la actividad enzimática. 
Polyamines are small polycationic organic molecules present in all living beings. They regulate plant development processes such as flowering time, stem elongation, early fruit development, and senescence. Thermospermine is a tetraamine, unique to plants and prokaryotes, whose deficiency in Arabidopsis thaliana -caused by a knockout mutation in the single thermospermine synthase gene, ACL5- provokes a dwarf phenotype, as well as severe defects in the metaxylem differentiation, and an altered deposition of cell-wall material in these vessels.

Aminopropyl transferases catalyze the synthesis of tri-and tetraamine, by adding an aminopropyl group to a di-or triamine, respectively. They show a high sequence similarity to each other, shared also with putrescine-Nmethyltransferases, another group of enzymes characteristic of Solanaceae. Phylogenetic studies have shown that aminopropyl transferases and putrescine$\mathrm{N}$-methyltransferases are evolutionarily related.

The goals that we considered in this thesis were:

- to establish the mechanism by which thermospermine controls xylem differentation; and

- to determine the structural differences between the various aminopropyl- and $\mathrm{N}$-methyltransferases that underlie their specificity.

The first goal was approached by a search for extragenic suppressors of acl5. We identified 40 suppressors, 11 of which present mutation in the 5'-UTR of three bHLH genes named $A J A X$. These mutations are located in a sequence that encodes a small peptide whose role is to repress the translation of the main ORF. Our in vitro studies reveal that the suppression is achieved by interfering with the synthesis or activity of this small peptide, therefore allowing the synthesis of AJAX proteins. The role of these transcription factors in the regulation of gene expression during xylem development partially overlaps with that of thermospermine, although not completely, as indicated by transcriptomic analyses of $A J A X 2$ overexpressing plants.

The second objective was approached by the comparison between active centers of aminopropyl transferases and putrescine- $\mathrm{N}$-methyltransferases, and subsequent identification of aminoacids with a potential key role in the establishment of differential activity. The corresponding aminopropyl transferases from Arabidopsis were produced in their native version and with the key residues mutated as in putrescine-N-methyltransferases, and their kinetic parameters were determined. In none of the cases we observed conversion of one specific activity into another, but we confirmed the importance of those residues for a normal level of enzyme activity. 
Les poliamines són petites molècules orgàniques policatiòniques presents en tots els éssers vius. En les plantes regulen diversos processos de desenvolupament, com la floració, el creixement de la tija, la fructificació i la senescència. La termoespermina és una tetraamina, exclusiva de les plantes $\mathrm{i}$ procariotes, la deficiència de la qual per la mutació de l'únic gen responsable de la síntesi, $A C L 5$, provoca un fenotip nan en Arabidopsis thaliana, acompanyat de greus defectes en la diferenciació del metaxilema i una severa alteració en el patró de formació de paret secundària dels vasos.

Les aminopropil transferases catalitzen la síntesi de tri- i tetraamines, mitjançant la incorporació d'un grup aminopropil a una di- o triamina, respectivament. Aquestes aminopropil transferases presenten un alt grau de similitud de seqüència entre si, compartit a més amb les putrescina-N-metil transferases, un altre grup d'enzims presents exclusivament en les solanàcies. Estudis filogenètics han mostrat que les aminopropil transferases i les putrescina-Nmetil transferases estan emparentades evolutivament.

Els objectius que ens plantegem en aquesta tesi van ser:

- $\quad$ establir el mecanisme pel qual la termoespermina controla la formació correcta del xilema, i

- determinar les diferències estructurals entre les diverses aminopropil transferases y putrescina-N-metil transferases responsables de las seua especificitat.

El primer objectiu l'abordàrem mitjançant la recerca de supressors extragenics de $a c l 5$. Dels 40 supressors dominants aïllats, 11 d' ells presenten mutacions en la regió $5^{\prime}$ UTR de tres gens $b H L H$, els quals denominem $A J A X$. Les mutacions es localitzen en una seqüència que codifica un petit pèptid el paper del qual és reprimir la traducció de l' ORF principal. Els nostres estudis in vitro indiquen que la supressió s' aconseguix interferint amb la síntesi o l' activitat del dit petit pèptid i permetent la síntesi de les proteïnes AJAX. El paper d' aquestos factors de transcripció en la regulació de l' expressió gènica durant el desenvolupament del xilema solapa en part amb el de la termoespermina, però no completament, segons indiquen les anàlisis transcriptomics efectuats en plantes superproductores d' AJAX2.

El segon objectiu es va abordar por mitja de la comparació dels centres actius de les aminopropil transferases $\mathrm{i}$ les putrescina-N-metil transferases, i la identificació $\mathrm{d}^{\prime}$ aminoàcids potencialment clau per a les seues activitats diferencials. Es van produir les corresponents aminopropil transferases recombinants d'Arabidopsis en les seues versions nadiues i amb els residus clau mutats com en una putrescina-N-metil transferasa, i es van comparar els paràmetres cinètics d' ambdues versions. En cap dels casos va ser possible convertir una activitat específica en una altra, però es va confirmar la importància de aquestos residus per a l' activitat enzimàtica. 



\section{ABREVIATURAS}

A. thaliana

A. tumefaciens

ABA

AdoMet

AdoMetdc

aRNA

ATP

BAC

BEHPA

C. reinhardtii

CAPS

cDNA

CDS

$\mathrm{cm}$

Col-0

CTP

Cy3

Cy5

D. stramonium

dCAPS

DMSO

E. coli

EMS

$\mathrm{eV}$

$\mathrm{g}$

GC

GC-MS

GFP

GTP

$\mathrm{h}$

HEPES

HFBA

HPLC

IAA

IPTG

$\mathrm{kb}$

La-0

La-er

LB

$\mathrm{m}$
Arabidopsis thaliana

Agrobacterium tumefaciens

ácido abscísico

S-adenosilmetionina

S-adenosilmetionina descarboxilada

aminoalil-RNA

adenosín trifosfato

cromosoma artificial bacteriano

bis (2-etilhexil) fosfato

Chlamydomonas reinhardtii

secuencia polimórfica de restricción amplificada

DNA complementario

secuencia codificante

centímetro

Columbia 0

citidina trifosfato

Cianina 3

Cianina 5

Datura stramonium

secuencia polimórfica de restricción derivada y amplificada dimetil sulfóxido

Escherichia coli

metanosulfonato de etilo

electronvoltio

gravedad

cromatografía de gases

cromatografía de gases acoplada a espectrometría de masas

proteína verde fluorescente

guanosín trifosfato

hora

ácido N-2-Hidroxietilpiperacina-N'-2'-Etanosulfónico

ácido hepta-flúor- $n$-butírico

cromatografía líquida de alta eficacia

ácido indol acético

isopropil- $\beta$-D-1-tiogalactopiranósido

kilobase

Landsberg 0

Landsberg erecta

medio de cultivo Luria-Bertani

metro 


$\begin{array}{ll}\text { M } & \text { molar } \\ \text { Mb } & \text { megabase } \\ \text { min } & \text { minuto } \\ \text { mJ } & \text { milijulios } \\ \text { ml } & \text { mililitro } \\ \text { mm } & \text { milímetro } \\ \text { mM } & \text { milimolar } \\ \text { MS } & \text { medio de cultivo Murashige \&Skoog } \\ \text { MTA } & \text { 5'-metiltioadenosina } \\ \text { ng } & \text { nanogramo } \\ \text { nm } & \text { nanómetro } \\ \text { OD } & \text { densidad óptica } \\ \text { ORF } & \text { open reading frame (marco abierto de lectura) } \\ \text { P. patens } & \text { Physcomitrella patens } \\ \text { p/v } & \text { ratio peso/volumen } \\ \text { pb } & \text { pares de bases } \\ \text { PCR } & \text { reacción en cadena de la polimerasa } \\ \text { pg } & \text { picogramo } \\ \text { pM } & \text { picomol } \\ \text { PMT } & \text { putrescina-N-metil transferasa } \\ \text { Put } & \text { putrescina } \\ \text { qRT-PCR } & \text { reacción en cadena de la polimerasa cuantitativa en tiempo } \\ & \text { real } \\ \text { mRNA } & \text { RNA mensajero } \\ \text { tRNA } & \text { RNA de transferencia } \\ \text { rpm } & \text { revoluciones por minuto } \\ \text { s } & \text { segundo } \\ \text { SDS } & \text { dodecilsulfato sódico } \\ \text { Spd } & \text { espermidina } \\ \text { SPDS } & \text { espermidina sintasa } \\ \text { Spm } & \text { espermina } \\ \text { SPMS } & \text { espermina sintasa } \\ \text { SSC } & \text { cloruro sódico }+ \text { citrato sódico } \\ \text { T. maritima } & \text { Thermotoga maritima } \\ \text { TLC } & \text { cromatografía en capa fina } \\ \text { Tm } & \text { temperatura de semihibridación } \\ \text { tSpm } & \text { termoespermina } \\ \text { tSPMS } & \text { termoespermina sintasa } \\ \text { uORF } & \text { upstream open reading frame (marco abierto de lectura } \\ \text { UTP } & \text { untina trifosfato } \\ \text { UTR } & \\ & \end{array}$


$\mathrm{V}$

$\mathrm{v} / \mathrm{v}$

$\mathrm{X}-\mathrm{Gal}$

$\mu \mathrm{g}$

$\mu 1$

$\mu \mathrm{m}$

Z. elegans voltio

ratio volumen/volumen

5-bromo-4-cloro-3-indolil- $\beta$-D-galactopiranósido microgramo

microlitro

micrómetro

Zinnia elegans 



\section{ÍNDICE}

I. Introducción............................................... 1

1. Biosíntesis de poliaminas.................................. 4

2. Las aminopropil transferasas............................ 6

3. Función y modo de acción de las poliaminas.................. 7

4. El xilema. Desarrollo vascular y poliaminas.................. 10

II. Objetivos...................................................... 15

III. Resultados.................................................. 19

A. Modo de acción de la termoespermina en el desarrollo de Arabidopsis thaliana ........................................ 21

1. Actividad bioquímica de ACL5 ........................... 24

1.1. ACL5: ¿espermina o termoespermina sintasa?............ 24

1.2. Determinación de termoespermina en Arabidopsis thaliana ........................................ $\quad 25$

2. Moduladores genéticos de la acción de $A C L 5 \ldots \ldots \ldots \ldots \ldots \ldots . . . . .29$

2.1. Variación fenotípica natural del mutante $a c l 5 \ldots \ldots \ldots \ldots . .29$

2.2. Caracterización genómica del alelo acl5-4 ............. 32

2.3. Búsqueda de supresores del mutante $a c l 5-4 \ldots \ldots \ldots \ldots . . \quad 34$

2.4. Caracterización fenotípica de los supresores dominantes

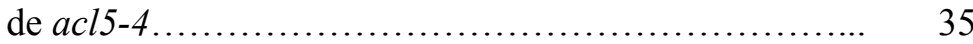

2.5. Clonación posicional de $A J A X 1$ y $A J A X 2 \ldots \ldots \ldots \ldots \ldots . . . . .43$

2.6. Caracterización molecular de los genes $A J A X \ldots \ldots \ldots \ldots . .48$

3. Análisis funcional de los genes $A J A X$ en el desarrollo vascular.

3.1. Superproducción de bHLH en los mutantes ajax......... 52

3.2. Relación funcional entre $A C L 5$ y los genes $A J A X \ldots \ldots \ldots . \quad 55$

B. Ingeniería enzimática de las aminopropil transferasas de plantas....................................................... 
1. Purificación de las enzimas SPDS, tSPMS y PMT ............ 70

2. Características cinéticas de SPDS, tSPMS y PMT............ 71

3. Modificación del centro activo de SPDS y tSPMS............. 75

IV. Discusión..................................................... 83

1. ACL5, AJAX y desarrollo vascular: ¿una ruta única o dos vías paralelas? ............................................ 85

2. Las poliaminas y el control traduccional de $A J A X \ldots \ldots \ldots \ldots . . . \quad 88$

3. Los genes $A J A X$ y el origen del xilema..................... 93

4. Mecanismos bioquímicos de las aminopropil transferasas.... 98

V. Conclusiones................................................. 105

VI. Materiales y métodos................................... 109

1. Características y manejo del material biológico............... 111

1.1. Material vegetal.................................. 111

1.1.1. Esterilizado y preparación de las semillas............. 111

1.1.2. Mutagénesis de semillas de Arabidopsis thaliana..... 112

1.1.3. Transformación de Arabidopsis thaliana ............. 112

1.1.4. Maceración y cuantificación de elementos del xilema............................................. 113

1.1.5. Microscopía..................................... 113

1.2. Cepas bacterianas.................................. 113

1.2.1. Transformación de bacterias......................... 114

2. Técnicas de bioquímica................................... 115

2.1. Extracción, identificación y cuantificación de poliaminas por GC-MS ............................. 115

2.2. Extracción, identificación y cuantificación de poliaminas por HPLC................................ 116

2.3. Purificación de proteínas............................... 117

2.3.1. Inducción de proteínas.............................. 117

2.3.2. Purificación de proteínas.......................... 117 
2.4. Ensayos enzimáticos................................. 117

3. Técnicas de biología molecular............................. 119

3.1. Extracción de ácidos nucleicos........................ 119

3.1.1. Extracción de RNA................................... 119

3.1.2. Extracción de DNA genómico........................ 119

3.1.3.Extracción de DNA plasmídico...................... 119

3.2. Generación de construcciones en vectores plasmídicos... 120

3.2.1. Reacción en cadena de la polimerasa (PCR)......... 120

3.2.2. Digestiones..................................... 120

3.2.3. Purificación de bandas de DNA separadas en geles de agarosa.......................................... 120

3.2.4. Ligaciones..................................... 120

3.2.5. Mutagénesis dirigidas.............................. 121

3.3. Construcciones generadas.......................... 121

3.3.1. Sobre-expresión de $A J A X$ en el mutante acl5 ........ 121

3.3.2. Transcripción in vitro de ajax $2 . . . \ldots \ldots \ldots \ldots \ldots \ldots . . . . . . . . .122$

3.3.3. Purificación de proteínas........................... 123

3.4. Genotipados.................................... 124

3.4.1. Genotipado de la deleción del mutante acl5-4....... 124

3.4.2. Genotipado de mutantes de inserción de T-DNA...... 124

3.5. Cartografiado de las líneas ajx1-4, ajx2-10 y ajx2-31..... 126

3.6. Secuenciación de los alelos supresores de $A J A X 1$,

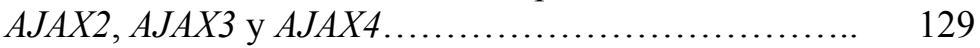

3.7. Análisis de expresión de genes....................... 130

3.7.1. Obtención de c-DNA............................... 130

3.7.2. Análisis qRT-PCR ............................... 130

3.8. Transcripción-traducción in vitro...................... 131

3.9. Análisis de expresión génica mediante micromatrices... 131

3.9.1. Extracción de RNA total........................... 131 
3.9.2. Amplificación de RNA................................ 131

3.9.3. Marcaje fluorescente del RNA amplificado........... 132

3.9.4. Hibridación de cy-dy-a RNA con las micromatrices.. 132

3.9.5. Lavado de las micromatrices...................... 133

3.9.6. Escaneo y análisis de las micromatrices............. 133

4. Análisis filogenético y estructural.......................... 134

4.1. Rastreo y análisis de secuencias......................... 134

4.2. Análisis estructural................................. 135

VII. Bibliografía............................................ 137

VIII. Anexos................................................. 153 




\section{INTRODUCCIÓN}



Desde el punto de vista biológico, se conoce como poliaminas a un grupo de compuestos alifáticos de bajo peso molecular, caracterizados por la presencia de grupos amino primarios (-NH2) y posibles grupos amino secundarios (-NH-). Las poliaminas con una presencia más extendida entre los organismos de los distintos reinos son: la putrescina, la espermidina y la espermina (Figura 1). Existen en plantas y bacterias, otras poliaminas menos comunes, como la cadaverina, el diaminopropano o la termoespermina, siendo esta última un isómero de la espermina.

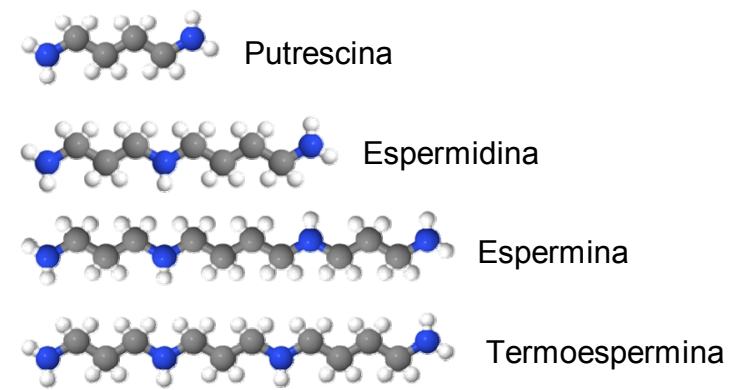

Figura 1. Estructura química de las principales poliaminas de interés biológico. En blanco se representan átomos de hidrogeno, en gris átomos de carbono y en azul átomos de nitrógeno

Aunque todos los seres vivos son capaces de sintetizar alguna poliamina, tanto la proporción relativa de cada una de ellas como la forma en que se presentan son muy variables. Generalmente, la putrescina y la espermidina se encuentran a una concentración más elevada que la espermina. Existe una fracción, normalmente minoritaria, compuesta por las formas libres de poliaminas (Torrigiani et al. 1987), mientras que la gran mayoría de ellas se encuentran conjugadas, ya sea a pequeñas moléculas, como ácidos cinámicos e hidroxicinámicos (Martin-Tanguy 1997), o a macromoléculas, como proteínas (Tiburcio et al. 1997).

Una de sus características químicas más relevantes, desde el punto de vista biológico, es que, a pH fisiológico, sus grupos amino primarios y secundarios están cargados positivamente, por lo que pueden establecer interacciones electrostáticas con otras moléculas con carga negativa como DNA, RNA, fosfolípidos o algunas proteínas. Además de su carácter policatiónico, la 
distribución de estas cargas también representa un factor muy importante, puesto que las cadenas de $\mathrm{C}$ entre los grupos amino son relativamente flexibles (Weiger et al. 1998; Dalla Via et al. 1999), lo cual hace que sean muy versátiles a la hora de interactuar con otras moléculas.

En el mundo vegetal, las poliaminas han sido consideradas como moduladores del crecimiento (Galston 1983) pero, en ningún caso pueden ser consideradas como hormonas vegetales pues, a diferencia de éstas, no tienen ni receptor ni ruta de señalización, no se sintetizan en una zona determinada de la planta sino que son ubicuas y, además, se encuentran a concentraciones celulares muy elevadas, del orden milimolar (Galston y Sawhney 1990).

\section{Biosíntesis de poliaminas}

La biosíntesis de las poliaminas se inicia con la descarboxilación de la Lornitina para formar putrescina, una diamina. Esta reacción es catalizada por la ornitina descarboxilasa (ODC). En plantas y algunos procariotas existe una ruta alternativa que se inicia con la descarboxilación de la L-arginina por una arginina descarboxilasa (ADC) para formar agmatina, que es hidrolizada por una agmatina iminohidrolasa (AIH) dando lugar a N-carbamilputrescina que finalmente, es transformada en putrescina por una $\mathrm{N}$-carbamilputrescina amidohidrolasa (CPA) (Figura 2). A su vez la L-ornitina y la L-arginina son convertibles entre sí; la L-ornitina se convierte en L-arginina a través de la vía de la citrulina mientras que, L-arginina se convierte en L-ornitina por la acción de la actividad arginasa.

A partir de la putrescina se produce la siguiente poliamina, la triamina espermidina, mediante la adición de un grupo aminopropilo a uno de los grupos amino. Esta reacción es catalizada por la espermidina sintasa (SPDS), siendo el dador del grupo aminopropilo la S-adenosilmetionina descarboxilada (AdoMetdc) que se forma a partir de la S-adenosilmetionina (AdoMet), siendo esta reacción realizada una S-adenosilmetionina descarboxilasa (SAMDC). Las tetraaminas alifáticas se sintetizan mediante la adición a la espermidina de otro grupo aminopropilo proveniente del AdoMetdc; según se produzca en un extremo u otro de la espermidina, se formarán dos tetraaminas distintas: la 
tetraamina simétrica espermina, cuya generación es catalizada por la espermina sintasa (SPMS), o su isómero asimétrico, la termoespermina, catalizada por la termoespermina sintasa (tSMPS).

Además, la putrescina es usada en las plantas solanáceas como precursor de la síntesis de alcaloides, tras ser convertida en N-metilputrescina por la putrecina$\mathrm{N}$-metil transferasa (PMT), que acopla un grupo metilo del AdoMet a la putrescina.

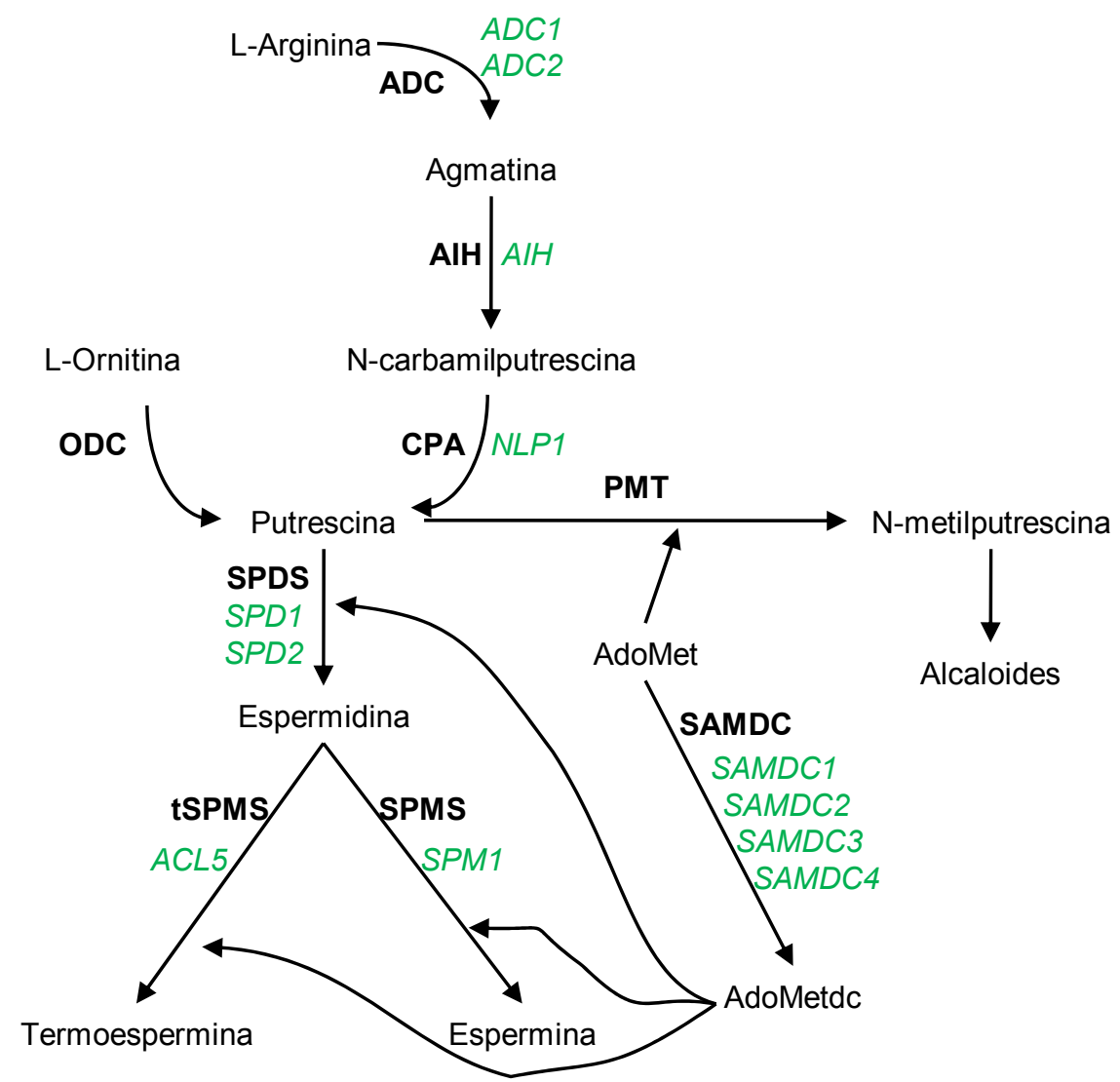

Figura 2. Ruta de biosíntesis de poliaminas. En negrita se marcan las actividades enzimáticas implicadas en cada paso de la síntesis. En verde se destacan los genes identificados en $A$. thaliana, responsables de cada actividad.

En Arabidopsis thaliana existe la particularidad de no haberse detectado la actividad ODC (Hanfrey et al. 2001) por lo que, la putrescina sólo puede 
sintetizarse a través de la actividad ADC. En $A$. thaliana existen 2 genes ( $A D C 1$ y 2) que codifican esta actividad, un gen que codifica la actividad AIH $(A I H)$ (Janowitz et al. 2003) y otro la CPA (NLP1) (Piotrowski et al. 2003). También existen dos genes que codifican la actividad SPDS (SPD1 y 2) (Hashimoto et al. 1998) uno para la SPMS (SPM1) (Panicot et al. 2002) y otro para la tSPMS (ACL5) (Knott et al. 2007). Por último, la actividad SAMDC es codificada por cuatro genes distintos (SAMDC1, 2, 3 y 4) (Franceschetti et al. 2001).

\section{Las aminopropil transferasas}

La síntesis de las triaminas y tetraaminas (espermidina, espermina y termoespermina) es realizada por las aminopropil transferasas, que son aquellas enzimas que usan como sustrato el AdoMetdc para transferir un grupo aminopropilo, formándose 5'-metiltioadenosina como subproducto de la reacción.

La primera aminopropil transferasa con una estructura cristalina resuelta fue la espermidina sintasa de Thermotoga maritima (Korolev et al. 2002). Además de esta estructura se conocen las de la espermidina sintasa de Caenorhabditis elegans (Dufe et al. 2005), Plasmodium falciparum (Dufe et al. 2007), Helicobacter pylori (Lu et al. 2007), humanos (Wu et al. 2007), Arabidopsis thaliana (código PDB: 2Q41) y Trypanosoma cruzi (código PDB: 3BWC), la termoespermina sintasa de Thermus thermophilus (código PDB: 1UIR) y la de la espermina sintasa de humanos (Wu et al. 2008). Incluso se ha propuesto un modelo de acción de las espermidina sintasas (Korolev et al. 2002; Wu et al. 2007). De todos estos trabajos se ha podido concluir que el centro activo de las aminopropil transferasas conocidas contiene una gran cantidad de residuos muy conservados (Hashimoto et al. 1998).

Además de las ya citadas, espermidina, espermina y termoespermina, existen algunas otras poliaminas menos comunes presentes en las plantas (Kuehn et al. 1990) como la norespermidina y norespermina en Medicago sativa (RodriguezGaray et al. 1989) o como la caldopentamina, homoespermidina y homoespermina en algunas plantas acuáticas (Hamana et al. 1998). Todas estas poliaminas poco frecuentes parecen provenir de reacciones, en las que las 
aminopropil transferasas se comportan de modo poco específico y transfieren los grupos aminopropilo a sustratos menos comunes. Esta promiscuidad de sustratos de las aminopropil transferasas es muy común en las bacterias; por ejemplo, en Thermus thermophilus, el ortólogo de la termoespermina sintasa es capaz de transferir el aminopropilo a la agmatina y a la norespermidina, además de a la espermidina (Ohnuma et al. 2005) y, en Pyrococcus furi el ortólogo de la espermidina sintasa puede usar como sustratos la agmatina y la cadaverina (Cacciapuoti et al. 2007) (Figura 3). La combinación de una elevada similitud de secuencia con una cierta promiscuidad de sustrato sugiere que la especificidad de cada aminopropil transferasa no es perfecta y que, además, debe residir en unos pocos aminoácidos.

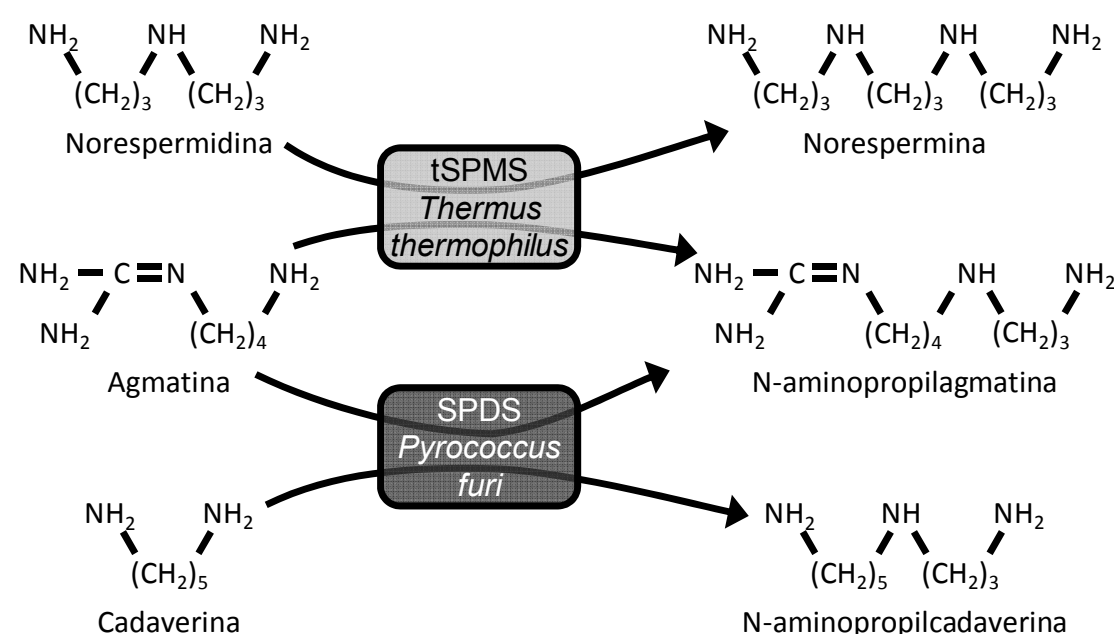

Figura 3. Reacciones de síntesis de poliaminas poco comunes, por parte de aminopropil transferasas con actividad para diversos sustratos.

\section{Función y modo de acción de las poliaminas}

A nivel celular, las poliaminas han sido relacionadas con el funcionamiento de numerosos procesos bioquímicos, desde la transcripción hasta el transporte de iones a través de la membrana plasmática (Williams 1997). En concreto, se ha propuesto que la espermidina participa en una modificación covalente del factor eIF4A de iniciación de la traducción (Park 2006) y en el ensamblaje de 
ribosomas (Vila-Sanjurjo et al. 2004), resultando en modificaciones de la actividad transcripcional y traduccional (Childs et al. 2003).

Los cambios transcripcionales relacionados con el contenido de poliaminas también podrían deberse a otros mecanismos moleculares descritos, como la modificación de la estructura de B-DNA a Z-DNA (Rich et al. 1984) o a cambios conformacionales del RNA (Igarashi y Kashiwagi 2000; Amarantos et al. 2002).

Por otra parte, se han observado cambios en la fluidez de las membranas atribuidos a la interacción entre poliaminas y lípidos de la membrana (Roberts et al. 1986), lo que sugiere que no todas las acciones de las poliaminas se deben necesariamente a efectos transcripcionales.

Como consecuencia de estas actividades moleculares, las poliaminas afectan a numerosos procesos biológicos, tanto de desarrollo como de tolerancia a situaciones de estrés. Por ejemplo, han sido relacionadas con procesos fundamentales para la vida como el crecimiento y la muerte celular (Thomas y Thomas 2001). En concreto, la levadura presenta un requerimiento absoluto de espermidina para crecer (Hamasaki-Katagiri et al. 1997) y esta función esencial, parece responder a un papel ancestral de esta poliamina, puesto que un mutante sin actividad espermidina sintasa de $A$. thaliana es inviable (Imai et al. 2004). Otras poliaminas son también necesarias en mayor o menor medida para el correcto crecimiento del organismo, aunque no lleguen a ser esenciales. Así, la falta de espermina en levaduras provoca retrasos en la división celular (Hamasaki-Katagiri et al. 1998) y en ratas causa malformaciones en el desarrollo del sistema nervioso (Wang et al. 2004) mientras que, la carencia de termoespermina en $A$. thaliana impide el alargamiento de los tallos y el crecimiento general de otros órganos, sin afectar a la viabilidad (Hanzawa et al. 1997).

Las poliaminas también pueden modular la muerte celular programada aunque existen datos contradictorios con respecto a si la promueven o la inhiben (Seiler y Raul 2005). Además, las poliaminas son necesarias para la transición entre diferentes fases del ciclo celular (Thomas y Thomas 2001) y de hecho, los 
inhibidores de su síntesis se han utilizado para el tratamiento del cáncer (Bachrach 2004).

Dada la gran diversidad de funciones que se han atribuido a las poliaminas en procesos fisiológicos de todos los organismos (Kumar et al. 1997; Igarashi y Kashiwagi 2000; Thomas y Thomas 2003), aquí mencionaré explícitamente sólo aquéllos que son relativos al desarrollo vegetal y otros procesos de la vida de las plantas, como por ejemplo:

- la deficiencia de putrescina provoca la formación de una raíz pivotante en tabaco (Ben-Hayyim et al. 1994).

- la rotura de la dominancia apical en tabaco está asociada a cambios en el balance entre las distintas poliaminas sin modificar su contenido global (Geuns et al. 2001).

- la sobre-expresión del gen $A D C 2$ en $A$. thaliana, genera plantas con altos niveles de putrescina que son incapaces de elongar los entrenudos del tallo (Alcázar et al. 2005).

- los niveles de espermina parecen determinar si el ovario se desarrolla como fruto o entra en un programa de senescencia (Carbonell y Navarro 1989).

- la adición exógena de espermidina promueven la transición floral en $A$. thaliana (Applewhite et al. 2000).

Además, las poliaminas también pueden participar en procesos de la respuesta al estrés, como por ejemplo:

- el doble mutante acl5 spm1 es más sensible al estrés salino (Yamaguchi et al. 2006) y al hídrico (Alcázar et al. 2006; Yamaguchi et al. 2007) y, ambos fenotipos son revertidos por adiciones exógenas de espermina.

- la espermina induce la formación de proteína PR y protege al tabaco contra la infección del virus del mosaico del tabaco (Yamakawa et al. 1998). 
Además de todos estos ejemplos, existe otro proceso de desarrollo regulado por las poliaminas: el desarrollo del sistema vascular, y más concretamente del xilema.

\section{EI xilema. Desarrollo vascular y poliaminas}

Las células del xilema se desarrollan a partir de las células meristemáticas del cambium y el procambium. El xilema está compuesto por varios tipos celulares aunque los que realmente cumplen la función conductora son las traqueidas y las tráqueas, a las que denominaremos conjuntamente como elementos traqueidales. Estos elementos traqueidales sufren un complejo proceso de desarrollo y diferenciación que incluye la deposición de la pared celular secundaria para soportar las presiones negativas generadas por la transpiración, y un proceso de muerte celular programada para conseguir una célula completamente vacía a modo de conducto (Figura 4).

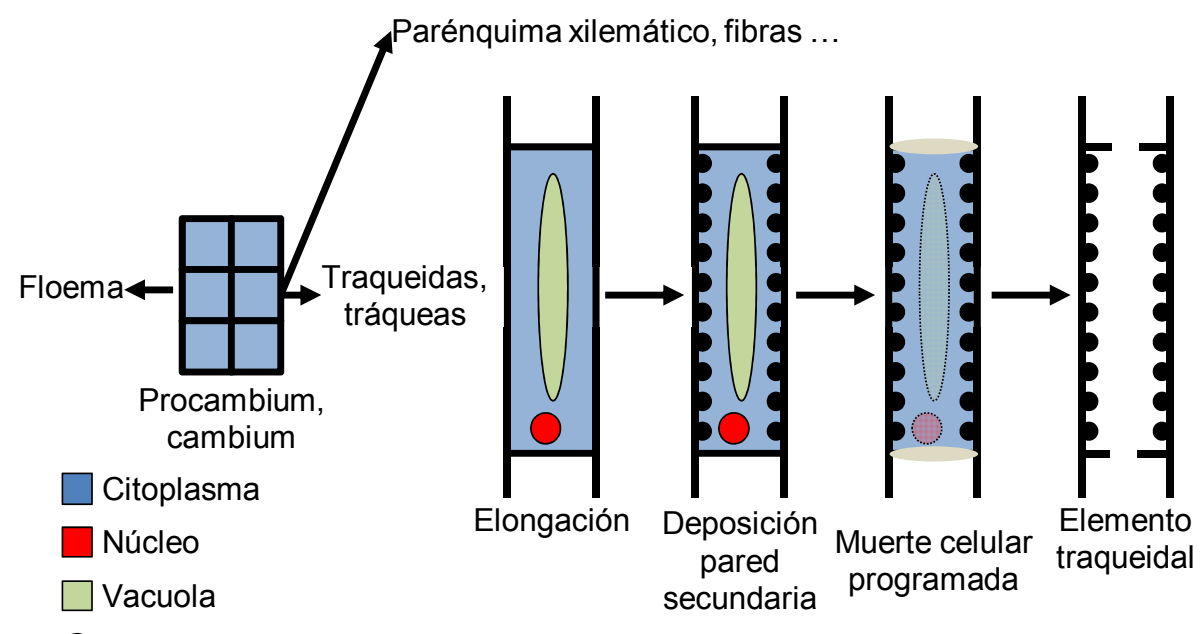

Pared celular secundaria

Figura 4. Proceso de diferenciación de los elementos traqueidales. Adaptado de Turner (Turner et al. 2007)

Este proceso de diferenciación es controlado por diversas hormonas vegetales (Turner et al. 2007). Una de ellas es la auxina, que es capaz de promover, junto con las citoquininas, la diferenciación de células del mesófilo de hoja de Zinnia 
elegans en elementos traqueidales (Milioni et al. 2001). También los brasinoesteroides parecen ser imprescindibles para este proceso, pues la inhibición de su síntesis detiene el proceso de diferenciación en el sistema de $Z$. elegans (Iwasaki y Shibaoka 1991).

Dentro de este proceso de formación de la pared secundaria, la síntesis de lignina es esencial, y requiere la presencia de $\mathrm{H}_{2} \mathrm{O}_{2}$ (Grant y Loake 2000), que puede provenir de la acción de diversas enzimas del catabolismo de poliaminas que se expresan en los tejidos vasculares (Paschalidis y Roubelakis-Angelakis 2005).

Otra de las pruebas de la relación entre las poliaminas y el desarrollo vascular, es el fenotipo de algunos mutantes de la biosíntesis de poliaminas, como bud2, un mutante defectivo en una de las cuatro $S A M D C$, que posee unos haces vasculares de mayor tamaño y un mayor contenido en lignina que los de una planta silvestre (Ge et al. 2006). Otro mutante, acl5, presenta un fenotipo de sobreproducción de haces vasculares (Hanzawa et al. 1997), además de un mayor grosor de sus tráqueas xilemáticas, fenotipo por el cual el mutante acl5 también fue aislado en otro trabajo independiente y denominado como thickvein (Clay y Nelson 2005).

Otros dos resultados relacionan a ACL5 con el desarrollo del xilema:

- la expresión de ACL5 es inducida por las auxinas (Hanzawa et al. 2000).

- esta expresión está localizada en células del procambiun que han iniciado su diferenciación a xilema (Clay y Nelson 2005; Muñiz et al. 2008).

Pero la evidencia definitiva de la implicación de ACL5 en la diferenciación del xilema es la ausencia de algunos tipos celulares xilemáticos en el mutante acl5. Durante la fase de crecimiento primario de la planta se desarrollan los elementos traqueidales de tipo protoxilema que, según la ornamentación de su pared, pueden ser de tipo anular o espiral; posteriormente, durante la fase de crecimiento secundario, se producen los de tipo metaxilema que se pueden 
clasificar en dos tipos: reticulado o punteado según su ornamentación (Figura 5) (Kubo et al. 2005). En acl5, la distribución de estos tipos celulares está alterada, ya que carece de células metaxilemáticas de tipo punteado (Muñiz et al. 2008). Este dato, unido a que en el mutante acl5 se produce una sobre-expresión de diversos genes de muerte celular y una incorrecta deposición de los elementos de la pared vegetal, indica que la causa primaria del fenotipo defectivo de acl5 podría ser la muerte prematura de las células en proceso de diferenciación hacia metaxilema. Efectivamente, la expresión forzada de la toxina A de la difteria exclusivamente en el dominio de expresión de ACL5, fenocopia el enanismo de acl5 (Muñiz et al. 2008), lo cual ha permitido atribuir un papel a la termoespermina en el proceso de desarrollo vascular, retrasando la muerte celular y permitiendo que se complete el desarrollo de las células del metaxilema (Muñiz et al. 2008).
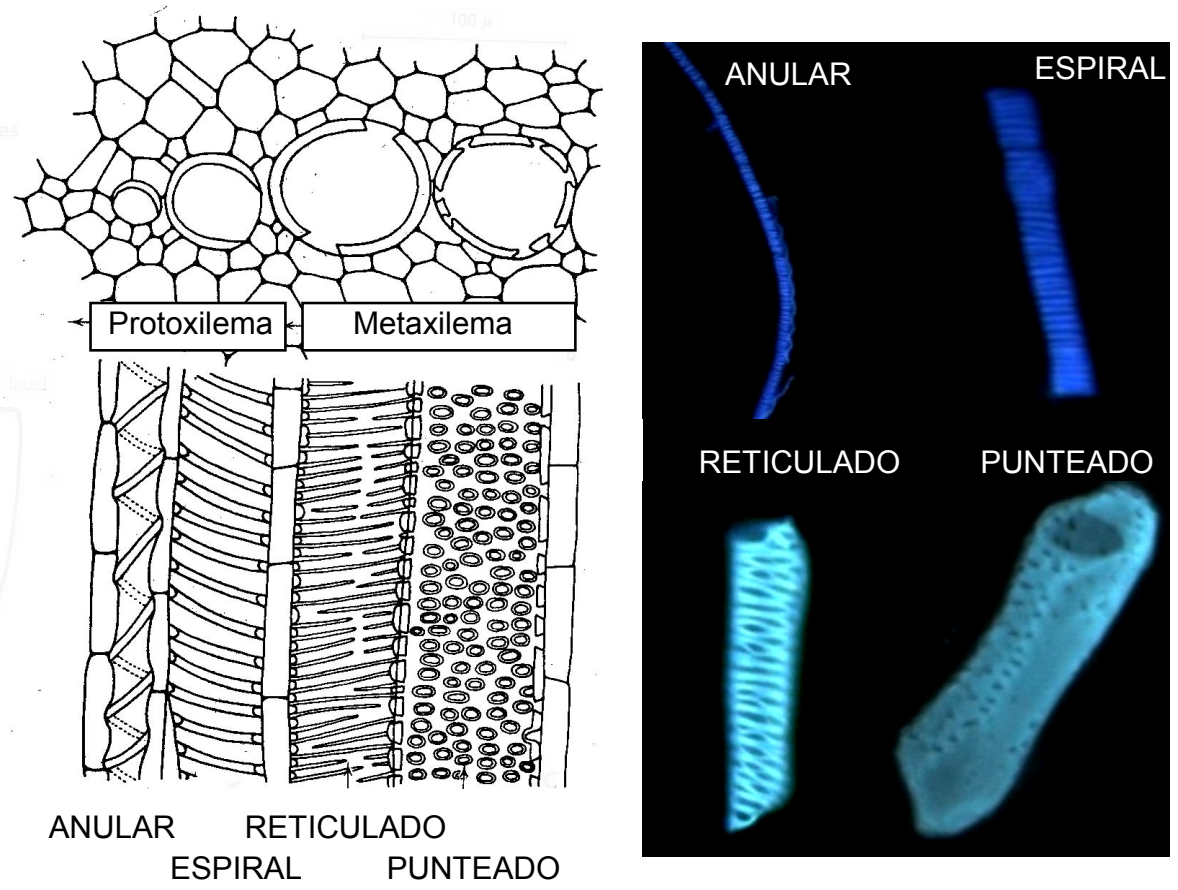

Figura 5. Tipos celulares del xilema. A la izquierda esquema ilustrativo (Esau 1977). A la derecha imágenes al microscopio óptico, bajo iluminación con luz ultravioleta, de elementos vasculares del xilema teñidos con calcoflúor. 


OBJETIVOS 

El conocimiento de las poliaminas presenta una gran laguna en relación con su mecanismo de acción. El hecho de haber encontrado un proceso de desarrollo bien definido, como es la formación del xilema, en cuyo control participa la termoespermina, nos proporciona un modelo de estudio de las bases moleculares de la acción de las poliaminas.

Por otra parte, la alta similitud de secuencia entre las aminopropil transferasas y las putrescina-N-metil transferasas ha permitido establecer que todas ellas provienen de un ancestro común que ha sufrido cambios discretos en el centro activo que han resultado en los cambios de especificidad observados ahora. Este modelo evolutivo nos brinda la posibilidad de intentar modificar de forma dirigida las actividades de estas enzimas.

Los objetivos de este trabajo son dos:

a) establecer los mecanismos moleculares por los cuales la termoespermina controla la correcta formación del xilema.

b) encontrar las diferencias estructurales entre las diversas aminopropil transferasas, que les confieren a cada una de ellas su actividad específica.

Para alcanzar cada uno de estos objetivos nos planteamos dos abordajes distintos:

a) obtención de supresores extragénicos del mutante acl5 y caracterización de los nuevos mutantes.

b) comparación estructural de los centros activos de diversas aminopropil transferasas y realización de un proceso de mutagénesis dirigida para modificar sus actividades enzimáticas. 

RESULTADOS 



\section{MODO DE ACCIÓN DE LA TERMOESPERMINA EN EL DESARROLLO DE Arabidopsis thaliana}



Como se ha indicado en la Introducción general, las poliaminas regulan numerosos procesos del desarrollo de las plantas como floración (Havelange et al. 1996; Applewhite et al. 2000), fructificación (Carbonell y Navarro 1989), respuesta al estrés salino (Alcázar et al. 2006; Yamaguchi et al. 2006) o respuesta a patógenos (Takahashi et al. 2003). Normalmente, la mayoría de estos procesos han sido relacionados con cambios en las concentraciones de las poliaminas más comunes como putrescina, espermidina o espermina, mientras que la termoespermina no ha sido considerada. Aunque había datos previos de la presencia de termoespermina y sus derivados en algunas plantas (Hamana et al. 1992; Hamana et al. 1998), su relevancia en plantas se ha descubierto muy recientemente, al determinarse que el gen ACL5 de A. thaliana tiene actividad termoespermina sintasa in vitro (Knott et al. 2007). Así pues, es razonable atribuir a la termoespermina una función en el proceso de elongación del tallo, ya que, el mutante acl5 presenta alteraciones en este proceso (Kakehi et al. 2008) probablemente controlando el proceso de muerte celular de las células que dan origen al xilema (Muñiz et al. 2008).

Si se conoce poco sobre los procesos de desarrollo en los que participa la termoespermina en plantas, todavía es menos lo que se conoce sobre cómo puede ser su mecanismo de acción para desencadenar respuestas, y lo poco que podemos inferir es a través de mecanismos de acción conocidos de otras poliaminas. Su naturaleza de moléculas policatiónicas les permite interactuar con moléculas de carga negativa como DNA, RNA, proteínas o membranas plasmáticas (Wallace et al. 2003); pero aparte de estos mecanismos de interacción de cargas se sabe que la espermidina es capaz de producir fenómenos de cambios de la pauta de lectura +1 en la traducción (Matsufuji et al. 1995), y se cree que puede modificar los niveles de traducción de pequeños péptidos reguladores situados aguas arriba de un gen (Hanfrey et al. 2002; Hanfrey et al. 2005).

Como la presencia de termoespermina en plantas es un descubrimiento reciente, y conociendo que su deficiencia provoca graves alteraciones en el desarrollo vascular en $A$. thaliana, nos pareció éste un sistema interesante para intentar 
dilucidar cuáles son los mecanismos de acción de las poliaminas y, más concretamente, el de la termoespermina.

\section{Actividad bioquímica de ACL5}

\subsection{ACL5: ¿espermina o termoespermina sintasa?}

El mutante acaulis5 (acl5) perteneciente a la familia acaulis (Tsukaya et al. 1993), fue descrito en una búsqueda de plantas con un tallo floral de reducida longitud (Hanzawa et al. 1997). La mutación responsable de este fenotipo enano fue identificada por clonación posicional, concluyéndose que el locus de ACL5 correspondía al gen At5g19530 (Hanzawa et al. 2000).

Inicialmente se asignó a ACL5 una actividad espermina sintasa, basándose en dos observaciones (Hanzawa et al. 2000):

- su grado de similitud con otras aminopropil transferasas, especialmente con diversas espermina sintasas.

- la detección mediante HPLC de un pico con un tiempo de retención similar a la espermina, en extractos de un Escherichia coli (que per se carece de espermina) sobre-expresante de ACL5.

La conclusión de que el fenotipo enano de acl5 podría deberse a una deficiencia total de espermina (Hanzawa et al. 2000) quedó invalidada al encontrarse una segunda espermina sintasa, SPM1, en A. thaliana (Panicot et al. 2002).

Además de la espermina, existen en las plantas otras tetraaminas menos abundantes y también menos estudiadas (Hamana et al. 1992; Hamana et al. 1998) como por ejemplo, la termoespermina, un isómero de la espermina. El descubrimiento reciente de que ACL5 tiene actividad termoespermina sintasa in vitro (Knott et al. 2007) abre la posibilidad que en realidad ACL5 sea la enzima responsable de sintetizar termoespermina, y no espermina, en plantas.

Los motivos de esta posible asignación errónea de la función de ACL5 se derivan de la gran similitud entre espermina y termoespermina, y son: 
- la secuencia de aminoácidos de los centros activos de espermina y termoespermina sintasas, son muy parecidos, un hecho que sin duda está relacionado con la utilización de los mismos sustratos (espermidina y AdoMetdc) para la síntesis de sus productos correspondientes. Este alto grado de similitud en la secuencia de las proteínas se extiende también a las espermidina sintasas y, de hecho, el gen SPM1 fue considerado en un primer momento como una espermidina sintasa en $A$. thaliana y denominado como SPD3 (Hanzawa et al. 2002).

- los métodos empleados habitualmente para determinar poliaminas en plantas están basados en una separación cromatográfica por HPLC de poliaminas dansiladas (Flores y Galston 1982), una técnica incapaz de discriminar entre espermina y termoespermina.

Con el fin de certificar in vivo la actividad termoespermina sintasa de ACL5 y de determinar los niveles de termoespermina en extractos de A. thaliana, decidimos desarrollar un método que permitiera la separación efectiva de las tetraaminas y su posterior cuantificación.

\subsection{Determinación de termoespermina en Arabidopsis thaliana}

En el momento de acometer este proyecto se conocían únicamente dos técnicas que permitían la separación entre espermina y termoespermina: la Cromatografía de Gases acoplada a un Espectrómetro de Masas (GC-MS) (Hamana et al. 1998) y la Cromatografía en Capa Fina (TLC) (Knott et al. 2007). Mientras que esta última carecía de carácter cuantitativo, la primera presentaba el inconveniente de requerir una gran cantidad de material de partida (500 $\mathrm{g}$ de tejido fresco).

Por estos motivos, nos propusimos como objetivo el desarrollo, en colaboración con el Servicio de Metabolómica del IBMCP, de un método de alta sensibilidad capaz de cuantificar la termoespermina en extractos de $A$. thaliana. Como punto de partida decidimos adaptar un método de determinación de poliaminas utilizado previamente en muestras de zumo de uva (Fernandes y Ferreira 2000), 
que combinaba una extracción de par iónico con GC-MS. Empleando una columna BPX35 (30 m x 0,32 $\mathrm{mm}$ x 0,25 $\mu \mathrm{m})$ y analizando los iones 226 y 254 (ver Materiales y Métodos, página 115) conseguimos separar la termoespermina de la espermina, además de identificar también la putrescina y la espermidina (Figura 6).

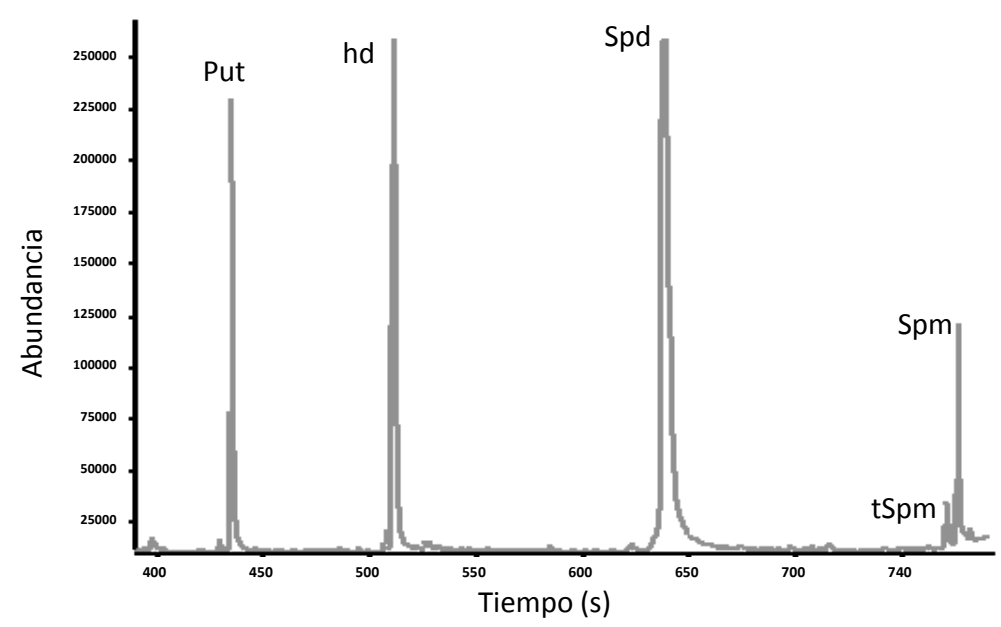

Figura 6. Cromatograma de iones específicos de las poliaminas (relación masa/carga de 226 y 254) de plántulas de A. thaliana, Put: putrescina, hd:1,6diamina-hexano, Spd: espermidina, tSpm: termoespermina, Spm: espermina.

El método resultaba reproducible y presentaba un grado de sensibilidad equivalente al de otros empleados anteriormente, como el de HPLC de poliaminas dansiladas, con la ventaja de poder efectuar la cuantificación a partir de muestras de tamaño muy inferior, en comparación con otros métodos (Rambla et al. 2010).

La aplicación de este método en extractos de $A$. thaliana ha permitido por una parte, confirmar que SPM1 y ACL5 codifican las únicas actividades que sintetizan espermina y termoespermina respectivamente, y por otra, establecer por primera vez que el contenido de termoespermina en plántulas de A. thaliana es alrededor de cinco veces inferior al de espermina (Figura 7). Otros aspectos a destacar en estas cuantificaciones son: 
- las trazas de espermina que se detectaron en el mutante spml podrían provenir del medio de cultivo en el que crecieron las plantas, ya que eran del mismo orden que las detectadas directamente en el medio (resultados no mostrados).

- la observación de que el contenido total de termoespermina sea menor que el de espermina en extractos crudos de plántulas enteras, podría enmascarar el hecho de que la concentración local de termoespermina en las pocas células que expresan ACL5 (Muñiz et al. 2008) podría ser mucho mayor.

- el mayor nivel de espermidina en los mutantes respecto al silvestre y, especialmente el de espermina en el mutante $a c l 5$, podría formar parte de un sistema compensatorio de la planta, como el de retroalimentación negativa de la expresión de ACL5 (Hanzawa et al. 1997).

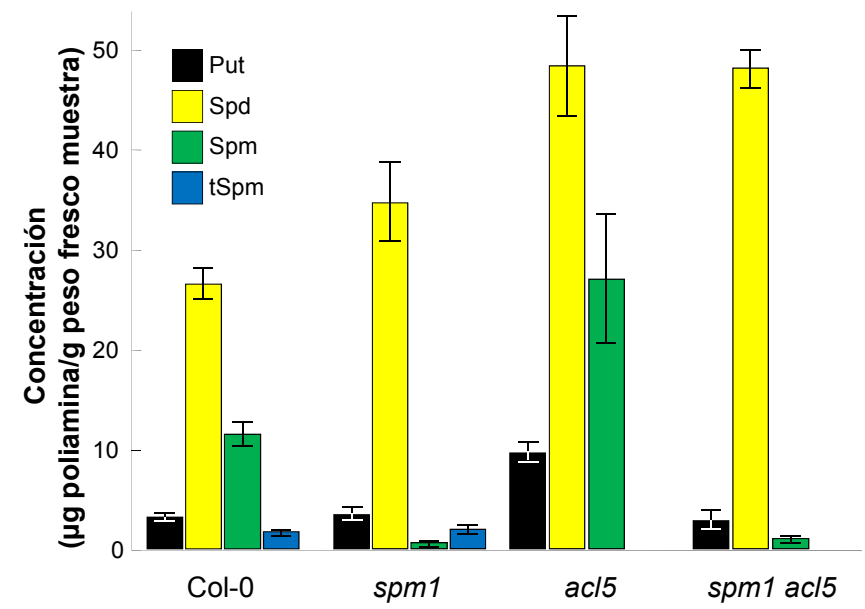

Figura 7. Niveles de poliaminas en los diversos mutantes de biosíntesis de espermina y termoespermina. Las medidas corresponden a plántulas de 14 días crecidas en medio MS. Las barras indican la desviación estándar de 3 muestras independientes

La expresión de los genes de biosíntesis de poliaminas está regulada por diversas hormonas vegetales (Hanzawa et al. 2002; Carbonell y Blazquez 
2009). En concreto, está descrito que las auxinas inducen la expresión de $A C L 5$, así como la de $A D C 2$ de forma transitoria, mientras que el ácido abscísico (ABA) induce la expresión de $A D C 2$ y SPM1. Para averiguar si esta inducción génica se traduce efectivamente en un aumento de los niveles de poliaminas decidimos cuantificarlas, en plántulas sometidas a tratamientos de 1 y $8 \mathrm{~h}$ con ABA o con ácido indolacético (IAA) (Figura 8). Tal y como se esperaba, los tratamientos con $\mathrm{ABA}$ indujeron la producción de putrescina, especialmente en las incubaciones más prolongadas. Sin embargo, la inducción de SPM1 no repercutió en una acumulación de espermina. Esta aparente inconsistencia podría explicarse teniendo en cuenta que SPM1 se ha descrito como uno de los elementos de un complejo multienzimático o metabolón, en el que también participan las espermidina sintasas SPD1 y SPD2 (Panicot et al. 2002). En este contexto, es razonable pensar que la inducción de sólo uno de los componentes de este metabolón no sea suficiente para que el producto final se acumule durante los tiempos empleados en el tratamiento. Por otra parte, el tratamiento con IAA produjo el aumento de los niveles de termoespermina y putrescina, en consonancia con las inducciones de $A D C 2$ y $A C L 5$.

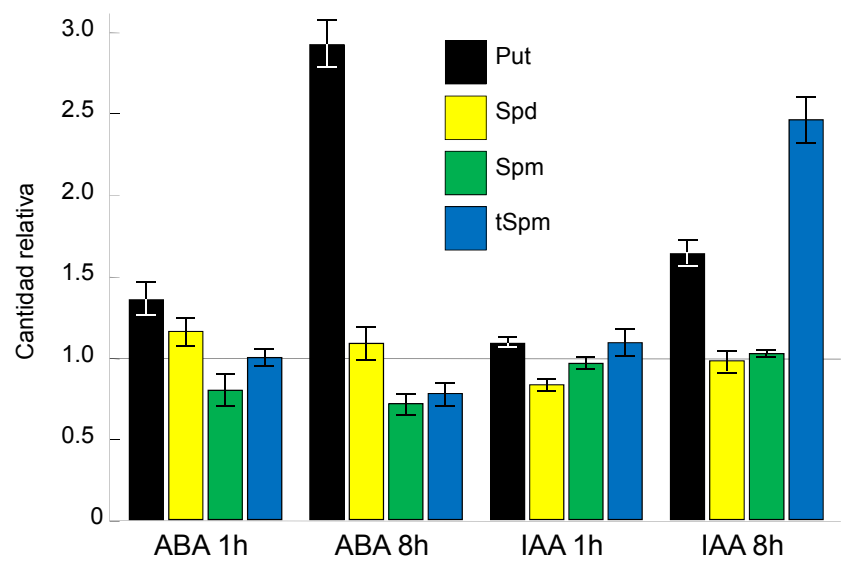

Figura 8. Variación de los niveles de poliaminas en plántulas de 12 días, tratadas con $50 \mu \mathrm{M}$ de ácido indolacético o ácido abscísico. Los valores representados muestran la variación relativa respecto a una muestra sin tratar. Las concentraciones absolutas ( $\mu \mathrm{g}$ de poliamina/g fresco) de las muestras sin tratar son, Put: 2,8, Spd: 56,5, Spm: 10,6, tSpm: 1,4. 


\section{Moduladores genéticos de la acción de ACL5}

El fenotipo enano de $a c l 5$, hace razonable atribuir a la termoespermina una función en el proceso de elongación del tallo (Kakehi et al. 2008). Hasta la fecha no se conocen dianas moleculares para la acción de ACL5 o la termoespermina por lo que, uno de los objetivos principales de nuestro trabajo fue identificar genes que actuaran como mediadores de la regulación del crecimiento del tallo por parte de la termoespermina. Con este fin, entre las distintas estrategias a nuestra disposición decidimos abordar la búsqueda de mutaciones extragénicas que modificasen el fenotipo enano de los mutantes acl5. Para ello, nos centramos en dos aproximaciones concretas:

- el examen de la variación fenotípica natural de mutantes acl5 en distintas variedades de $A$. thaliana.

- el rastreo de supresores extragénicos de acl5 en poblaciones mutagenizadas.

En esta sección se describe el aislamiento y la caracterización de ambos tipos de modificadores genéticos.

\subsection{Variación fenotípica natural del mutante acl5}

En el momento de iniciar esta Tesis se disponía de cinco alelos mutantes para ACL5 (Figura 9). El primero, acl5-1, se caracteriza por la mutación de un ácido glutámico por una lisina en el cuarto exón de $A C L 5$; el segundo, acl5-2, resultó ser un alelo independiente con la misma lesión que acl5-1; el tercer alelo se describió a raíz de una búsqueda en una colección de plantas con inserciones de transposones, utilizando la estrategia de dos componentes Activator/Dissociation (Long et al. 1997); este alelo fue llamado acl5-3 y tenía insertado el transposón en el sexto intrón de $A C L 5$. En la progenie del cruce entre acl5-3 y una línea que contenía una transposasa apareció otra línea, acl54, que había perdido la inserción del transposón pero mantenía el fenotipo enano; esto se debía a que durante la transposición se había escindido parte de $A C L 5$ generándose un mutante nulo. Más recientemente, en nuestro laboratorio 
se ha caracterizado una línea de inserción de T-DNA de la colección generada en el Salk Institute (Alonso et al. 2003), localizada en el sexto exón del gen $A C L 5$, y que denominamos acl5-5.

Los cuatro alelos distintos de acl5 presentan una gradación en el defecto de crecimiento del mutante: mientras acl5-3 y acl5-4 presentan una altura muy inferior a la del silvestre, en acl5-1 y acl5-5 este efecto está un poco más atenuado (Figura 9). Además, otras características del fenotipo de acl5 como el reducido tamaño de las hojas de roseta o la rugosidad de las silicuas están acentuadas en $a c l 5-3$ y acl5-4.

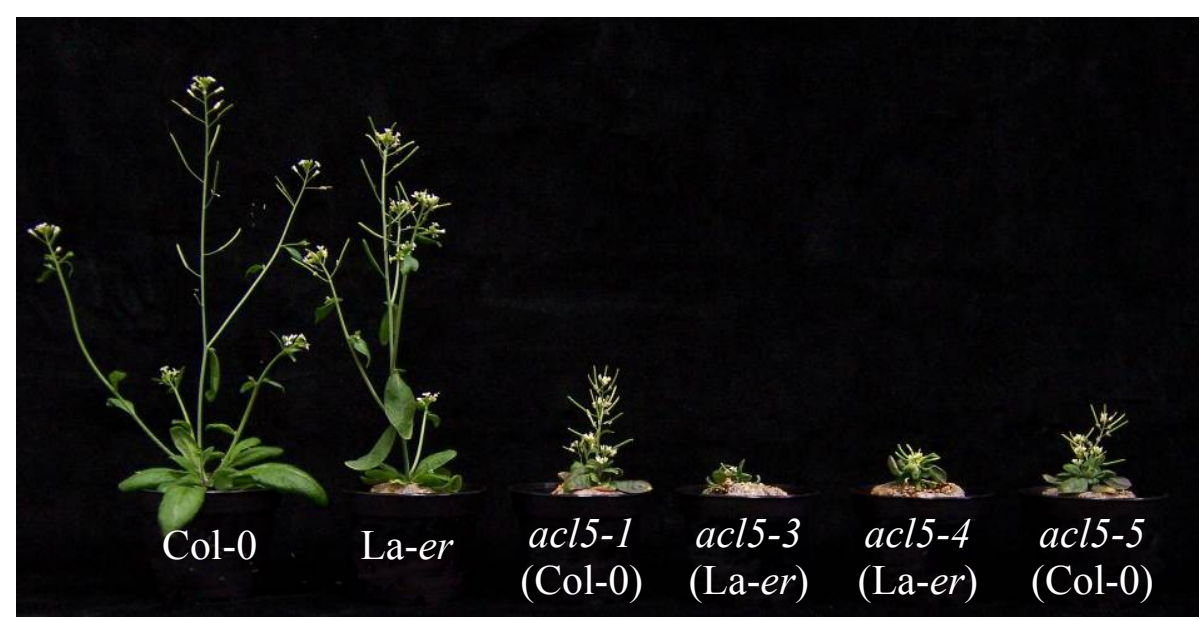

Figura 9. Alelos del mutante ac/5. El alelo ac/5-2 no se muestra por ser idéntico al ac/5-1. Entre paréntesis se indica el fondo genético en el que se encuentra cada mutación.

Una causa que explicaría las diferencias de severidad del fenotipo, sería la diferente naturaleza de las mutaciones en cada alelo; así, un alelo nulo provocaría un efecto mayor que uno hipomorfo. Esta explicación concuerda con que uno de los alelos débiles, acl5-1, presenta una alteración molecular que consiste en tan sólo una sustitución aminoacídica, mientras que sus niveles de RNA no son inferiores a los de una planta silvestre (Hanzawa et al. 2000); sin embargo, esta hipótesis no parece concordar con el fenotipo de los otros tres alelos. Los mutantes acl5-3, acl5-4 y acl5-5 son mutantes nulos de RNA, pero 
mientras el fenotipo de los dos primeros es muy severo, el de acl5-5 es más leve.

Una explicación alternativa de la gradación sería la existencia de un modulador de $A C L 5$, debido al distinto fondo genético de cada uno de los alelos. El alelo acl5-1 fue encontrado en un fondo genético Landsberg erecta (La-er) y más tarde introgresado en un fondo Columbia-0 (Col-0) mediante 3 ciclos de retrocruces (Hanzawa et al. 2000); acl5-5 también se encuentra en un fondo Col-0, mientras que acl5-3 y acl5-4 están en el fondo La-er. Así pues, los alelos más leves, acl5-1 y acl5-5, se encuentran en fondo Col-0, mientras los más severos están en fondo La-er.

Una de las principales diferencias entre ambos fondos es la pérdida de función del gen ERECTA (ER), característica del fondo genético La-er (van Zanten et al. 2009) siendo esta mutación, la responsable de múltiples efectos pleiotrópicos que afectan, por ejemplo, a la arquitectura floral (Douglas et al. 2002), a la respuesta al estrés biótico (Godiard et al. 2003) o a la transpiración (Masle et al. 2005).

Para comprobar si la causa de la gradación del fenotipo de los alelos mutantes de $A C L 5$ era la mutación del gen ER, presente en las líneas en fondo La-er, decidimos analizar el fenotipo de enanismo en poblaciones en las que sólo estuvieran segregando las mutaciones de acl 5 y er. Para ello, cruzamos el alelo acl5-4 (en fondo La-er), que tiene un genotipo doble mutante acl5 y er, con una planta Landsberg (La-0), que tiene un genotipo doble silvestre ACL5 y ER. Si nuestra hipótesis fuese correcta, en la generación F2 observaríamos un 18,75\% de plantas enanas con fenotipo leve (genotipo acl5 ERECTA) y un $6,25 \%$ de plantas enanas con fenotipo severo (genotipo acl5 er); mientras que si fuese errónea, encontraríamos únicamente plantas enanas con fenotipo severo. Como se puede ver en la Figura 10, en la generación F2 aparecieron tanto plantas enanas leves como severas, y en proporciones parecidas a las esperadas, lo cual indica que $E R$ es un modulador del fenotipo de $a c l 5$, y sugiere que $E R$ y $A C L 5$ interaccionan genéticamente para controlar el tamaño del tallo. 


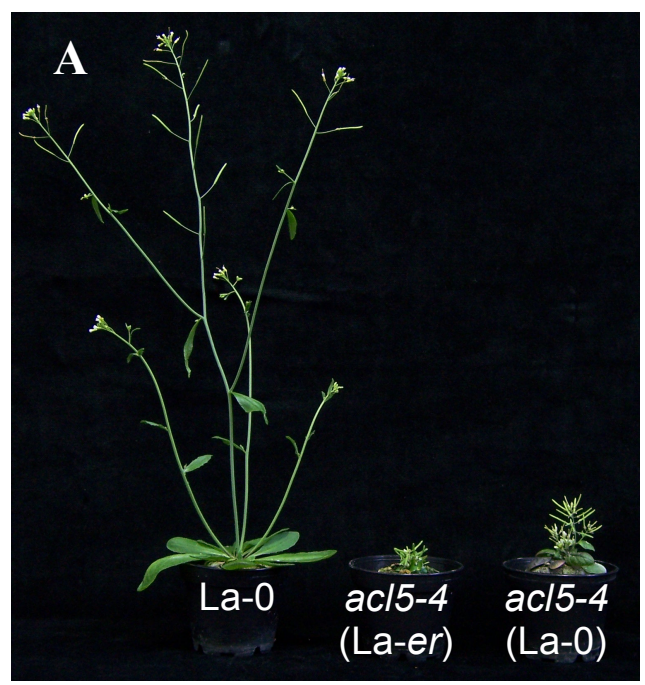

B

Segregación de la F2 del cruce La-0 x acl5-4 (La-er)

\begin{tabular}{|c|c|c|}
\hline Fenotipo & Cantidad & $\%$ \\
\hline Fenotipo silvestre & 119 & 66.5 \\
\hline Fenotipo acl5-4 (La-0) & 48 & 26.8 \\
\hline Fenotipo acl5-4 (La-er) & 12 & 6.7 \\
\hline
\end{tabular}

Figura 10. Cruce entre La-0 x ac/5-4 (La-er)

A- Plantas parentales y resultado de la segregación en la F2, ac/5-4 (La-0).

B- Tabla con la segregación en la F2 del cruce.

\subsection{Caracterización genómica del alelo acl5-4}

Otra estrategia para encontrar moduladores de ACL5 sería la búsqueda de supresores extragénicos del mutante acl5 mediante un proceso de mutagénesis con metanosulfonato de etilo (EMS), siendo el criterio de búsqueda, la recuperación del fenotipo enano del mutante.

Para evitar la posible aparición de falsos positivos por reversión de la mutación acl5, decidimos utilizar el alelo acl5-4 (mutante por deleción) en lugar de acl51 (mutante puntual) para la mutagénesis. Además, el fenotipo más severo de acl5-4 nos permitiría encontrar líneas supresoras más débiles del fenotipo enano. El único problema que planteaba acl5-4, era el desconocimiento de la secuencia del fragmento delecionado, del que únicamente sabíamos que debía tener un tamaño de $2,4 \mathrm{~Kb}$ (Hanzawa et al. 2000); por ello decidimos caracterizar la deleción, para poder diseñar un sistema de genotipado por PCR de las líneas supresoras y, además, para asegurarnos que la deleción no afectaba a ningún gen contiguo a $A C L 5$. 
Una primera aproximación para conocer con precisión la secuencia del fragmento delecionado consistió en amplificar por PCR pequeños fragmentos en las regiones $5^{\prime}$ y $3^{\prime}$ de $A C L 5$ en el mutante acl5-4. De esta manera se determinó que la deleción afectaba a la zona $5^{\prime}$ del gen. A continuación se digirió el DNA genómico del mutante acl5-4 con Xba I, se forzó la formación de moléculas circulares de DNA mediante ligación intramolecular, y se realizó una PCR con los oligos inversos indicados en negro en la Figura 11, para determinar con precisión las secuencias flanqueantes a la deleción. De esta manera se pudo concluir que la deleción abarca desde la posición -693 hasta la +1370 tomando como referencia la posición de la adenina del codón de inicio de ACL5. La información obtenida mediante este análisis permite descartar que la deleción afecte a la región codificante de ningún gen vecino. Además, se pudo diseñar un método de genotipado por PCR, basado en la utilización de dos oligonucleótidos que flanquean la región delecionada y, un tercero, dentro de dicha región (ver Materiales y Métodos, página 124).

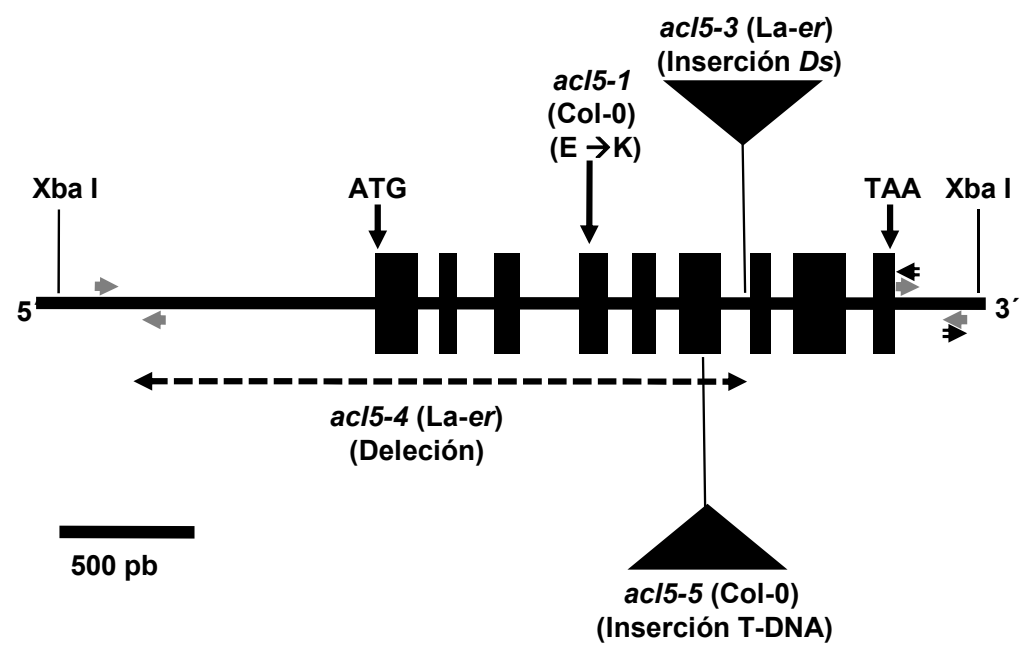

Figura 11. Caracterización genómica de los alelos del mutante ac/5. Las cajas negras representan los exones del gen $A C L 5$, estando indicados el codón de inicio (ATG) y el codón de parada (TAA). En el $4^{\circ}$ exón se muestra el cambio de aminoácido del alelo acl5-1. Los triángulos indican las inserciones de los alelos ac/5-3 y ac/5-5. La línea punteada abarca la deleción de $2 \mathrm{~Kb}$ del alelo ac/5-4, las flechas grises indican los oligonucleótidos usados en las PCRs de las regiones $3^{\prime}$ y 5 '; las flechas negras dobles indican los oligonucleótidos usados en la PCR, en la que se usó como molde el producto de la autoligación. 


\subsection{Búsqueda de supresores del mutante $a c l 5-4$}

Con la intención de encontrar mutaciones que suprimieran el defecto de crecimiento causado por la ausencia de termoespermina, se mutagenizaron con EMS alrededor de 20000 semillas de acl5-4. El análisis de la generación M1 indicó que la mortalidad causada por el tratamiento rondaba el $67 \%$, y entre las 7000 plantas supervivientes encontramos 80 líneas con una mayor altura que el parental mutante (Figura 12). Las semillas de estas líneas fueron recogidas individualmente pues podrían tratarse de líneas supresoras dominantes, y las semillas del resto de plantas fueron recogidas en 86 grupos. El rastreo de las familias M2 se inició analizando 1250 semillas de cada uno de los ocho primeros grupos, encontrando 13 líneas supresoras recesivas ( 1 en el $1^{\mathrm{er}}$ grupo, 3 en el $2^{\circ}, 2$ en el $3^{\circ}, 1$ en el $5^{\circ}, 1$ en el $7^{\circ}$ y 5 en el $8^{\circ}$ ).

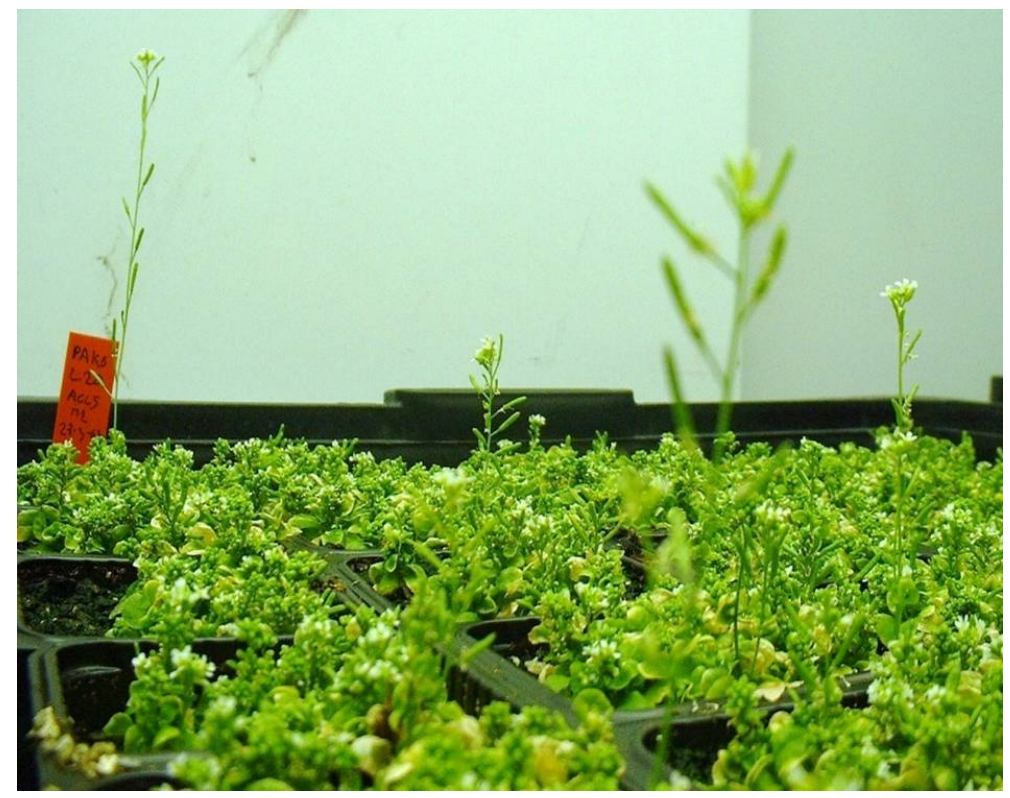

Figura 12. Generación M1 de plantas ac/5-4 mutagenizadas con EMS; se pueden apreciar diversas líneas supresoras de mayor altura que el mutante ac/5-4. 
Ante la gran cantidad de supresores potenciales que habíamos identificado en el rastreo, decidimos cesar el análisis de la M2 y concentrar el esfuerzo en los obtenidos a partir de la M1, por su posible naturaleza dominante.

\subsection{Caracterización fenotípica de los supresores dominantes de $a c l 5-4$}

Para comprobar el fenotipo supresor de los mutantes aislados durante el rastreo de la M1, se sembraron alrededor de 30 semillas de cada una de las 80 líneas identificadas y se analizó la segregación del fenotipo de recuperación del tamaño del tallo. Esto permitió eliminar 40 líneas que no mantenían el fenotipo supresor en su progenie, o que simplemente no germinaron.

Para evitar que se diluyesen nuestros esfuerzos ante tan extenso número de líneas, decidimos priorizar el estudio de todas aquellas que cumplieran tres criterios de selección:

$1^{\circ}$. Se descartarían aquellas líneas que fuesen contaminaciones de plantas silvestres y no supresores con genotipo acl5-4. Para ello, genotipamos cada una de las líneas siguiendo el método descrito previamente, comprobando que todas ellas eran portadoras del alelo acl5-4 y no había ninguna contaminación (Figura $13)$. 


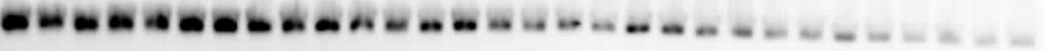

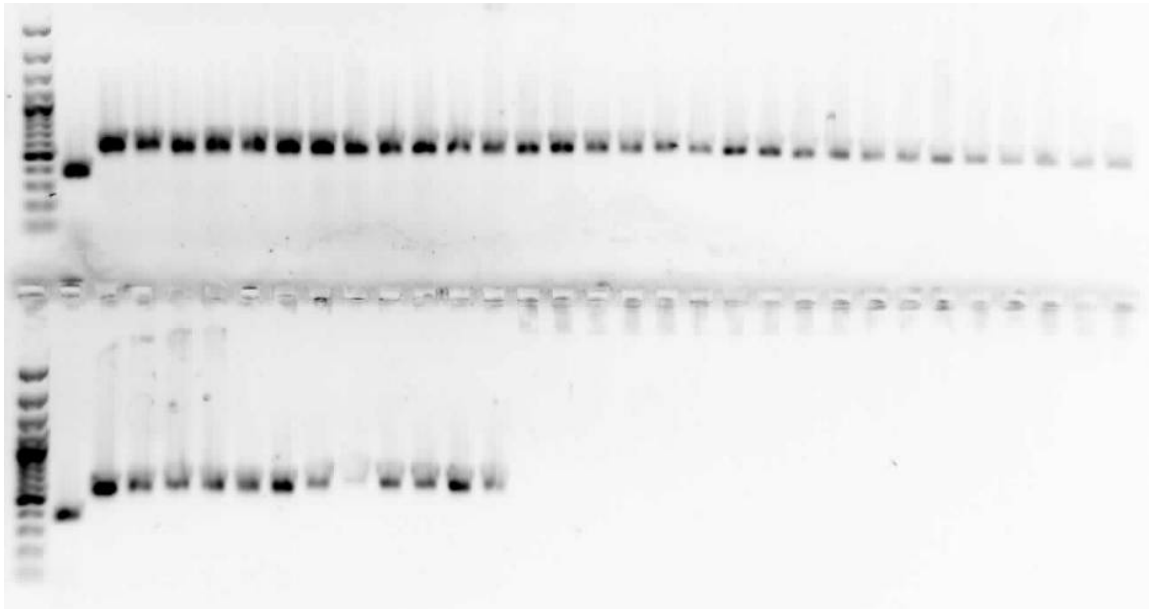

Figura 13. Gel de agarosa para genotipar la deleción del alelo ac/5-4 mediante PCR con DNA genómico de las líneas supresoras, en el carril superior el orden de las muestras, de izquierda a derecha, es La-er, ac/5-4, líneas I, IV, V, VI, VII, VIII, X, XII, XIV, XVI, XVII, XVIII, XX, XXI, XXIII, XXIV, XXVI, XXVII, XXVIII, XXIX, $X X X I, X X X I X, X L V I, X L V I I I, L, L I$, LII y LIII; en el carril inferior el orden de las muestras, de izquierda a derecha, es Col-0, acl5-4, líneas LIV, LVIII, LIX, LX, LXV, LXVI, LXVII, LXIX, LXXVII, LXXIX y LXXX. Una banda de $548 \mathrm{pb}$ corresponde al genotipo ac/5-4 y una banda de $376 \mathrm{pb}$ corresponde a genotipo silvestre. El marcador de DNA es el GeneRulerTM 100 bp Plus DNA Ladder (Fermentas).

$2^{\circ}$. Eliminar aquellas líneas que no segregasen del modo esperado para una mutación monogénica dominante. Así pues, analizamos la segregación del fenotipo supresor en la progenie de cada línea seleccionada en la M1 y descartamos todas aquéllas con menos de un 50\% de individuos supresores (Tabla 1).

$3^{\circ}$. Priorizar el estudio de las líneas que no presentaran problemas adicionales de germinación. Para establecer esta categoría consideramos que las líneas en las que germinaban menos de un tercio de 30 semillas sembradas presentaban graves defectos de germinación y, por tanto, fueron apartadas (Tabla 1). 
Tabla 1. Tabla de segregación de la población M2 de las 80 líneas M1. Sólo se muestran las 40 líneas M1 que contenían plantas con fenotipo supresor en la M2, las otras 40 líneas fueron eliminadas al no volver a presentar fenotipo supresor en la M2. El color marrón señala aquellas líneas eliminadas por germinar menos de un tercio de las semillas. El color gris señala las líneas eliminadas por tener un porcentaje menor al $50 \%$ de plantas supresoras en la M2.

\begin{tabular}{|c|c|c|c|c|c|c|c|}
\hline Línea & $\begin{array}{l}\text { Fenotipo } \\
\text { supresor }\end{array}$ & $\begin{array}{c}\text { Fenotipo } \\
\text { acl5 }\end{array}$ & $\begin{array}{l}\text { Porcentaje } \\
\text { supresores }\end{array}$ & Línea & $\begin{array}{l}\text { Fenotipo } \\
\text { supresor }\end{array}$ & $\begin{array}{c}\text { Fenotipo } \\
\text { acl5 }\end{array}$ & $\begin{array}{l}\text { Porcentaje } \\
\text { supresores }\end{array}$ \\
\hline$T$ & 3 & 0 & $\overline{100}$ & XXXI & 18 & 9 & 67 \\
\hline IV & 15 & 8 & 65 & XXXIX & 16 & 2 & 89 \\
\hline V & 16 & 8 & 67 & XLVI & 1 & 6 & 14 \\
\hline VI & 17 & 8 & 68 & XLVIII & 14 & 7 & 67 \\
\hline VII & 19 & 7 & 73 & L & 12 & 14 & 46 \\
\hline VIII & 15 & 4 & 79 & LI & 11 & 8 & 58 \\
\hline$x$ & 25 & 3 & 89 & LII & 2 & 0 & 100 \\
\hline XII & 10 & 12 & 45 & LIII & 4 & 21 & 16 \\
\hline XIV & 4 & 19 & 17 & LIV & 5 & 1 & 83 \\
\hline $\mathrm{XVI}$ & 20 & 6 & 77 & LVIII & 20 & 4 & 83 \\
\hline$X V I I$ & 27 & 2 & 93 & LIX & 2 & 17 & 11 \\
\hline XVIII & 17 & 4 & 81 & LX & 18 & 5 & 78 \\
\hline$X X$ & 4 & 10 & 29 & LXV & 6 & 17 & 26 \\
\hline XXI & 16 & 2 & 89 & LXVI & 19 & 5 & 79 \\
\hline XXIII & 5 & 5 & 50 & LXVII & 1 & 3 & 25 \\
\hline XXIV & 12 & 4 & 75 & LXIX & 18 & 9 & 67 \\
\hline XXVI & 16 & 8 & 67 & LXXVII & 17 & 9 & 65 \\
\hline XXVII & 12 & 6 & 67 & LXXIX & 18 & 6 & 75 \\
\hline XXVIIII & 18 & 3 & 86 & LXXX & 3 & 1 & 75 \\
\hline XXIX & 3 & 1 & 75 & & & & \\
\hline
\end{tabular}

Una vez finalizado el proceso de selección, renombramos a estas 24 líneas dobles mutantes (acl5-4 + mutación responsable del fenotipo supresor) con el nombre de ajax (ajx) en referencia a Ajax $^{1}$

1 Ajax: Héroe mitológico griego. En La llíada de Homero se le describe como un guerrero de gran altura y fuerza colosal, que se suicidó tras una disputa con Ulises por la armadura de Aquiles. 
Con el objetivo de seleccionar un número razonable de mutantes para someter a un cartografiado génico, decidimos aplicar un criterio de diversidad y clasificación fenotípica como alternativa al análisis de complementación, que habría sido un abordaje más ortodoxo, pero más complicado y dilatado en el tiempo al haber requerido la realización de 276 cruces entre las distintas líneas ajax. Este análisis fenotípico se centró en la capacidad de supresión del defecto causado por la pérdida de función de $A C L 5$ en diversos caracteres.

El primer carácter analizado fue la altura de cada línea. Atendiendo a este carácter, las distintas líneas presentaban una notable variación en el nivel de supresión (Figura 14).

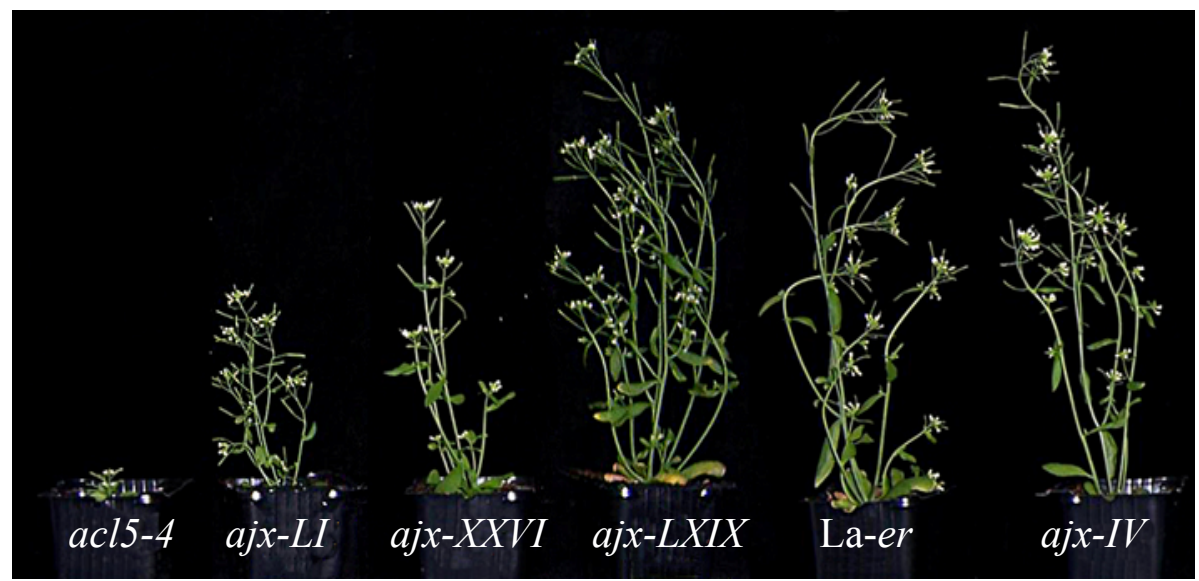

Figura 14. Líneas supresoras ajx de diversas alturas.

Esta gradación podía deberse a variaciones alélicas dentro de un mismo gen mutado (es decir, alelos distintos con distinta actividad supresora) o a mutaciones en genes distintos. En previsión de que se tratara de una combinación entre ambas posibilidades, establecimos tres categorías distintas en función de la altura final de 14 líneas representativas (Figura 15), razonando que sería más fácil evitar la duplicidad innecesaria del trabajo de cartografiado si nos centrábamos en un mutante de cada una de las distintas categorías. 


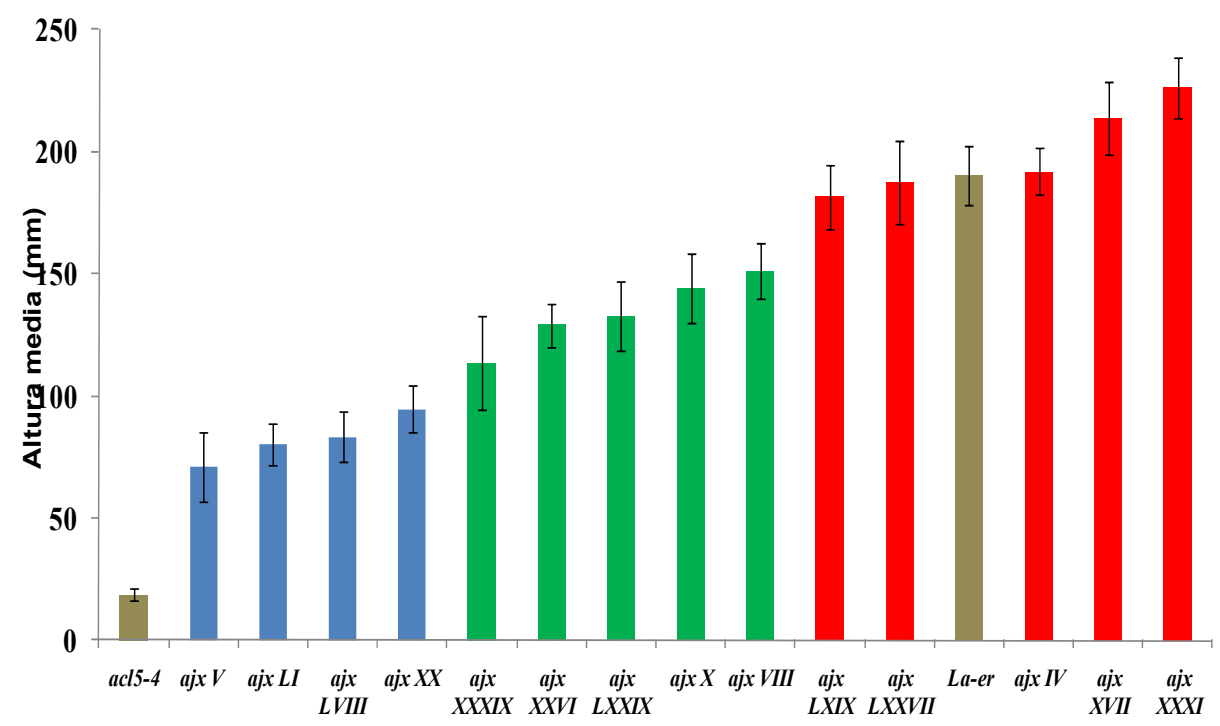

Figura 15. Altura de las líneas supresoras ordenadas de menor a mayor. En color gris las líneas control ac/5-4 y La-er, en color azul las líneas de altura sensiblemente menor al silvestre, en color verde las líneas de altura levemente inferior al silvestre, en color rojo las líneas de altura similar al silvestre. La altura media se calculó sobre un mínimo de 10 individuos, las barras de error representan la desviación estándar.

El segundo carácter analizado fue la capacidad de supresión de la proliferación de los haces vasculares mostrada por el mutante acl5 (Hanzawa et al. 1997; Muñiz et al. 2008). Para ello se examinaron al microscopio secciones transversales de los tallos de las distintas líneas supresoras. Al igual que con la altura de la planta, se detectó una gradación entras las diferentes líneas ajx (Figura 16). Curiosamente, se apreció una relación directa entre la capacidad de supresión de la proliferación de haces vasculares y la altura de cada línea. Únicamente la línea ajx-IV escapó a esta regla, al tener una altura similar al silvestre y una gran cantidad de haces vasculares. 


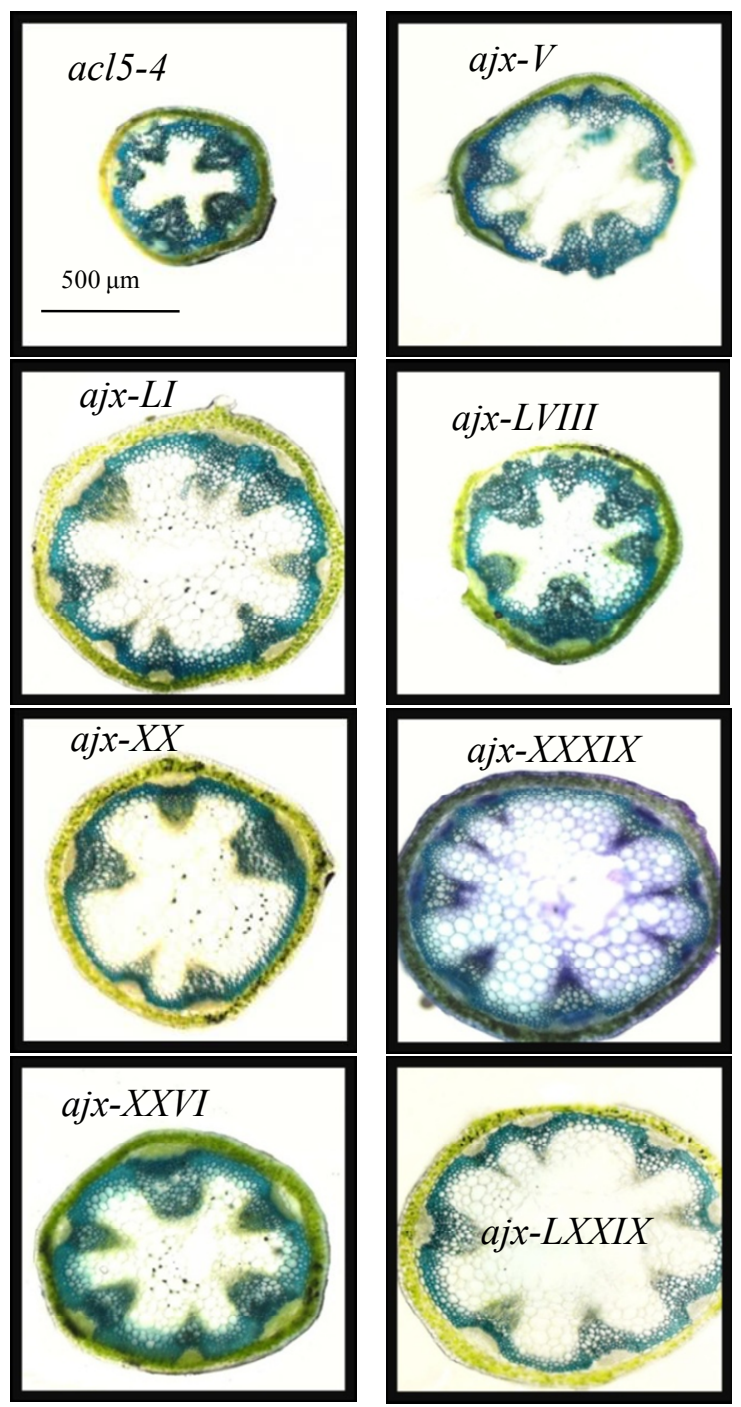

Figura 16 (I). Cortes histológicos de los supresores (I). Cortes transversales de tallos basales de plantas de 6 semanas teñidos con azul de toluidina. Las líneas están ordenadas al igual que en la figura anterior de menor a mayor altura. 


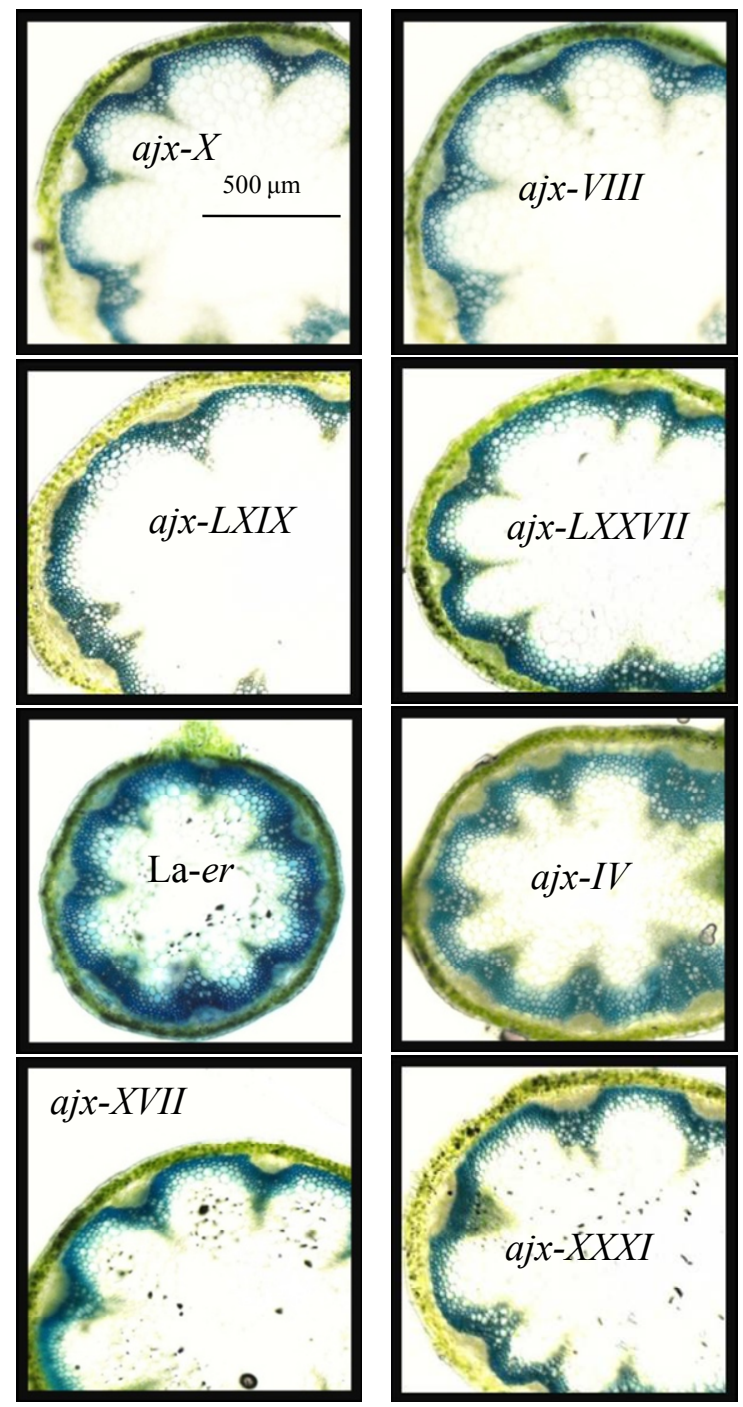

Figura 16 (II). Cortes histológicos de los supresores (II). Cortes transversales de tallos basales de plantas de 6 semanas teñidos con azul de toluidina. Las líneas están ordenadas al igual que en la figura anterior de menor a mayor altura. 
A la vista de estos resultados, establecimos como prioridad la clonación posicional de los genes mutados en las líneas ajx-X, ajx-XXXI y ajx-IV. Las dos primeras correspondían a las dos categorías de mayor altura de tallo, mientras que la tercera presentaba un comportamiento especialmente atractivo en principio, por no coincidir perfectamente la altura de la planta con la capacidad de suprimir el defecto de los haces vasculares.

El particular fenotipo de ajx-IV nos llevó a analizar otro carácter defectivo de la mutación $a c l 5$, que además se ha propuesto como la causa primaria del defecto de dicho mutante: la incapacidad de formar metaxilema (Muñiz et al. 2008). Este tipo celular del xilema lo componen células muertas que forman la auténtica canalización funcional para el transporte de agua y sales minerales. Su identidad se reconoce principalmente por la ornamentación punteada de su pared celular. Puesto que $a j x-I V$ parece mantener el defecto de hiperproliferación del tejido vascular, la cuestión a resolver era si dicha proliferación se producía a costa del metaxilema, como en acl5. Como se ve en la Figura 17, tanto ajx-IV como las otras dos líneas seleccionadas para la clonación posicional (ajx- $X$ y aj $x-X X X I)$ recuperaban con la misma eficiencia la proporción de células de metaxilema, hasta alcanzar valores equivalentes a los observados en el silvestre. 


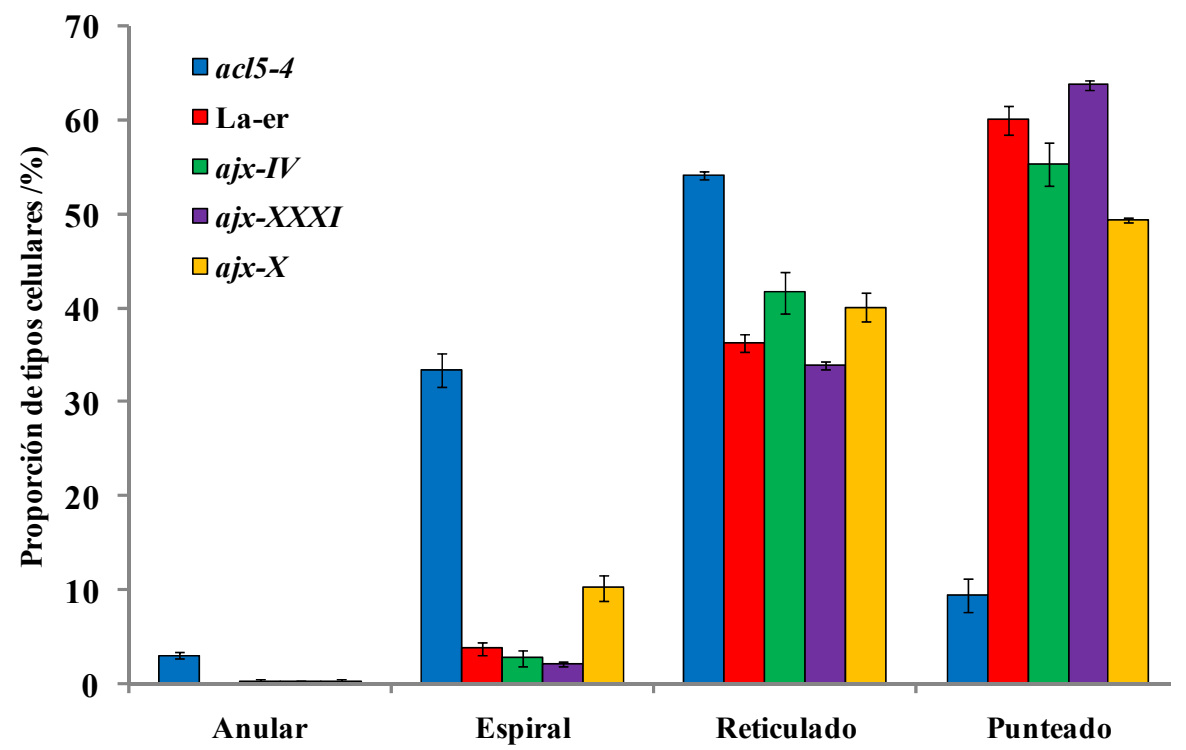

Figura 17. Cuantificación de los tipos celulares de protoxilema y metaxilema en las líneas supresoras. Las barras de error representan la desviación estándar.

\subsection{Clonación posicional de $A J A X 1$ y $A J A X 2$}

Para llevar a cabo la clonación posicional de los genes mutados de las líneas $a j x-I V, a j x-X$ y $a j x-X X X I$, se generaron mediante cruce, poblaciones $\mathrm{F} 2$ entre dichos mutantes (cuyo genotipo relevante sería $a c l 5-4$ ajx-D en fondo La-er) y el mutante $a c l 5-5$ (en fondo Col-0). En una primera fase se seleccionaron 50 individuos con fenotipo enano (homocigotas para acl5 y para el locus silvestre de $A J A X^{C o l}$ ) de cada una de dichas poblaciones. Dichos individuos se utilizaron para realizar un cartografiado de baja resolución en el Servicio de Cartografiado Génico de la Universidad Miguel Hernández de Elche. Fruto de este análisis se pudo concluir que ajx-IV portaba una mutación supresora en el cromosoma 5, mientras que ajx- $X$ y ajx- $X X X I$ portaban mutaciones en una misma región del cromosoma 1. Puesto que este resultado sugería un probable alelismo entre estas dos últimas mutaciones, se decidió proseguir únicamente con el cartografiado de dos de las tres líneas, ajx-IV y ajx-XXXI, posponiendo la comprobación del 
alelismo para cuando se conociera la identidad del gen mutado en esta última línea.

El cartografiado de alta resolución de ajx-IV y ajx-XXXI se efectuó a partir de mutantes enanos de la F2 de los cruces previamente mencionados, en los que se analizó la frecuencia de recombinación de diversos marcadores moleculares polimórficos para las accesiones Col-0 y La-er. Dicho análisis se llevó a cabo tanto en el Servicio de Cartografiado Génico de la Universidad Miguel Hernández de Elche, como en nuestro laboratorio (ver Materiales y Métodos, página 126). Como resultado, el intervalo para la presencia de los loci mutados quedó reducido a 81 y $93 \mathrm{~Kb}$ en las líneas ajx- $I V$ y ajx-XXXI, respectivamente (Figuras 18 y 19).

Figura 18. Clonación posicional del gen AJAX1.

A- Representación del cromosoma 5 de A. thaliana entre $23 \mathrm{Mb}$ y $29 \mathrm{Mb} ; \alpha-$ marcador MUA2, $\beta$ - marcador $\mathrm{K} 8 \mathrm{~K} 14$; los números indican las plantas recombinantes con al menos un alelo Col-0 para cada marcador.

B- Representación de la región de $136 \mathrm{~Kb}$ con 3 BACS solapantes, resultante del análisis de alta resolución; $\chi$ - Marcador Cer455797, $\delta$ - Marcador Cer458067, $\varepsilon$ - Marcador Cer440084.

C- Representación de la región de $81 \mathrm{~Kb}$ con 22 genes candidatos, desde el At5g64230 hasta el At5g64440, resultante del análisis de dCAPS. En rojo el gen At5g64340 donde se encontró la mutación.

D- Representación de la secuencia genómica del gen At5g64340. En letra negra mayúscula, la ORF principal; en letra verde mayúscula, las UORF; en letra azul la secuencia de aminoácidos; en letra lila y subrayada base $(C \rightarrow T)$ y aminoácido $(P \rightarrow S)$ mutagenizados. Un triángulo negro indica un codón de inicio de traducción, un triángulo rojo indica un codón de continuación de traducción de un exón. 
A

\section{Cromosoma 5}
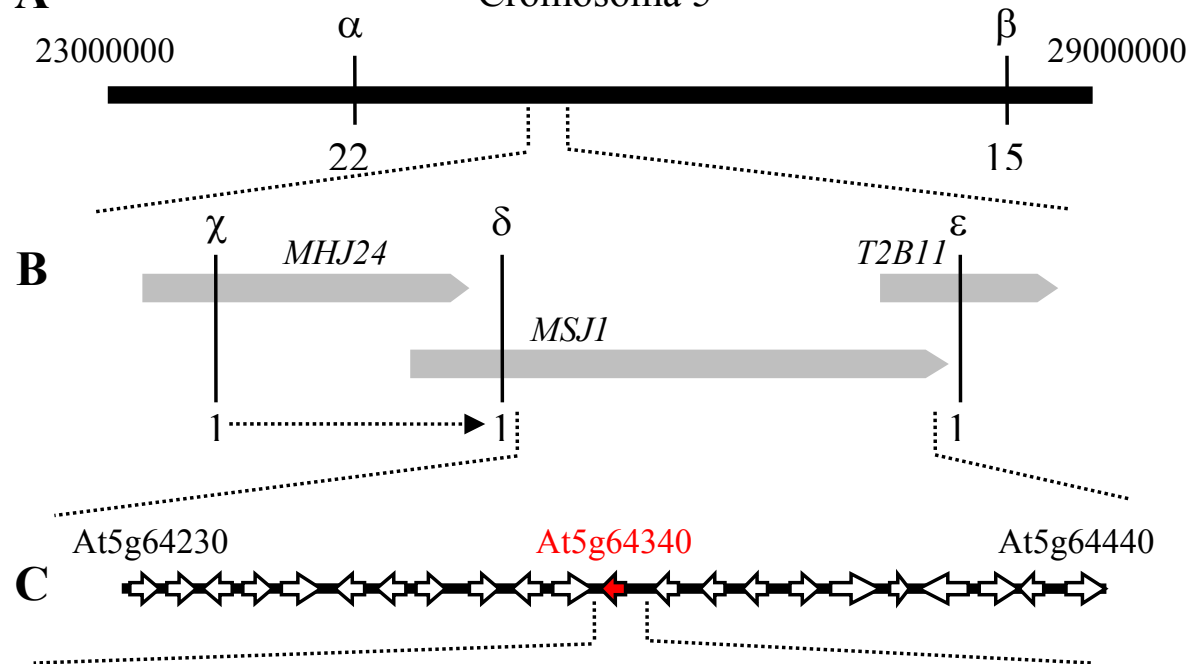

D

tactaagtaggtttgagtgatcagaatcaattagagtgtgtataagaggaagagaaagagaaaacago AIG IGI ATI GCC GTA TAC CGI AAA GTI - Met Cys lle Ala Val Tyr Arg Lys Val ITG AGC ITG AAI CTG TAI IGC CGI GIG ATA CTG TAG attgtttcacotttgaagcaacacottcaagagtcaatcottttctttcttattcato Leu Ser Leu Asn Leu Tyr Cys Arg Val IIe Leu

ttccottcttttcggtatattataacactttgaa ATG GGA TCA CAA CAT TTC TAT GTG TAC CAI IGT GAA CAA AGA ATC AGC TAG - Met Gly Ser Gln His Phe Tyr Val Tyr His Cys Glu Gln Arg lle Ser actaaagctcactctcottccacaaacaaacttcctcotttggtttggtatctgtctactttcttcaatcaagatttcotcaaagtt ATG GTG TGC Met Val Cys

CAA TCA CCT GGT AAG ACA AGA TIT CGA GGA ITG AAG TAC GAG ACC GGA AAC GCT AAC GAA TCA ACA ATT GTA GTG AGA GTT GIn Ser Pro Gly Lys Thr Arg Phe Arg Gly Leu Lys Tyr Glu Thr Gly Asn Ala Asn Glu Ser Thr IIe Val Val Arg Val ATT GAA TGC TAT CAA CCG ATG GAT A.AT TGC CAG gtttgtaccagacaataatgctcttgttatcatacttttagcttatatagttctagtcttcta IIe GIu Cys Tyr GIn Pro Met Asp Asn Cys GIn

acactgtggtttgtgattattcttgtgtttcag GCI GAG TAC ITC AGA CIT CTA CIC AAA CCA GIC ACG IAG ttggttggtgacatttogo - Ala GIu Tyr Phe Arg Leu Leu Leu Lys Pro Val Thr

tgcatttttcaatctgtgattgtttttcgttcgtctttctttactattttctcgaaaggacacaagaagtattgcattcactcagttgagcaacttaacaatcgg tatgctctttccctctaattacgcttgtgatattactgactttatcttettgagctgattttgcctctgtttgtcctgcagtgttgtactttttgaagttcco ttgagotaaactgotaagago ATG CCT CTG GAT AAG AGG CAA CGG GAT TTG CCT CTG GGC TTA AGT CCT CAA GCT TGC TTC AAG - Met Pro Leu Asp lys Arg Gin Arg Asp Leu Pro Leu Gly Leu Ser Pro Gin Ala Cys Phe Lys GAT ATA GTA GGT CGG TCT GTC CTT CCT AGA ATT CCT CTC CCT GAG CTI GGG AAA CTA TAT GCA GCT AAG CTI CAG GCT CGC Asp lle Val Gly Arg Ser Val Leu Pro Arg lle Pro Leu Pro Giu Leu Gly Lys Leu Tyr Ala Ala Lys Leu Gin Ala Arg TGT ITG CAG CCA CCA CCA ITC CAG TCT ITG CTG TGC AGT CAT GAT AAG GAG TCT TAT GGA AAA AGA ITC TCA CGG TCT GAC Cys Leu Gln Pro Pro Pro Phe Gln Ser Leu Leu Cys Ser His Asp lys Glu Ser Tyr Gly Lys Arg Phe Ser Arg Ser Asp ATG CGG TCT TGG TGC GCT GCT GCT ACT ACT ACT ACT ACT CCA CTT GGA GCA TTA GAG TCT TCT CAG AAA AGA CTT TTG ATA Met Arg Ser Trp Cys Ala Ala Ala Thr Thr Thr Thr Thr Pro Leu Gly Ala Leu Giu Ser Ser Gin Lys Arg Leu Leu IIe ITC GAT CAG TCA GGA GAC CAG ACT CGT CTA TTA CAA TGT CCA TIT CCT CTA CGG TTI CCA TCT CAT GCG GCT GCA GAA CCA Phe Asp Gin Ser Gly Asp Gin Thr Arg Leu Leu Gln Cys Pro Phe Pro Leu Arg Phe Pro Ser His Ala Ala Ala Glu Pro GTG AAA CTC TCT GAG TTA CAA GGT ATA GAG A.A. GCT TTC A.A GA.A GAT GGT GAA GAG TTT CAC A.AG AGT GAT GGA ACA GAG Val Lys Leu Ser Glu Leu GIn Gly lle Glu Lys Ala Phe Lys Glu Asp Gly GIu Glu Phe His Lys Ser Asp Gly Thr GIu TCA GAA ATG CAT GAA GAC ACT GAG GAG ATC AAT GCA TTG CTA TAT TCA GAT GAT GAT TAT GAT GAT GAT TGC GAG AGT GAT Ser Glu Met His GIu Asp Thr Glu Glu lle Asn Ala leu leu Tyr Ser Asp Asp Asp tyr Asp Asp Asp Cys Glu Ser Asp GAT GAA GTA ATG AGC ACT GGI CAC TCT CCT TAT CCA AAT GAA GGA GTT TGC A.AC AAA AGG GA. TTA GAA GAA ATC GAT GGI Asp Glu Val Met Ser Thr Gly His Ser Pro Tyr Pro Asn Glu Gly Val Cys Asn Lys Arg Glu Leu Glu Glu IIe Asp Gly CCT TGT AAA AGG CAG AAA CTA CTG GAT AAG GTC AAC AAC ATC AGC GAC TTA TCA TCA CTT GIG GGC ACT GAG AGC TCC ACA Pro Cys Lys Arg Gin Lys Leu Leu Asp Lys Val Asn Asn IIe Ser Asp Leu Ser Ser Leu Val Gly Thr Glu Ser Ser Thr CA.A CTC A.AT GGA TCT TCC TIT CTT A.AG GAC A.A.A A.AG CTC CCT GAA TCA A.A. ACC ATA TCG ACC A.A. GAG GAC ACT GGT TCT GIn Leu Asn Gly Ser Ser Phe Leu Lys Asp Lys Lys Leu Pro Glu Ser Lys Thr Ile Ser Thr Lys Glu Asp Thr Gly Ser GGT CTG AGC AAC GAG CAG TCG AAG AAA GAC AAG ATC CGC ACA GCT CTG AAA ATA CTC GAG AGC GTA GTC CCT GGT GCA AAA Gly Leu Ser Asn GIu GIn Ser Lys Lys Asp Lys IIe Arg Thr Ala Leu Lys IIe Leu Glu Ser Val Val Pro Gly Ala Lys GGA AAC GAA GCG CTC TTA CTT CTG GAC GAA GCA ATT GAT TAC CTA AAG TIG CTG AAA CGA GAC TTA ATC TCC ACA GAG GTI

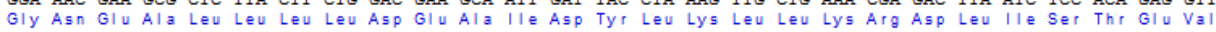
AAG AAC CAA AGC TCC ACC ACT CAC AAG TCA CCA ATC TTG TTG CTT AAA GAG ACA ACA TGG GGA ACA AGA AAT CTG CAG ACA Lys Asn Gin Ser Ser Thr Thr His lys Ser Pro lle Leu Leu Leu lys Glu Thr Thr Trp Gly Thr Arg Asn Leu Gln Thr GAT AAG GCG TGA aagattctgacgagttaaacgtgtgaagtgggtttttgggtacgtatcotctgcaccagctttttagctgtatatagtggactactttta Asp Lys Ala

agtattatatatgctactgcaatttcaaaagttaaagagaaagaggtcacttcttcttctctctgtgtggaatgaaagccaagtcgtcatggtcattgat 
Para localizar las mutaciones correspondientes dentro de los intervalos, escogimos una estrategia de secuenciación de los genes comprendidos en dichos intervalos, a partir de DNA genómico de ajx-IV y ajx-XXXI. Tras secuenciar tres genes en ajx-IV,y doce en ajx-XXXI, localizamos en cada línea una mutación del tipo $\mathrm{G} / \mathrm{C} \rightarrow \mathrm{A} / \mathrm{T}$, acorde a lo esperable para una mutación inducida por EMS (Greene et al. 2003).

La mutación en ajx-IV se encuentra en la región correspondiente a la 5 '-UTR del gen At5g64340, que pasó a denominarse AJAX1 (AJX1), mientras que el alelo mutante se renombró como ajx1-4. Sorprendentemente, la mutación de ajx-XXXI se localizaba asimismo en la región 5'-UTR del gen At1g29950, que pasó a denominarse $A J A X 2$ (AJX2); el correspondiente alelo mutante se renombró como ajx2-31. En los correspondientes RNA mensajeros, las mutaciones identificadas afectan a un pequeño marco abierto de lectura (uORF, upstream Open Reading Frame) diferente al marco abierto de lectura principal del gen (ORF, Open Reading Frame) y, en ambos casos, resultan en un cambio de aminoácido en el pequeño péptido supuestamente codificado por la uORF.

Figura 19. Clonación posicional del gen AJAX2.

A- Representación del cromosoma 1 de A. thaliana entre $8 \mathrm{Mb}$ y $12 \mathrm{Mb} ; \alpha-$ marcador AthZFPG, $\beta$ - marcador SNP10026; los números indican las plantas recombinantes con al menos un alelo $\mathrm{Col}-0$ para cada marcador.

B- Representación de la región de 222 Kb con 4 BACS solapantes, resultante del análisis de alta resolución; $\chi$ - Marcador Cer479911, $\delta$ - Marcador Cer480732, $\varepsilon$ - Marcador Cer479895.

C- Representación de la región de $93 \mathrm{~Kb}$ con 21 genes candidatos, desde el At1g29830 hasta el At1g30020, resultante del análisis de dCAPS. En rojo el gen At1g29950 donde se encontró la mutación.

D- Representación de la secuencia genómica del gen At1g29950. En letra negra mayúscula, la ORF principal; en letra verde mayúscula, las UORF; en letra azul la secuencia de aminoácidos; en letra lila y subrayada base $(C \rightarrow T)$ y aminoácido $(\mathrm{L} \rightarrow \mathrm{F})$ mutagenizados. Un triángulo negro indica un codón de inicio de traducción, un triángulo rojo indica un codón de continuación de traducción de un exón. 
A

Cromosoma 1

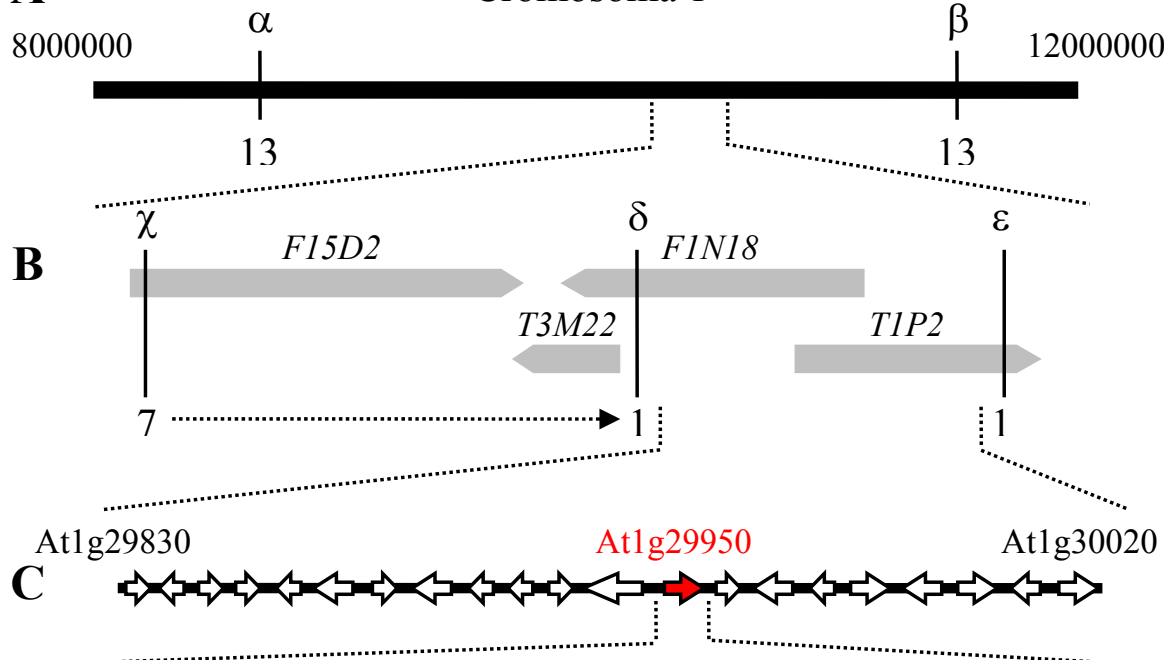

D

tttggtttgtgatcatgaaatcgaaaacatttattctggatcogatgttaatgtctttagtcatgatcotatctttttgtttgttgtacgcag ATC

CCT AAA GIT GTG CIT TTT TAT TAT CTG AAT CAG GAA TTA GAA ATT TCC CAT TTT TTT GTT TCT CTG TTT TCT TTT Pro Lys Val Val Leu Phe Tyr Tyr Leu Asn GIn Glu Leu Glu Ile Ser His Phe Phe Val Ser Leu Phe Cys Phe GCC AGT AGI TAI III AGG ATI CTA CCI CGA Agttagtgccttcaacttcctatactgaaatatattagtatttgaatagcgttggtc Ala Ser Ser Tyr Phe Arg Ile Leu Pro Arg

ctaattttgtttgtttgtgcagAG TIT GTG AGA AGA GGA ACG GTA TTT AAT ACA CTI ACA AAT ITG ATA ITG GAA GAA - Phe Val Arg Arg Gly Thr Val Phe Asn Thr Leu Thr Asn Leu Ile Leu GIu GIu CCA AAG ATG CCC TGG ACA GCA TTC TTC ATG TTT TTC AAC AGA ACT TGC ACT CGT CTG GTT GTC TTT ITC CTC GTT Pro Lys Met Pro Trp Thr Ala Phe Phe Met Phe Phe Asn Arg Thr Cys Thr Arg Leu Val Val Phe Phe Leu Val AII CIG TAA ttttgttcotttcaggtgagccagcctctcattcacatcttgtgttttgtcttacattggtaccttgtggaagcaaatttgttg Ile Leu

ttgccacctatatacagcttcttgtgttaaactattggcatctcttccttgttttgcaggtgttgtttcoggaattcggaatagttotttgttgttg tgottattatactggttagtttgtgaga ATG TGC AII GII GGA A.AC A.AG A.AG GGA A.AC CGA TCA ITG A.AG GAA ATA GGA

- Met Cys IIe Val Gly Asn Lys Lys Gly Asn Arg Ser Leu Lys Glu lle Gly

ACI TIT ATG ATG ACI ACA IGT TIC ATI GCI AAI TAC CAA TCC GII CAA GIT IGC CAG gtacatgcctctctttgatttag Thr Phe Met Met Thr Thr Cys Phe lle Ala Asn Tyr Gin Ser Val Gin Val Cys Gin

tatttcctaacacttctatcgcttaggcaacactgatttatgtcattaaagaactctatcctcttgatgacatgtggatagctatttgttagagtatt aaccatagttttctgatattcaaccttcttataatcattgcag GCT GAA TAI ITC AGA CAG TTG CTI A.AG CCT GTA ACG TAG -Ala Glu Tyr Phe Arg GIn Leu Leu Lys Pro Val Thr

tctagcgtctggagttttcggaattggggttttgagcggctatctacttttgatttcgaaaaatttactgtgagttgttaaagagtctggtattctg aagagctgtctgtgggggagcttctggtttggggggtaagggctctggtggaactcgtgatatctttagtatgatggccataacttgatatagcattt ggttcogtgtgtcaacttagtgtagtagtaactgagcagctggaagcttacaaaggogacaaatoggtagtagaaaatattcaagcagcttgcagtttg aggtgtacalottgttttctctttgcgtttcotttttacgtttgcacgggttttctg ATG CAG AAC AAT CAG TIT CCT CAC TIC TCA - Met GIn Asn Asn GIn Phe Pro His Phe Ser

GAT GAA GIG GGT GAC AGA AAT ATG CAC AAC CCG TAT GCA TCA GGG TCA TCC TAT GAT GCT TTG TIC CCA CCA TGI Asp Glu Val Gly Asp Arg Asn Met His Asn Pro Tyr Ala Ser Gly Ser Ser Tyr Asp Ala Leu Phe Pro Pro Cys GCA A.AG ITG CCA TAC CAT GGT GTT GAA CTT CAA CCG TCT GCG GTC TGT CCA AAG AAC TTT GTC ATC TTC GAT CAA Ala lys Leu Pro Tyr His Gly Val Glu Leu Gin Pro Ser Ala Val Cys Pro Lys Asn Phe Val IIe Phe Asp Gin ACA TAT GAC CGC AGC CAA GTG ATG TAC CAT CCT GAG CTG ACT CAT AAG CTC ATG AAT ACC CCT TCG TTG AAC AAT Thr Tyr Asp Arg Ser Gln Val Met Tyr His Pro Glu Leu Thr His lys Leu Met Asn Thr Pro Ser Leu Asn Asn TTA GCT TCG ACG TTT CAG AAC GAG TAT GTT GGG GGA AGT TAT GGT AAC TAT GGT AAC TAT GAG CAA GAA GTA TCC Leu Ala Ser Thr Phe GIn Asn Glu Tyr Val Gly Gly Ser Tyr Gly Asn Tyr Gly Asn Tyr Glu Gln Glu Val Ser TCT TCT TAT CAA GAA GAT CCA AAT GAG ATC GAT GCT CIC TTG AGC GCA GAT GAA GAT TAT GAA GAG AAT GAT GAT Ser Ser Tyr GIn Glu Asp Pro Asn Glu lle Asp Ala Leu Leu Ser Ala Asp Glu Asp Tyr Glu Glu Asn Asp Asp A.AT GAA GGT GAA GAG GAT GGT GGT GAT TCA GAA GAA GTC AGC ACT GCT CGT ACT TCT TCC AGG GAT TAT GGA AAC Asn GIu Gly Glu GIu Asp GIy GIy Asp Ser Glu Glu Val Ser Thr Ala Arg Thr Ser Ser Arg Asp Tyr Giy Asn ACC ACA GCA GAA TCT TGI TGT TCC AGT TAT GGT TAC AAC AAC AAC AAC AAC AAC AAC TCA AGG AAG CAG AGT TTA Thr Thr Ala Glu Ser Cys Cys Ser Ser Tyr Gly Tyr Asn Asn Asn Asn Asn Asn Asn Ser Arg Lys Gln Ser Leu TCG GGC AGT GCT AGT AGT AGT AAC AAT GAT GGG AAA GGA CGT AAA AAG ATG AAG AAG ATG ATG GGA GTA TTG AGG Ser Gly Ser Ala Ser Ser Ser Asn Asn Asp Gly Lys Gly Arg Lys Lys Met Lys Lys Met Met Giy Val Leu Arg AGA ATT GIC CCT GGA GGA GA.A CAG ATG A.AT ACA GCT TGC GTT CTT GAT GA.A GCT GTT CAG TAT CTC A.AG TCA CTI Arg lle Val Pro Gly Gly GIu GIn Met Asn Thr Ala Cys Val Leu Asp Glu Ala Val Gln Tyr Leu Lys Ser Leu A.A.A ATC GAA GCT CAG A.A. CTT GGC GTT GGA CAT TTC TCA A.AC CA.A TCT TGA atgctacogatattcggttcttccatcacta Lys IIe GIu Ala GIn Lys Leu Gly Val Gly His Phe Ser Asn GIn Ser

ttgtttctcgggaggtaaatcatcggtctagcgctatctggaccttctcttatttcctccetctatactcacttccttttgttggcaggatggta 


\subsection{Caracterización molecular de los genes $A J A X$}

AJAX1 y AJAX2 codifican factores de transcripción de la familia básica-HéliceLazo-Hélice (bHLH), que están encuadrados dentro del subgrupo 13 según Toledo-Ortiz (Toledo-Ortiz et al. 2003) (Figura 20). Además de AJAX1 (At5g64340) y $A J A X 2$ (At1g29950) en este grupo figuran también At5g09460 y At5g50010 a los que, a partir de ahora denominaremos $A J A X 3$ ( $A J X 3)$ y $A J A X 4$ ( $A J X 4)$ respectivamente. Los cuatro miembros de esta subfamilia destacan por ser los únicos bHLH que presentan una 5'-UTR larga con uORFs conservadas. Además carecen de un dominio básico bien definido (Figura 20C), por lo que podrían catalogarse como proteínas HLH. Este tipo de proteínas es incapaz de unirse directamente al DNA, sino que regulan la transcripción a través de la interacción física con otras proteínas con dominio de unión al DNA ,casi siempre un bHLH (Hornitschek et al. 2009). Durante el transcurso de esta Tesis, $A J A X 1$ fue también identificado en otro laboratorio como supresor de acl5 y fue denominado SAC51 (Imai et al. 2006). 
A

B
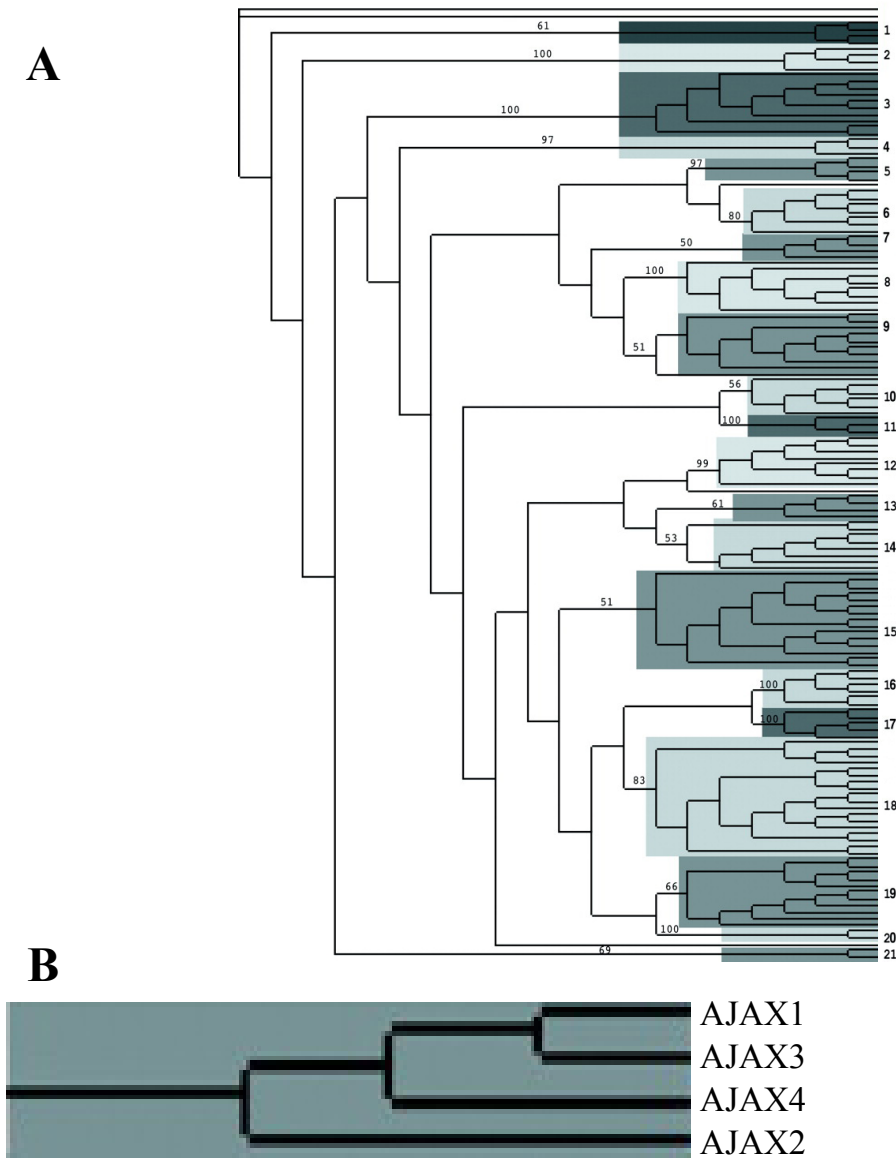

AJAX1

AJAX3

AJAX4

Grupo 13

AJAX2

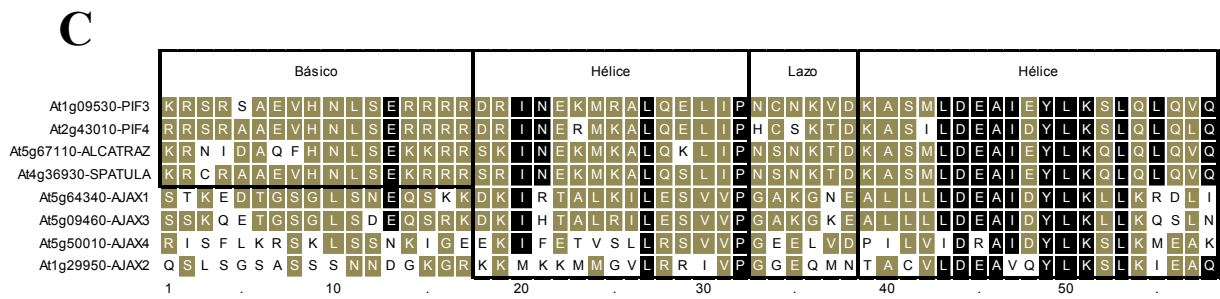

Figura 20. La familia de las proteínas bHLH en Arabidopsis thaliana.

A- Árbol filogenético con las 147 hipotéticas proteínas bHLH de Arabidopsis thaliana, divididas en 21 subfamilias (Toledo-Ortiz et al. 2003).

B- Detalle de la subfamilia número 13 que comprende AJAX1,2,3 y 4.

C- Alineamiento de aminoácidos del dominio bHLH de los 4 genes de la subfamilia 13 (sin dominio básico de unión a DNA) y de otros 4 genes con función bHLH conocida (con dominio de unión a DNA). 
Para averiguar si el resto de las líneas supresoras dominantes encontradas en nuestro rastreo presentaban mutaciones en alguno de los cuatro genes $A J A X$, examinamos la secuencia de dichos genes en todas las líneas disponibles (Figura 21).

A

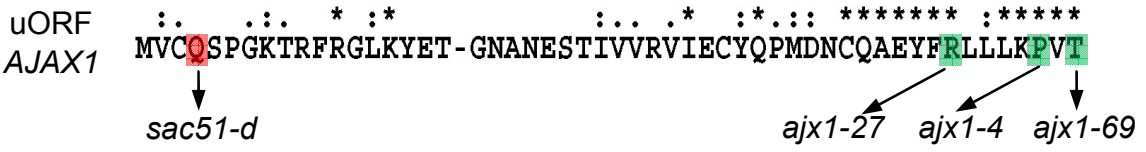

uORF

AJAX2

-MCIVGNKKGNRSLKEIG- - - - TFMMTTCF IANYQSVQVCQAEYFRQLIKPVT

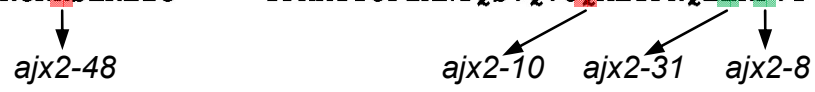

UORF

AJAX3

MVSQSAGQTRFRTFKYENNGDSSRPTIVVRVIACFQPMDNCQAEYFRHILKPVT

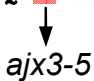

uORF

AJAX4

MVCQSAGQTRFRTLKHEH-GITG- -NIVVRVIACFQPLQDCQAEYFRQLLKPVT

B

\begin{tabular}{|c|c|c|c|c|c|c|}
\cline { 2 - 7 } \multicolumn{1}{c|}{} & sac51-d & ajx1-27 & ajx1-4 & ajx1-69 & ajx2-48 & ajx2-10 \\
\hline Aminoácido silvestre & $\mathrm{Q}$ & $\mathrm{R}$ & $\mathrm{P}$ & $\mathrm{T}$ & $\mathrm{R}$ & $\mathrm{Q}$ \\
\hline Aminoácido mutado & $\mathrm{STOP}$ & $\mathrm{I}$ & $\mathrm{S}$ & $\mathrm{M}$ & STOP & STOP \\
\hline
\end{tabular}

\begin{tabular}{|c|c|c|c|c|c|}
\cline { 2 - 6 } \multicolumn{1}{c|}{} & ajx2-31 & ajx2-8 & ajx3-5 & ajx3-58 & ajx3-18 \\
\hline Aminoácido silvestre & $\mathrm{L}$ & $\mathrm{P}$ & $\mathrm{R}$ & $\mathrm{L}$ & $\mathrm{V}$ \\
\hline Aminoácido mutado & $\mathrm{F}$ & $\mathrm{S}$ & STOP & $\mathrm{F}$ & $\mathrm{M}$ \\
\hline
\end{tabular}

Figura 21. Alelos de los genes $A J A X$ con capacidad supresora de ac/5

A- Alineamiento de las secuencias de aminoácidos de las uORF de AJAX1, 2, 3 y 4. Los aminoácidos marcados con un cuadro de color son aquellos que mutan, los rojos indican que la mutación produce un codón de parada de la traducción y los verdes indican que la mutación produce un cambio de aminoácido. El número de cada alelo corresponde al número de la línea ajx. Los asteriscos, dos puntos y puntos, indican de mayor a menor grado la conservación de cada aminoácido

B- Tabla con las mutaciones de todos los alelos de AJAX1, 2, 3 y 4. El término STOP indica un codón de parada. 
Salvo en el caso de $A J A X 4$, para el que no encontramos ninguna mutación entre las 37 líneas supresoras analizadas, la secuenciación permitió identificar nuevos alelos mutantes en $A J A X 1 / S A C 51$ y en $A J A X 2$, así como mutaciones equivalentes en $A J A X 3$, siempre en la misma uORF de la 5'-UTR (Figura 21). En varios de estos casos, las mutaciones provocaban la aparición de un codón de parada prematuro, mientras que en los casos en los que se producía una sustitución aminoacídica, ésta siempre se localizaba en la sección C-terminal altamente conservada del péptido supuestamente codificado por las uORF. 


\section{Análisis funcional de los genes $A J A X$ en el desarrollo vascular}

\subsection{Superproducción de bHLH en los mutantes ajax}

La coincidencia de todas las mutaciones identificadas en una uORF equivalente de las regiones 5'-UTR de los tres genes $A J A X$ y el carácter dominante de la supresión, nos hicieron plantear la hipótesis de que la uORF ejercería un papel negativo sobre la traducción de la ORF principal que codifica el posible factor de transcripción con el dominio HLH, al igual que ocurre con otros genes de $A$. thaliana (David-Assael et al. 2005; Nishimura et al. 2005). Las mutaciones de la uORF anularían este efecto represor para permitir la acumulación de dicho factor de transcripción y, por consiguiente, la supresión de acl5. Para poner a prueba esta hipótesis, decidimos investigar el efecto de la presencia de diversas formas de la uORF sobre la traducción de $A J A X 2$ en un sistema de transcripción-traducción in vitro.

Las cuatro construcciones que examinamos contenían la ORF principal de $A J A X 2$ bajo el control de un promotor activo en el sistema de germen de trigo, como se indica en la Figura 22A. La primera carecía de la uORF; la segunda contenía la versión silvestre de la uORF justo antes de la ORF principal; la tercera contenía la versión del alelo ajx2-31 de la uORF (una mutación que provoca el cambio de un aminoácido conservado); y la cuarta contenía el alelo ajx2-48 de la uORF (provoca una parada prematura en la traducción de la uORF).

Aunque nunca pudimos detectar la presencia del pequeño péptido codificado por la uORF, sí que pudimos detectar cambios en la producción de la proteína codificada por la ORF principal, dependiendo de la versión clonada de la uORF en la región 5' (Figura 22B). Así, mientras que la presencia de la uORF silvestre reducía sensiblemente la traducción de la ORF principal, hasta a un $10 \%$ del nivel de proteína sin ninguna uORF, cualquiera de los dos alelos mutantes clonados permitió recuperar la capacidad de producción del bHLH hasta un $35 \%$ del nivel de proteína sin ninguna uORF. 

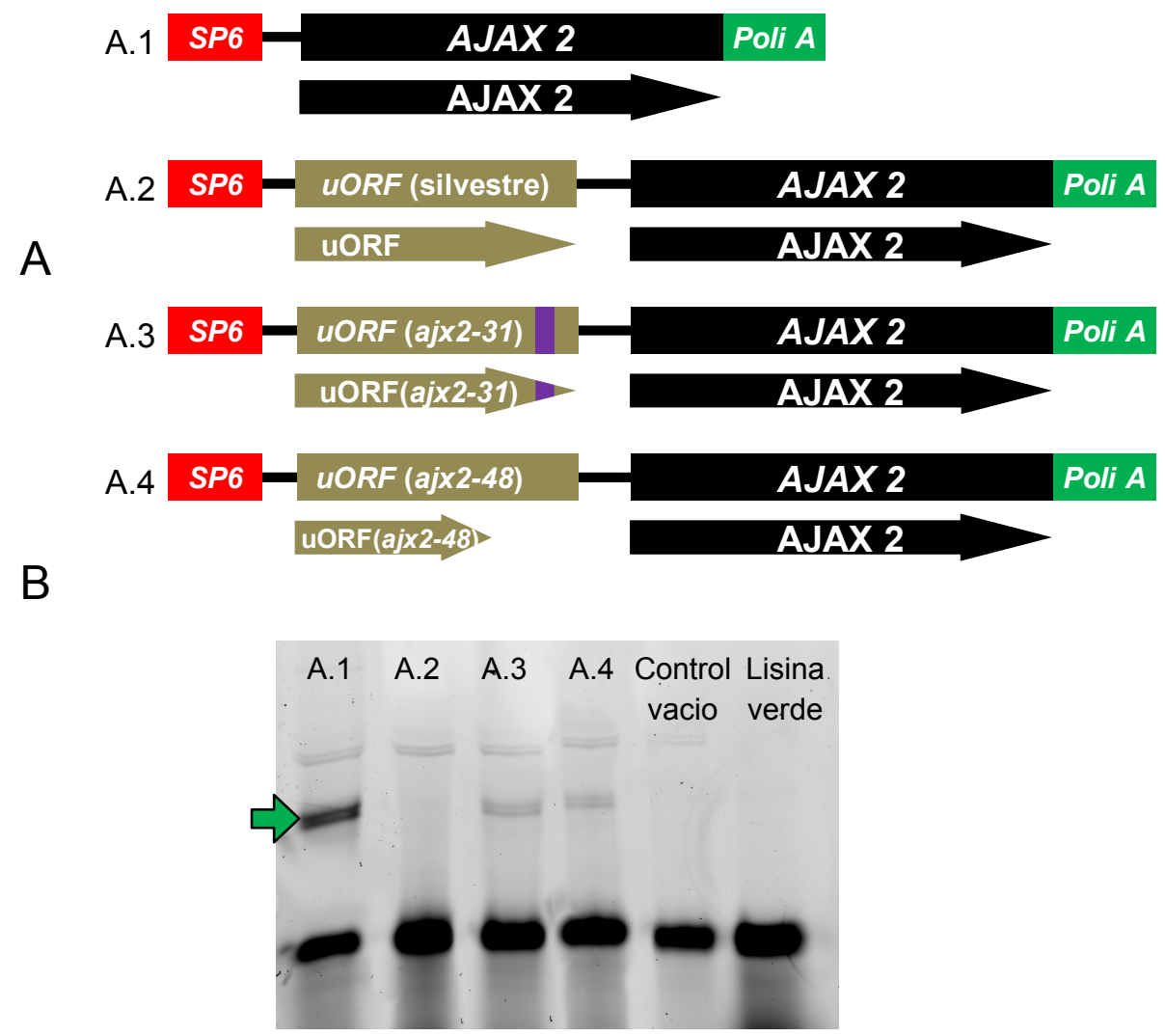

Figura 22. Transcripción-traducción in vitro de AJAX2.

A- Esquema de las construcciones generadas con el plásmido pSP64, que incorpora el sitio de reconocimiento de la RNA polimerasa SP6 en $5^{\prime}$ y una caja Poli $A$ en $3^{\prime}$. La construcción $A 1$ contiene únicamente la ORF principal de AJAX2, las A2, A3 y A4 contienen esta ORF principal bajo el control de la uORF; en la $A 2$ en su versión silvestre, en la A3 la versión mutante de ajx2-31(en morado la posición de la mutación) y en la A4 la versión truncada de ajx2-48.

B- Efecto de la uORF en la traducción de AJAX2. Productos del ensayo de transcripción-traducción in vitro marcados con FluoroTect ${ }^{\mathrm{TM}}$ Green $_{\mathrm{Lys}}$ (Promega), analizados en geles de mono:bisacrilamida (la flecha verde indica la posición de AJAX2).

Si el efecto inhibidor de la traducción de la ORF principal por parte de la uORF observado en el sistema de transcripción/traducción in vitro es reflejo de lo que ocurre también in vivo, se podría concluir que la supresión de acl5 por parte de las mutaciones ajx se debe a una superproducción del factor de transcripción bHLH codificado por los genes $A J A X$. En tal caso, una predicción que se puede 
poner a prueba experimentalmente es que la expresión de la ORF principal de AJAX2 (sin su región 5'-UTR) debería rescatar el fenotipo enano de acl5 (Figura 23).
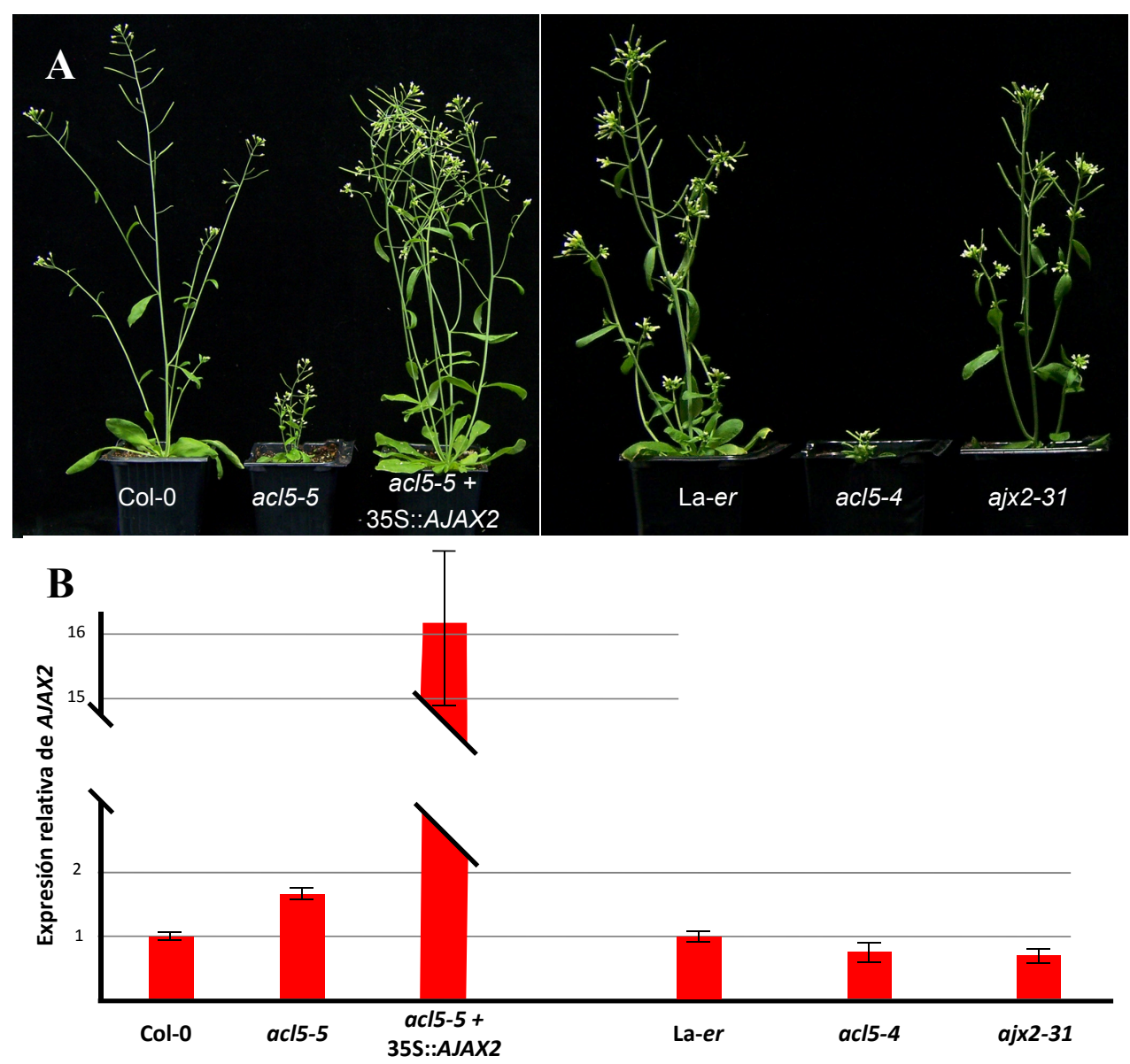

Figura 23. Sobre-expresión del gen AJAX2

A- Plantas Col-0, ac/5-5, sobre-expresante AJAX2 en fondo ac/5-5, La-er, ac/5-4 y ajx2-31

$\mathrm{B}$ - Expresión relativa de AJAX2 en hojas caulinares de plantas adultas de Col-0, ac/5-5, ac/5-5 + 35S::AJAX2, La-er, ac/5-4, ajx2-31.

En efecto, las plantas acl5 que fueron transformadas con $35 S:: A J A X 2$ recuperaron un tamaño comparable al de plantas silvestres y al de plantas acl5 ajx2-31 (Figura 23A), en consonancia con su elevado nivel de expresión de la 
ORF principal del gen $A J A X 2$ (Figura 23B). Es importante hacer notar que la expresión de $A J A X 2$ no estaba alterada en las plantas ajx2-31, lo cual concuerda con que el efecto de las mutaciones en la uORF de los genes $A J A X$ no consiste en modificar su nivel de transcripción sino que, muy probablemente, se restringe al control traduccional de la ORF principal.

\subsection{Relación funcional entre $A C L 5$ y los genes $A J A X$}

Una vez establecido el mecanismo molecular de supresión por parte de las mutaciones en la uORF de los genes $A J A X$, surgía al menos una pregunta referente al papel de estos genes. En concreto, ¿son los genes $A J A X$ parte integrante del mecanismo de control del desarrollo vascular por ACL5 (o su producto, la termoespermina) o se debe la supresión a que las mutaciones activan un mecanismo paralelo que compensa la falta de ACL5?

En el primer caso, la función de ACL5 sería permitir la producción de los factores de transcripción codificados por los genes $A J A X$ y éstos se encargarían de impedir la activación prematura de la muerte celular durante la diferenciación del xilema (Muñiz et al. 2008). Las predicciones de este modelo serían:

- la termoespermina podría regular la traducción de la ORF principal de los genes $A J A X$.

- un mutante de pérdida de función de los genes $A J A X$ mostraría un fenotipo parecido al del mutante acl5 (dependiendo de una posible redundancia funcional con otros genes no identificados).

- las modificaciones causadas por la mutación acl5 sobre la expresión génica estarían mediadas, en primer lugar, por la falta de actividad de los HLH codificados por los genes $A J A X$.

Para comprobar la primera de nuestras predicciones, estudiamos el efecto de la adición de termoespermina al sistema de germen de trigo de transcripcióntraducción in vitro de la construcción que expresa ambas ORFs en tándem (Figura 22A). En contra de lo esperado, la adición de hasta $0,5 \mathrm{mM}$ de termoespermina no sólo no mejoró el nivel de traducción de la ORF principal, 
sino que se redujo la traducción de la proteína HLH (Figura 24). No obstante, es probable que este efecto no tenga relevancia fisiológica, sino que sea un artefacto provocado al alterar algún parámetro físico del proceso de traducción con la presencia de una alta concentración de poliaminas, ya que se observó la misma reducción en la traducción cuando se añadió espermina en lugar de termoespermina (Figura 24). Por lo tanto, este experimento no permitía extraer conclusiones acerca de la relación funcional entre la termoespermina y los genes $A J A X$.

A

\section{SP6 - UORF (silvestre)}

uORF
AJAX 2

AJAX 2

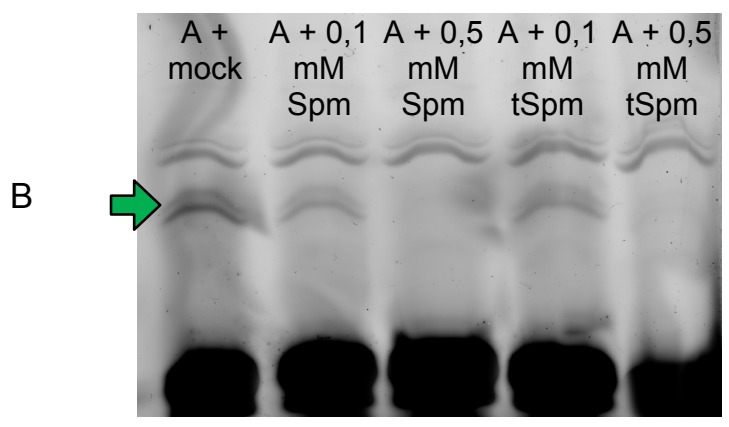

Figura 24. Efecto de la adición de espermina y termoespermina en la transcripción-traducción in vitro de AJAX2.

A- Esquema de la construcción, con la uORF y ORF de AJAX2, en tándem.

B- Productos del ensayo de transcripción-traducción in vitro, con adición de 0,1 $\mathrm{mM}$ y $0,5 \mathrm{mM}$ de espermina (Spm) y termoespermina (tSpm).

Con respecto a nuestra segunda predicción, el alto parecido de secuencia entre los cuatro genes $A J A X$, su relación filogenética, y el hecho de haber encontrado mutaciones supresoras de acl5 en $A J A X 1, A J A X 2$ y $A J A X 3$, sugería una muy probable redundancia funcional entre ellos. Por tanto, para conseguir un mutante de pérdida de la función AJAX era necesario obtener como mínimo el triple mutante ajxl ajx2 ajx3. En las colecciones de líneas de inserción de TDNA a disposición pública figuraban al menos dos para $A J A X 1$ y dos para $A J A X 2$, dentro de la secuencias correspondientes a sus cDNAs (Figura 25A). Sin embargo, sólo había una línea de inserción cercana al locus de $A J A X 3$ que, 
probablemente no inactivaría a dicho gen ya que estaba situada 845 pb aguas arriba del codón de inicio de $A J A X 3$ (Figura 25A). Puesto que una estrategia alternativa de construir un microRNA artificial (Schwab et al. 2006) dirigido a $A J A X 3$ no tuvo éxito (resultados no mostrados), la única herramienta con la que podíamos contar sería una triple línea de T-DNA obtenida mediante cruces a partir de una de las inserciones en $A J A X 1$ y $A J A X 2$, y la única disponible para $A J A X 3$. Dicha línea mostró una reducción casi total en la expresión de $A J A X 1$ y de $A J A X 2$, pero sólo del 50\% para el gen $A J A X 3$ (Figura 25B). Como era de esperar, esta línea no mimetizo ni el fenotipo enano de acl5 (Figura 25C) ni en la incorrecta formación de los haces vasculares (resultados no mostrados). Por consiguiente, no es posible concluir si la pérdida real de función AJAX fenocopia a la mutación acl5. 


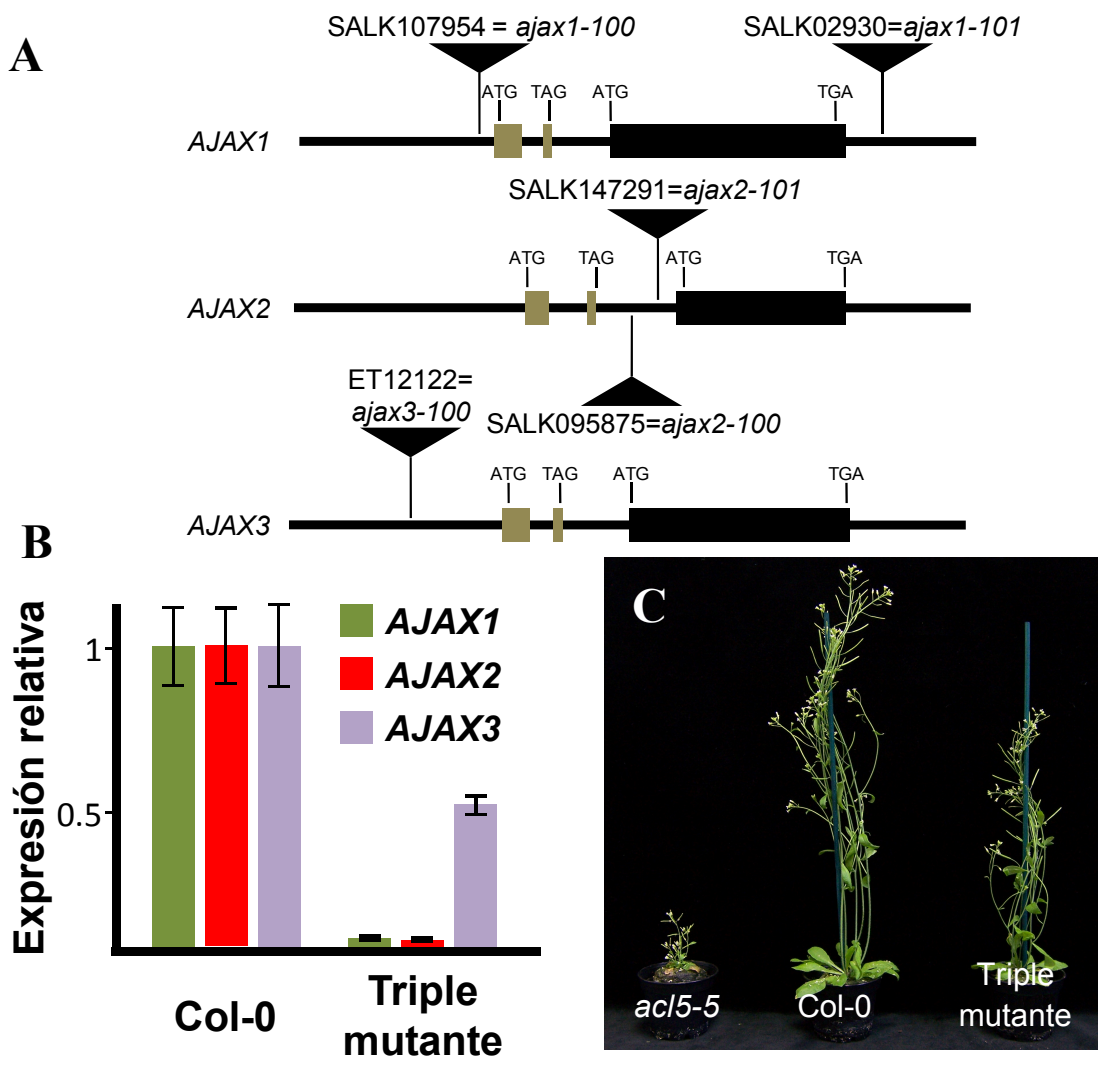

Figura 25. Generación del triple mutante de los genes supresores AJAXs.

A- Líneas de inserción de T-DNA de los genes AJAX1, AJAX2 y AJAX3; las cajas negras representan el exón de la ORF principal, las cajas grises representan los exones de las uORFs, los triángulos indican la posición de cada una de las líneas de inserción, identificándose cada una de ellas con su número y el nombre que les hemos asignado; además se representa el codón de inicio y de parada de cada ORF.

B- Expresión de los genes $A J A X 1, A J A X 2$ y AJAX3 en plántulas de Col-0 y un triple mutante ajax1-100 + ajax2-100 + ajax3-100.

C- Plantas de ac/5-5, Col-0, triple mutante ajax1-100 + ajax2-100 + ajax3-100.

Por último, para averiguar si los factores de transcripción bHLH codificados por los genes $A J A X$ median la regulación de la expresión génica ejercida por ACL5, decidimos realizar un abordaje transcriptómico, comparando mediante hibridación de micromatrices de DNA el fenotipo molecular de acl5 con el de tres formas distintas de supresión del fenotipo enano: 
- un alelo ACL5 silvestre, de una línea Col-0.

- la supresión de acl5 por $35 S:: A J A X 2$ (sólo la ORF principal), generado previamente en esta Tesis.

- la aplicación exógena de $0,1 \mathrm{mM}$ de termoespermina, que alivia ligeramente el enanismo de acl5 (Kakehi et al. 2008).

De la comparación entre los grupos de genes afectados en cada una de las condiciones podríamos a continuación, inferir el grado de implicación de al menos $A J A X 2$ (y por extensión, todos los $A J A X$ ) en la regulación del desarrollo vascular por $A C L 5$.

Los análisis de micromatrices se realizaron con muestras de RNA de tres réplicas biológicas de plántulas de 14 días cultivadas en placas de MS (ver Materiales y Métodos, página 132). Cada micromatriz se hibridó con mezclas de RNAs marcados con fluoróforos distintos dependiendo de la muestra, según el siguiente esquema:

- acl5 vs. Col-0

- acl5 vs. acl5 + 35S::AJAX2

- acl5 vs. acl5 + 0,1 $\mathrm{mM}$ termoespermina

Las medias de las tres réplicas biológicas en cada caso fueron filtradas según los siguientes criterios:

- sólo se consideraron los valores con presencia en, al menos, dos de las réplicas.

- se etiquetaron como genes diferencialmente aumentados o reprimidos los que se expresaban al menos 1,75 veces más en una condición que en otra. Los resultados de los análisis para las condiciones individuales se pueden consultar en el CD anexo a esta Tesis. 


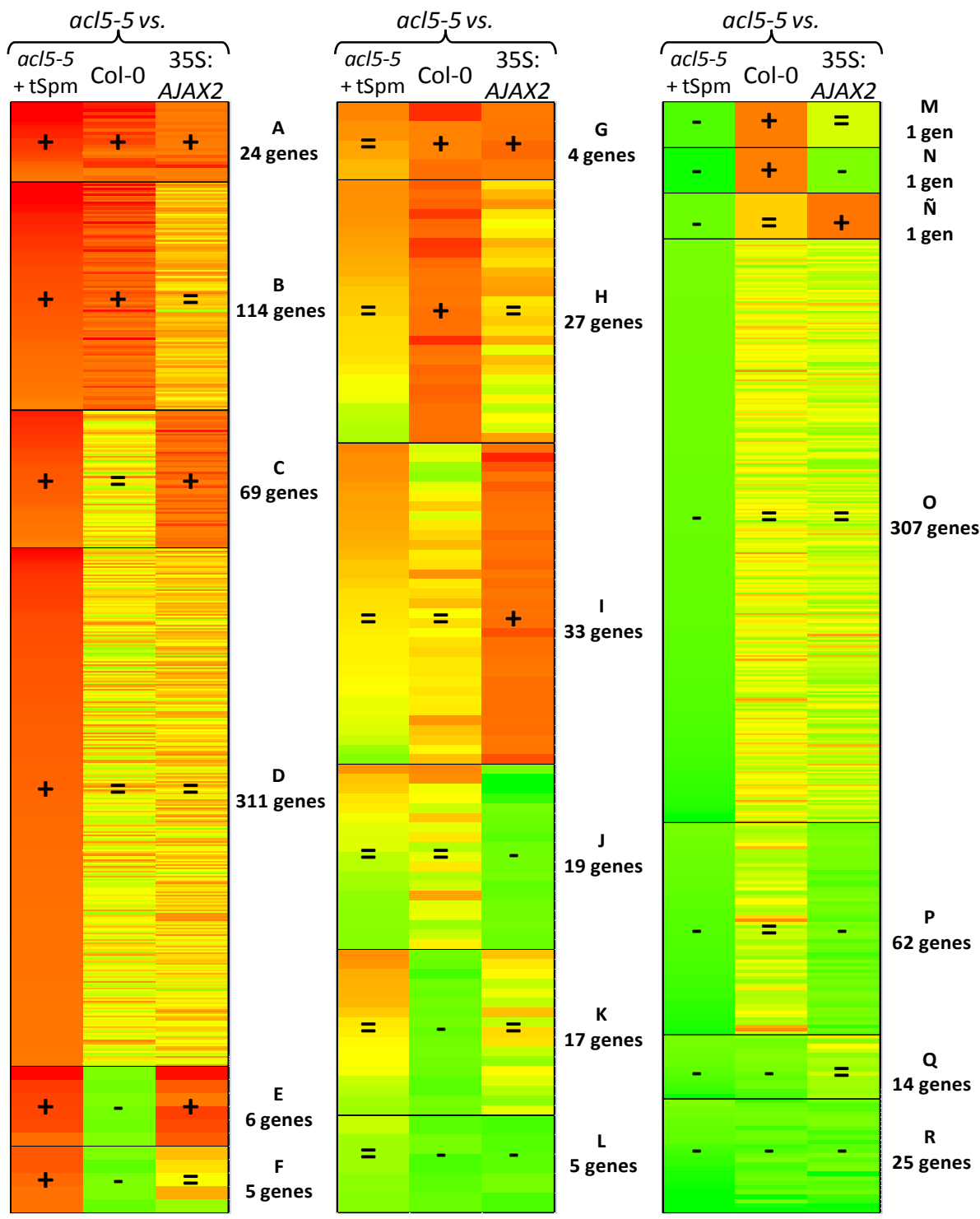

Figura 26(I). Esquema de los resultados obtenidos con micromatrices. El nivel de expresión está representado según la gradación de colores: el rojo indica genes inducidos (también señalados con el signo +) en el mutante ac/5, el amarillo indica genes con un nivel de expresión parecido entre acl5 y la otra condición (señalados como =), y el color verde indica genes reprimidos en acl5 (señalados como -). Los genes están divididos en grupos, de tamaño no proporcional al número de genes que contienen, según su comportamiento entre las tres condiciones; siendo nombrados alfabéticamente indicando su número de genes. 
Para comparar los efectos causados sobre el fenotipo molecular de acl5 se realizó un análisis de agrupamiento de los genes considerando, como criterio mínimo, que en cada grupo sus genes estuviesen diferencialmente aumentados o reprimidos en al menos una de las tres comparaciones. El resultado fueron 19 grupos de genes diferencialmente expresados frente a acl5 en, al menos, una de las condiciones (Col-0, 35S::AJAX2, o 0,1 mM termoespermina) (Figura 26).

Cuando analizamos la figura 26 podemos sacar dos grandes conclusiones:

- Las agrupaciones más grandes de genes, D y O (311 y 301 genes respectivamente), corresponden a las alteraciones causadas exclusivamente por el tratamiento con termoespermina. Es probable que se trate de artefactos generados por la presencia de una poliamina cualquiera en gran cantidad, o en particular por la termoespermina; en ninguno de los dos casos parecería tener relevancia fisiológica para el desarrollo de la vasculatura, considerando que dichos genes no están alterados en el mutante $a c l 5$.

- Los grupos A y R (24 y 25 genes respectivamente) podrían contener aquellas dianas con especial relevancia para la regulación del desarrollo vascular por ACL5, ya que son los genes regulados en el mismo sentido por las tres condiciones. Teniendo en cuenta que la complementación por termoespermina en las condiciones del tratamiento no es perfecta (Kakehi et al. 2008), esta lista podría extenderse a los grupos G y L (4 y 5 genes respectivamente), cuya expresión está alterada en acl5 y se recupera tanto en Col como en $35 S:: A J A X 2$, pero no de forma aparente en el tratamiento con termoespermina.

Para comprender mejor como suprime $A J A X 2$ el fenotipo enano, comparamos los genes alterados en la hibridación acl5-5 vs. Col-0, con respecto a las otras dos hibridaciones (Figura 27). 


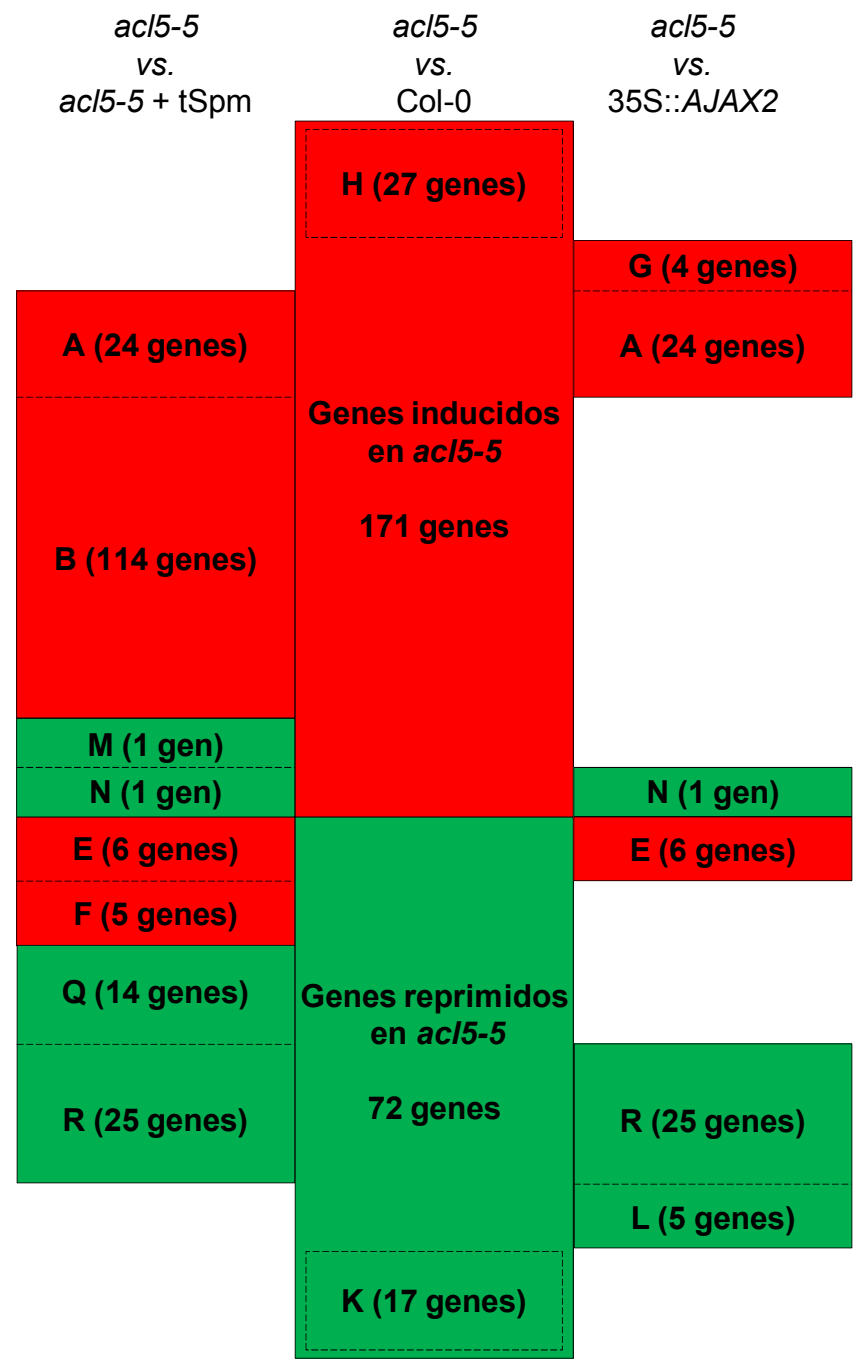

Figura 27. Esquema comparativo de los genes inducidos y reprimidos en ac/55 con un silvestre Col- 0 , con respecto a las otras dos comparaciones, en verde se indican los genes reprimidos y en rojo los genes inducidos en ac/5. En la columna central se representan los genes diferenciales de la micromatriz entre acl5-5 y Col-0, en las columnas laterales se muestran los genes comunes a dos o tres de las comparaciones. 
Analizando la figura 27 pudimos concluir que:

- De los 171 genes inducidos y 72 genes reprimidos en la comparación acl5-5 vs. Col-0, sólo hay 28 genes entre los inducidos (grupos G y A) y 30 de los reprimidos (grupos $\mathrm{R}$ y L), que sean comunes a la comparación acl5-5 vs. 35S::AJAX2. Este bajo número nos indica que gran parte de los fenotipos moleculares de acl5 no son recuperados por la expresión constitutiva de $A J A X 2$.

- A pesar de la importancia ya mencionada de los grupos A y R como posibles dianas de la regulación del desarrollo vascular por ACL5, si tenemos en cuenta que la complementación por termoespermina es muy parcial (Kakehi et al. 2008), podríamos considerar a los grupos G y L (4 y 5 genes respectivamente) como también posibles dianas muy importantes, pues su alteración provocada una supresión completa del enanismo de acl5.

$\mathrm{Al}$ analizar la identidad de los genes expresados diferencialmente en el mutante acl5 mediante GO (ontología génica) se encontró un enriquecimiento particularmente acusado en aquéllos cuyos productos se localizan (y cumplen una función) en la pared celular y en el apoplasto (o espacio intercelular) (Figura 28). Este resultado extiende las observaciones anatómicas del mutante acl5 en las que se detectaban graves defectos en la estructura de la pared celular durante la diferenciación del xilema (Muñiz et al. 2008). Pero lo que es aún más interesante es que son precisamente esas dos categorías funcionales las mismas que mejor se recuperan en las plántulas que expresan $35 S:: A J A X 2$ en un fondo acl5.

En definitiva, se observa que la supresión por parte de $A J A X 2$ de los defectos de crecimiento del tallo y de la diferenciación del xilema provocados por acl5, está acompañada por una supresión parcial respecto al número e identidad concreta de los genes afectados, pero perfectamente coincidente respecto a las categorías funcionales afectadas. 
Enriquecimiento de los genes diferenciales de la comparación acl5-5 vs. Col-0 según su localización celular

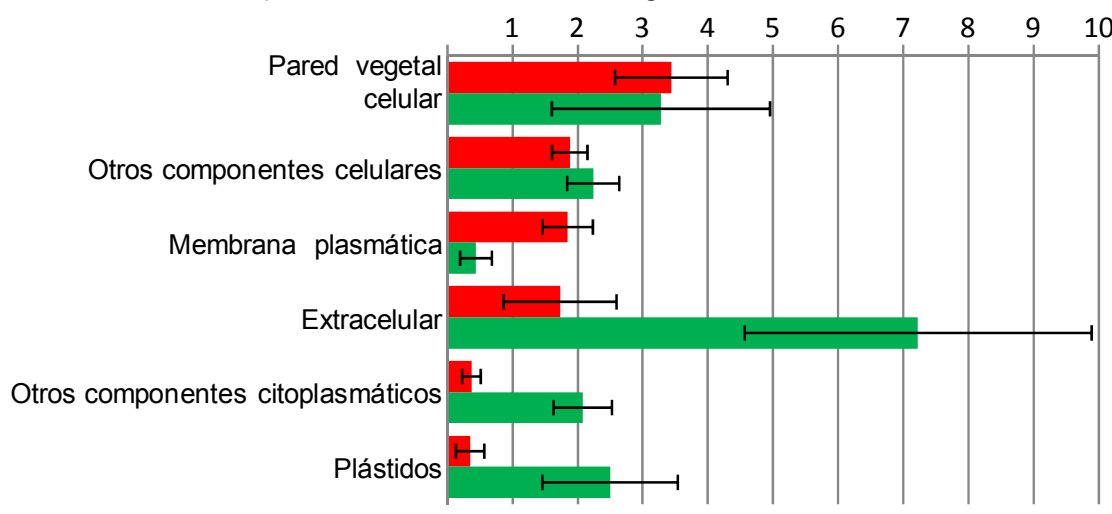

Enriquecimiento de los genes diferenciales de la comparación ac/5-5 vs. 35S::AJAX2 según su localización celular

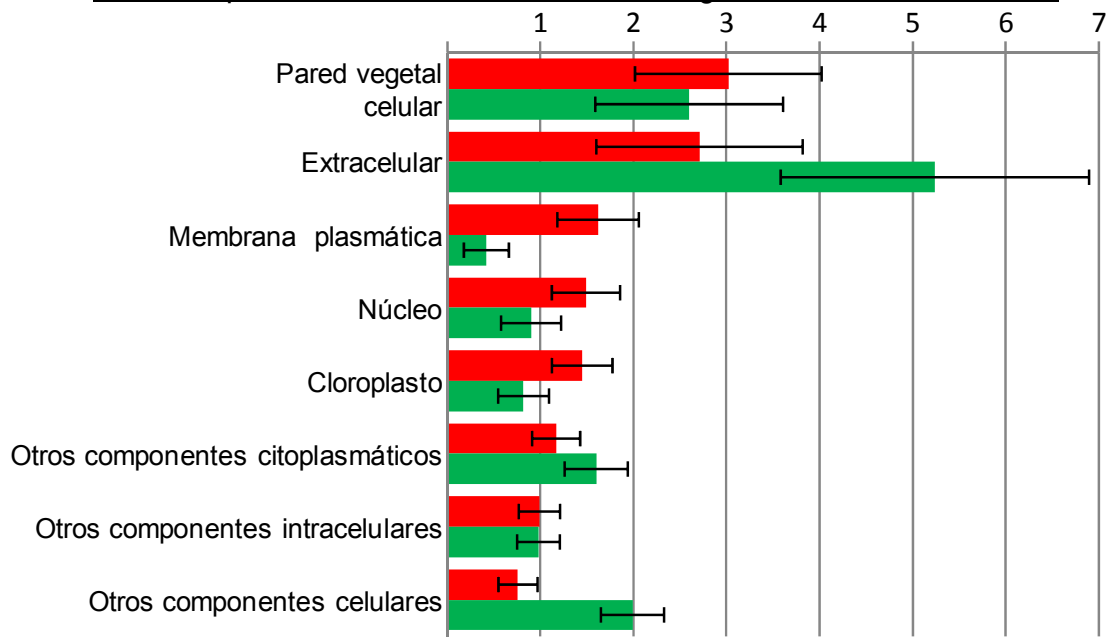

Figura 28. Esquema de genes sobre-representados según su localización celular; en rojo se indican los genes inducidos en el mutante $a c / 5$, y en verde los reprimidos. El grado de sobre-representación está referido a su proporción en el genoma de $A$. thaliana. Únicamente se representan aquellos grupos con una sobre-representación estadísticamente significativa y superior a 1. 


INGENIERÍA ENZIMÁTICA DE LAS AMINOPROPIL TRANSFERASAS DE PLANTAS 

Las aminopropil transferasas catalizan la síntesis de tri- y tetraaminas mediante la incorporación de un grupo aminopropilo cedido por la AdoMetdc a una di- o triamina, respectivamente. En plantas, las aminopropil transferasas más características son la SPDS, SPMS y tSPMS. Estas enzimas presentan un alto grado similitud de secuencia entre sí (Hanzawa et al. 2002; Panicot et al. 2002), compartido además con las putrescina-N-metil transferasas (PMT) (Teuber et al. 2007). Al contrario que las aminopropil transferasas, las PMT, están exclusivamente presentes en las plantas solanáceas y catalizan la síntesis de Nmetilputrescina por la adición de un grupo metilo proveniente del AdoMet a una molécula de putrescina (Figura 29).

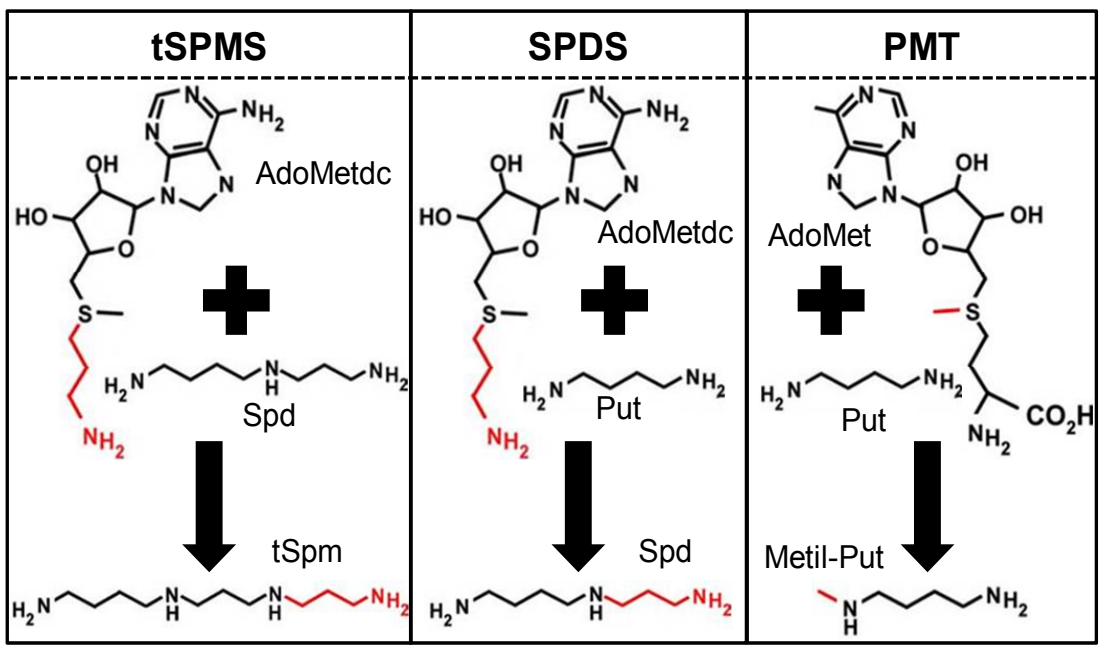

Figura 29. Esquema de las reacciones enzimáticas catalizadas por dos aminopropil transferasas (tSPMS y SPDS) y una putrescina-N-metil transferasa (PMT). En rojo se marca el grupo que es transferido del AdoMetdc o el AdoMet, a la poliamina correspondiente.

Estudios filogenéticos han mostrado que las aminopropil transferasas y las PMT están emparentadas evolutivamente (Minguet et al. 2008). De hecho, este análisis indica que las actividades SPDS, SPMS, tSPMS y PMT provienen de una SPDS ancestral que ha sufrido diversos episodios independientes de duplicación y neofuncionalización en cada uno de los reinos de los seres vivos (Minguet et al. 2008). Lógicamente, los cambios de función suponen cambios en la capacidad de las enzimas para reconocer nuevos sustratos y ejecutar las 
reacciones catalíticas correspondientes. Por ello, la investigación del mecanismo molecular que ha permitido estos cambios de función nos pareció interesante desde al menos, dos puntos de vista:

- para entender la facilidad aparente con la que las SPDS generan nuevas actividades enzimáticas, dado el alto número de sucesos independientes en que esto ha sucedido, durante la evolución.

- para aprender a diseñar enzimas con propiedades catalíticas deseadas (ingeniería enzimática).

Con esta intención decidimos identificar los aminoácidos del centro activo de SPDS, tSPMS y PMT que podrían justificar sus preferencias de sustrato (Put vs. Spd; AdoMet vs. AdoMetdc), y comprobar experimentalmente el efecto de sustituir dichos residuos sobre las afinidades y la capacidad de trabajo de cada una de esas enzimas.

\section{Purificación de las enzimas SPDS, tSPMS y PMT}

Puesto que las enzimas SPDS y tSPMS de A. thaliana no habían sido descritas anteriormente desde el punto de vista de sus parámetros cinéticos, el primer objetivo de esta parte del trabajo fue expresar en bacterias versiones recombinantes de una espermidina sintasa, AtSPD1, y una termoespermina sintasa, AtACL5, y purificarlas para su posterior análisis. El sistema empleado para la producción de estas proteínas, fue el de expresar fusiones C-terminales de una etiqueta de 6 histidinas (6xHis), de AtSPD1 (At1g23820) y AtACL5 (At5g19530) (ver Materiales y Métodos, página 117). Para la producción de la PMT, empleamos una construcción equivalente cedida por la Dra. Birgit Dräger (Universidad Martin Lutero de Halle-Wittenberg) conteniendo la PMT de Datura stramonium (Biastoff et al. 2006).

Los protocolos concretos de inducción y de purificación con columnas de níquel a partir de extractos crudos de E. coli, se pusieron a punto para cada una de las proteínas. Como resultado, pudimos contar con preparaciones aceptablemente enriquecidas en cada una de las enzimas (Figura 30), a concentraciones que variaron entre 0,2 y $1 \mathrm{mg} / \mathrm{ml}$. 

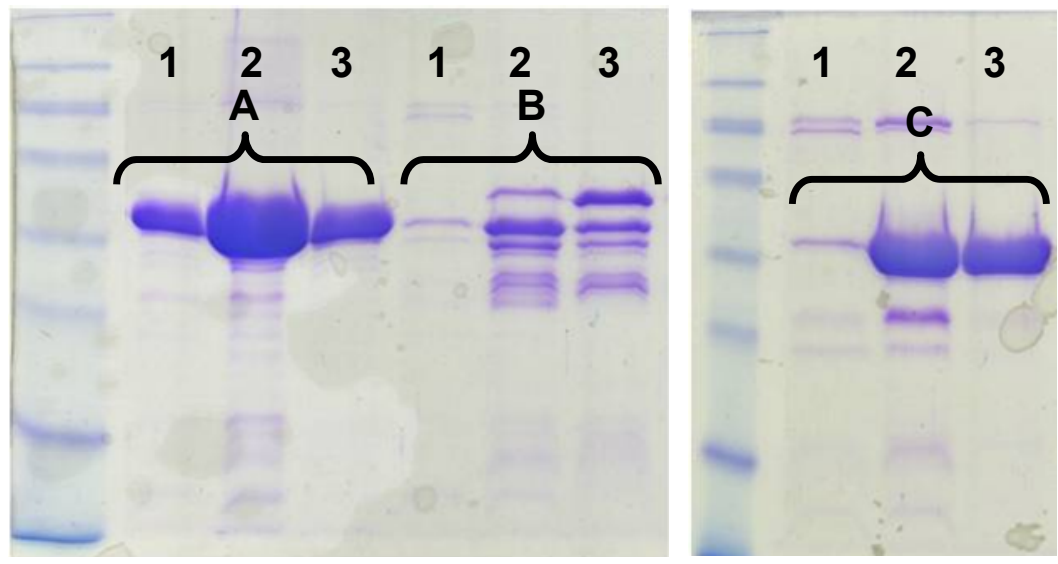

Figura 30. Purificación de AtACL5, AtSPD1 y DsPMT. Geles de mono:bisacrilamida, con el marcador de proteínas SeeBlue ${ }^{\circledR}$ Pre-Stained (Invitrogen) y los resultados de diferentes eluciones (1-10\% imidazol, 2-20\% imidazol, 3-30\% imidazol) de la purificación de las construcciones:
A- $\mathrm{pET} 28 \mathrm{~b}+$ AtACL5
B- $\mathrm{pET} 28 \mathrm{~b}+$ AtSPD1
C- $\mathrm{pET} 21 \mathrm{~d}+D s P M T$

\section{Características cinéticas de SPDS, tSPMS y PMT}

El cálculo de los parámetros cinéticos de AtSPD1 y AtACL5 se realizó como se indica en Materiales y Métodos, página 117. Como resumen cabe indicar que en los ensayos enzimáticos se empleó una concentración de proteína de $10 \mathrm{mg} / \mathrm{ml}$, y que uno de los dos sustratos (la poliamina Put o Spd, y el AdoMetdc) se mantenía a concentración fija y saturante, mientras que el otro variaba entre los siguientes valores: $0,25-50 \mathrm{mM}$ para Put, 0,25-50 mM para Spd, y 0,05-2 mM para AdoMetdc. La determinación de las velocidades iniciales de reacción se efectuó tomando alícuotas de la mezcla de reacción a intervalos de 15 min y valorando en ellas el contenido de producto, por derivatización de las poliaminas y posterior cuantificación por HPLC. 

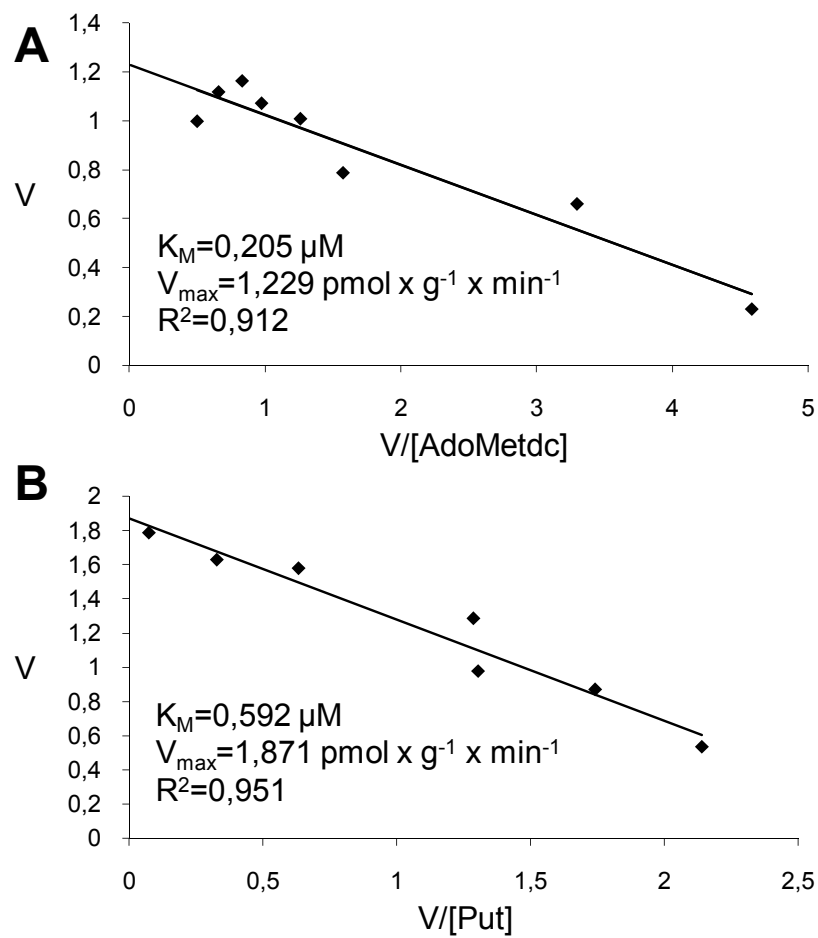

Figura 31. Gráficos de Eddie-Hofstee para el cálculo de las $k_{M}$ y las $V_{\max }$ de AtSPD1. En el eje de las ordenadas se expresa la velocidad inicial de la reacción como picomol de espermidina producido por gramo de muestra y por minuto, en el eje de las abscisas se expresa el cociente de la velocidad inicial partido la concentración inicial del sustrato variable, esta última expresada como mM A-Gráfico de reacción con concentración de Put fija, y AdoMetdc variable. B-Gráfico de reacción con concentración de AdoMetdc fija, y Put variable.

De esta manera pudimos determinar que AtSPD1 presentaba unos valores de $\mathrm{K}_{\mathrm{M}}$ de $592 \mu \mathrm{M}$ para la putrescina y $205 \mu \mathrm{M}$ para el AdoMetdc (Figura 31), mientras que AtACL5 mostraba unos valores de $\mathrm{K}_{\mathrm{M}}$ de $775 \mu \mathrm{M}$ para la espermidina y $230 \mu \mathrm{M}$ para el AdoMetdc (Figura 32). 

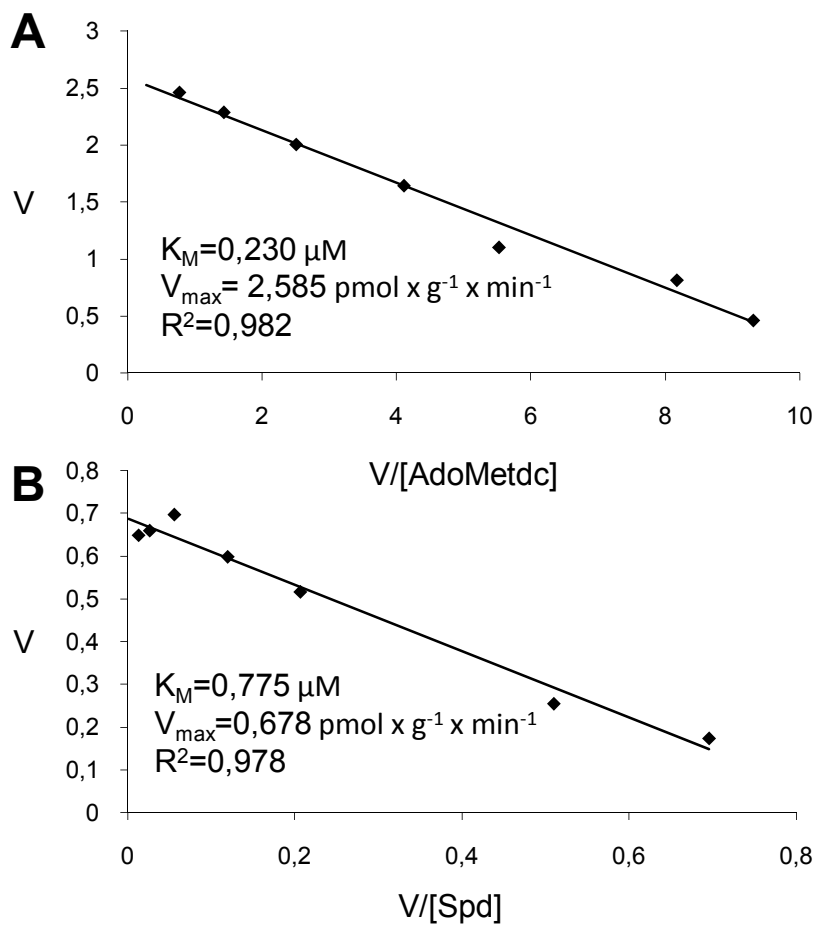

Figura 32. Gráficos de Eddie-Hofstee para el cálculo de las $k_{M}$ y las $V_{\max }$ de AtACL5. En el eje de las ordenadas se expresa la velocidad inicial de la reacción como picomol de termoespermina producido por gramo de muestra y por minuto, en el eje de las abscisas se expresa el cociente de la velocidad inicial partido la concentración inicial del sustrato variable, esta última expresada como mM A-Gráfico de reacción con concentración de Spd fija, y AdoMetdc variable. B-Gráfico de reacción con concentración de AdoMetdc fija, y Spd variable.

El valor de la $\mathrm{K}_{\mathrm{M}}$ de $A t \mathrm{SPD} 1$ para la putrescina resulta ser de los más elevados entre los descritos en la literatura, tanto entre las SPDS (Tabla 2) como entre las PMT (Tabla 3) de diversos organismos estudiados. Lo mismo sucede para la $K_{M}$ del AdoMetdc (Tabla 2). Son varias las posibles explicaciones para esta observación. En primer lugar, podría resultar que la cola de 6xHis interfiriese en el caso de la SPD1 de $A$. thaliana con su actividad enzimática, o que la proteína requiriese cierta modificación postraduccional que no se produce en $E$. coli, aunque este fenómeno no se aprecia en otras SPDS recombinantes caracterizadas (Biastoff et al. 2009b); en segundo lugar, podría suceder que el ensayo enzimático in vitro no se esté efectuando en las condiciones óptimas, en 
las que normalmente actúa la SPD1 de $A$. thaliana. Aunque el pH del ensayo era el óptimo (resultados no mostrados), sí es cierto que se ha descrito que AtSPD1 participa en un complejo multienzimático, o metabolón, junto con AtSPD2 (la otra SPDS de $A$. thaliana) y AtSPM1 (la SPMS de A. thaliana) (Panicot et al. 2002). Por lo tanto, no sería extraño que en el contexto del metabolón variasen los parámetros cinéticos de $A t$ SPD1.

Tabla 2. Tabla con los valores de $\mathrm{k}_{\mathrm{M}}$ para diversas SPDS.

\begin{tabular}{|c|c|c|l|}
\hline Origen SPDS & $\begin{array}{c}\mathbf{K}_{\mathbf{M}}{ }^{\text {Put }} \\
(\mu \mathbf{M})\end{array}$ & $\begin{array}{c}\mathbf{K}_{\mathbf{M}}{ }^{\text {Adometdc }} \\
(\mu \mathbf{M})\end{array}$ & \multicolumn{1}{|c|}{ Referencia } \\
\hline Arabidopsis thaliana & 592 & 205 & Este trabajo \\
\hline Bazo humano & 80 & 7 & (Kajander et al. 1989) \\
\hline Brassica pekinensis & 32 & 6,7 & $\begin{array}{l}\text { (Sindhu y Cohen 1984) } \\
\text { (Yamanoha y Cohen 1985) }\end{array}$ \\
\hline Caenorhabditis elegans & 158 & 110 & (Dufe et al. 2005) \\
\hline Cerebro oveja & 40 & 0,3 & (Raina et al. 1984) \\
\hline Datura stramonium & 33 & 64 & (Biastoff et al. 2009b) \\
\hline Escherichia coli & 15 & 2,2 & (Bowman et al. 1973) \\
\hline Glycine max & 32 & 0,4 & (Yoon et al. 2000) \\
\hline Plasmodium falciparum & 52 & 35 & (Haider et al. 2005) \\
\hline Próstata rata & 100 & 1,1 & $\begin{array}{l}\text { (Samejima y Yamanoha } \\
\text { 1982) }\end{array}$ \\
\hline Próstata rata & 15 & - & (Pegg et al. 1981) \\
\hline Senecio vulgaris & 21 & 4 & (Graser y Hartmann 2000) \\
\hline Sulfolobus solfataricus & 3850 & 7,9 & (Bachrach U 1989) \\
\hline Thermotoga maritima & 20 & - & (Korolev et al. 2002) \\
\hline Trypanosoma brucei & 200 & 0,1 & (Bitonti et al. 1984) \\
\hline
\end{tabular}

Tabla 3. Tabla con los valores de $\mathrm{k}_{\mathrm{M}}$ para diversas PMT.

\begin{tabular}{|c|c|c|l|}
\hline Origen PMT & $\begin{array}{c}\mathbf{K}_{\mathbf{M}}{ }^{\text {Put }} \\
(\boldsymbol{\mu} \mathbf{M})\end{array}$ & $\begin{array}{c}\mathbf{K}_{\mathbf{M}}{ }^{\text {Adomet }} \\
(\boldsymbol{\mu M})\end{array}$ & \multicolumn{1}{|c|}{ Referencia } \\
\hline Calystegia sepium & 120 & - & (Teuber et al. 2007) \\
\hline Datura stramonium & 281 & - & (Teuber et al. 2007) \\
\hline Datura stramonium & 108 & 42 & (Biastoff et al. 2006) \\
\hline Datura stramonium & 310 & 100 & (Walton et al. 1994) \\
\hline Hyoscyamus albusa & 277 & 203 & (Hibi et al. 1992) \\
\hline Lycopersicum esculentum & 113 & - & (Teuber et al. 2007) \\
\hline Solanum dulcamara & 169 & - & (Teuber et al. 2007) \\
\hline Solanum tuberosum & 242 & - & (Stenzel et al. 2006) \\
\hline
\end{tabular}


En el caso de AtACL5 es más difícil juzgar sus parámetros cinéticos debido a que la nuestra es la primera caracterización de una tSPMS. Al compararlo con las afinidades descritas de algunas SPMS (Tabla 4), también resultan bastante elevadas. Quizás ACL5 requiere también una modificación postraduccional que no se produce en E. coli.

Tabla 4. Tabla con los valores de $\mathrm{k}_{M}$ para diversas SPMS.

\begin{tabular}{|c|c|c|l|}
\hline Origen SPMS & $\begin{array}{c}\mathbf{K}_{\mathbf{M}}{ }^{\text {Spd }} \\
(\mu \mathrm{M})\end{array}$ & $\begin{array}{c}\mathbf{K}_{\mathbf{M}}{ }^{\text {Adometdc }} \\
(\mu \mathrm{M})\end{array}$ & \multicolumn{1}{|c|}{ Referencia } \\
\hline Bazo humano & 200 & 1 & (Kajander et al. 1989) \\
\hline Bazo oveja & 84 & - & (Jean et al. 1988) \\
\hline Cerebro oveja & 60 & $0,1-1$ & $\begin{array}{l}\text { (Pajula y Raina 1979) } \\
\text { (Pajula 1983) }\end{array}$ \\
\hline Próstata rata & 20 & - & (Pegg et al. 1981) \\
\hline Sulfolobus solfataricus & 1540 & 7,9 & (Bachrach U 1989) \\
\hline
\end{tabular}

Con respecto a la DsPMT no fue necesario realizar ningún ensayo pues sus $\mathrm{K}_{\mathrm{M}}$ eran ya conocidas, $108 \mu \mathrm{M}$ para la putrescina y $42 \mu \mathrm{M}$ para el AdoMet (Biastoff et al. 2006).

\section{Modificación del centro activo de SPDS y tSPMS}

La comparación directa de las secuencias primarias de las cuatro aminopropil transferasas de $A$. thaliana (AtSPD1, AtSPD2, AtSPM1 y AtACL5) y la PMT de D. stramonium (DsPMT) (Figura 33) muestra un grado de similitud tan alto a lo largo de toda la proteína, que resultaba imposible determinar los aminoácidos esenciales para la actividad enzimática, y mucho menos seleccionar los residuos diferenciales entre las distintas enzimas, que justificasen la especificidad de sustrato de cada una de ellas. 

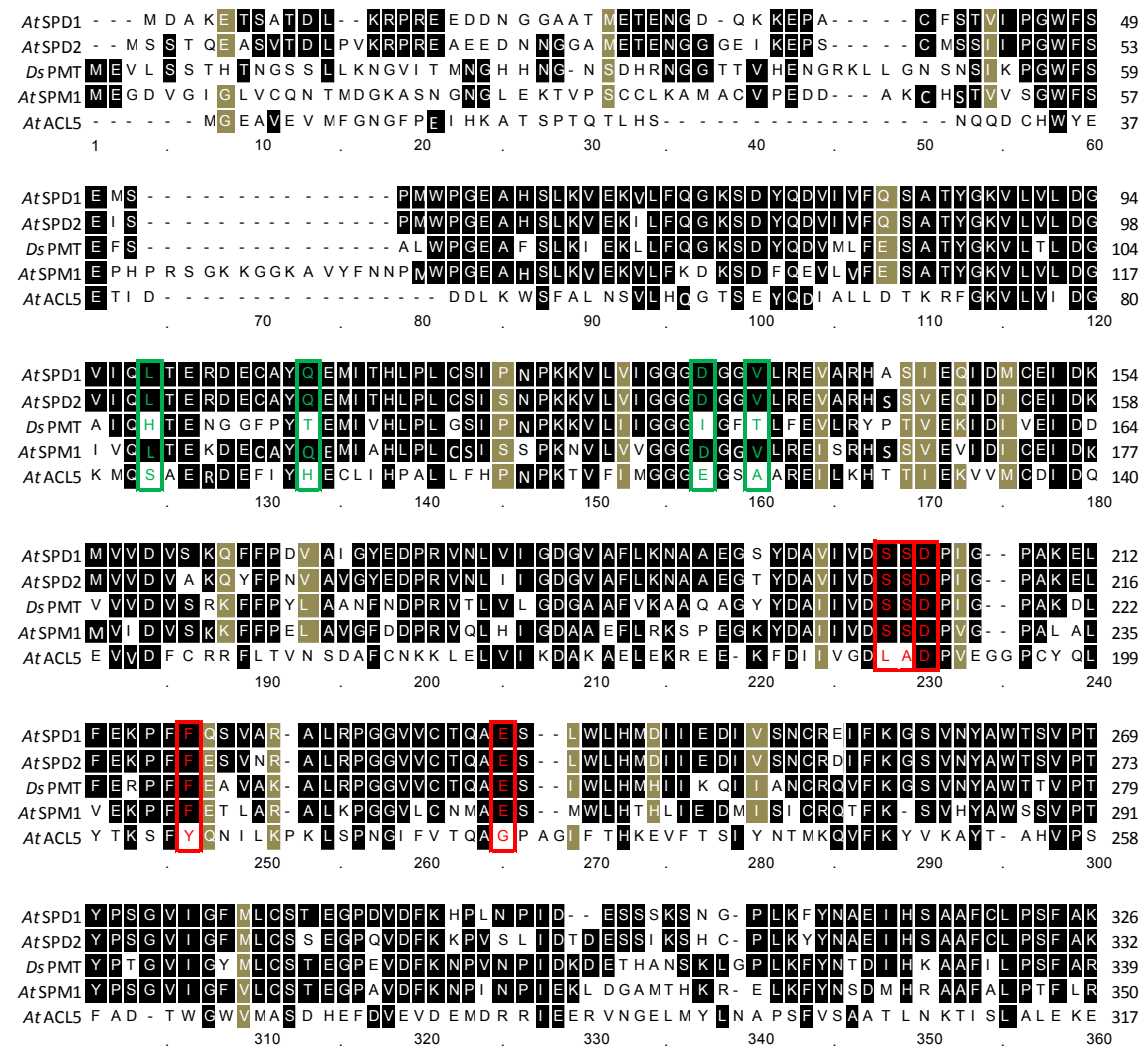

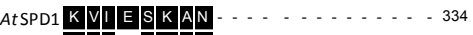

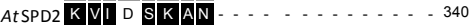

DSPMT S MI E S . . . . . . . . . . . 344

AtSPM1 R EVI A L LA S . . . . . . . . 359

Figura 33. Alineamiento de los aminoácidos de las aminopropil transferasas de $A$. thaliana y de la PMT de $D$. stramonium. En negro se marcan los aminoácidos completa o mayoritariamente conservados y en gris los parcialmente conservados. En verde se resaltan los aminoácidos mutagenizados para convertir una SPDS en una PMT, y en rojo los aminoácidos mutagenizados para convertir una ACL5 en SPD1.

Por ello, parecía una estrategia más apropiada elaborar modelos tridimensionales de estas enzimas, para comparar las estructuras y las identidades de los distintos aminoácidos que componen sus centros activos. Este abordaje in silico fue facilitado por la disponibilidad de la estructura tridimensional de una SPDS de T. maritima obtenida por cristalografía de rayos $\mathrm{X}$ (Korolev et al. 2002), así como otras estructuras con evidencia experimental, 
como las SPDS y SPMS de humanos (códigos PDB: $2 \mathrm{O} 06$ y 2O0L) y la tSPMS de Thermus thermophilus (código PDB: 1UIR). A pesar de la distancia evolutiva, estas estructuras muestran un alto grado de similitud conformacional en el centro activo, lo que indicaba que la modelización sería una estrategia razonable para obtener información tridimensional sobre la estructura de la PMT, cuyo punto de divergencia respecto a SPDS es incluso más reciente.

Con la colaboración del Dr. Alberto Marina (Unidad de Cristalografía de Macromoléculas del Instituto de Biomedicina de Valencia, CSIC), obtuvimos los modelos de las estructuras tridimensionales de las cuatro aminopropil transferasas y la PMT (ver Materiales y Métodos, página 135). Las comparaciones de SPDS frente a PMT (Figura 34), y de SPDS frente a tSPMS (Figura 35), nos permitió sacar las siguientes conclusiones:

- En los sitios de unión para AdoMet y AdoMetdc en PMT y SPDS, respectivamente, pueden detectarse cambios significativos. En concreto, los aminoácidos D131 y Q107 de la AtSPD1, ambos cargados negativamente, son incompatibles con el grupo carboxilo del AdoMet (Korolev et al. 2002). En la PMT, estos dos aminoácidos son sustituidos por I141 y T117, ampliando la cavidad en la que debe situarse este extremo de la molécula. Otras sustituciones importantes serían las de V134 y L98 por T144 y H108 respectivamente, que cambian residuos hidrofóbicos por residuos polares, que parecen necesarios para estabilizar el grupo carboxilo del AdoMet (Figura 27).

- En el centro activo de ACL5 (tSPMS) es más difícil identificar los residuos diferenciales que justifiquen la preferencia de la espermidina como sustrato, frente a la putrescina de SPD1. Parece ser que la putrescina podría acomodarse perfectamente en el espacio utilizado en ACL5 para la espermidina, pero esta putrescina quedaría poco fijada, por lo que no podría realizarse la reacción. Una de las diferencias más notables entre ambas estructuras, con respecto a la fijación del sustrato, es la del aminoácido D204 de SPD1 que, aunque está conservado en ACL5 (como D189), se encuentra más alejado de la espermidina permitiendo su correcto acomodo, pero sin llegar a interaccionar con 
ella; la posición de este ácido aspártico (D) puede ser debida a los aminoácidos previos, que en SPD1 son los aminoácidos S202 y S203, mientras que en ACL5 son L187 y A188 y, también, otro modo de aproximar dicho residuo seria la sustitución de este ácido aspártico por un ácido glutámico (E), con una cadena lateral un poco más larga, que podría aproximarse el grupo carboxilo a la poliamina. Otra diferencia que puede explicar el acoplamiento de la poliamina, es la posición de la cadena D189-A188-L187-D186 en ACL5, comparada con D204-S203S202-D201 en SPD1. En ACL5 la presencia del Y205 podría interactuar con el D186 creando una rigidez en toda la cadena, alejándola de la poliamina, mientras en SPD1 esa posición está ocupada por F218, siendo la fenilalanina un aminoácido que al carecer del grupo hidroxilo no puede interactuar con la cadena. Por último, estaría la posición E236 de la SPD1 que, aunque se encuentra un poco alejada de la putrescina, podría estabilizarla, mientras que, en ACL5, este aminoácido es la G224, sin ningún tipo de cadena lateral. 
Resultados

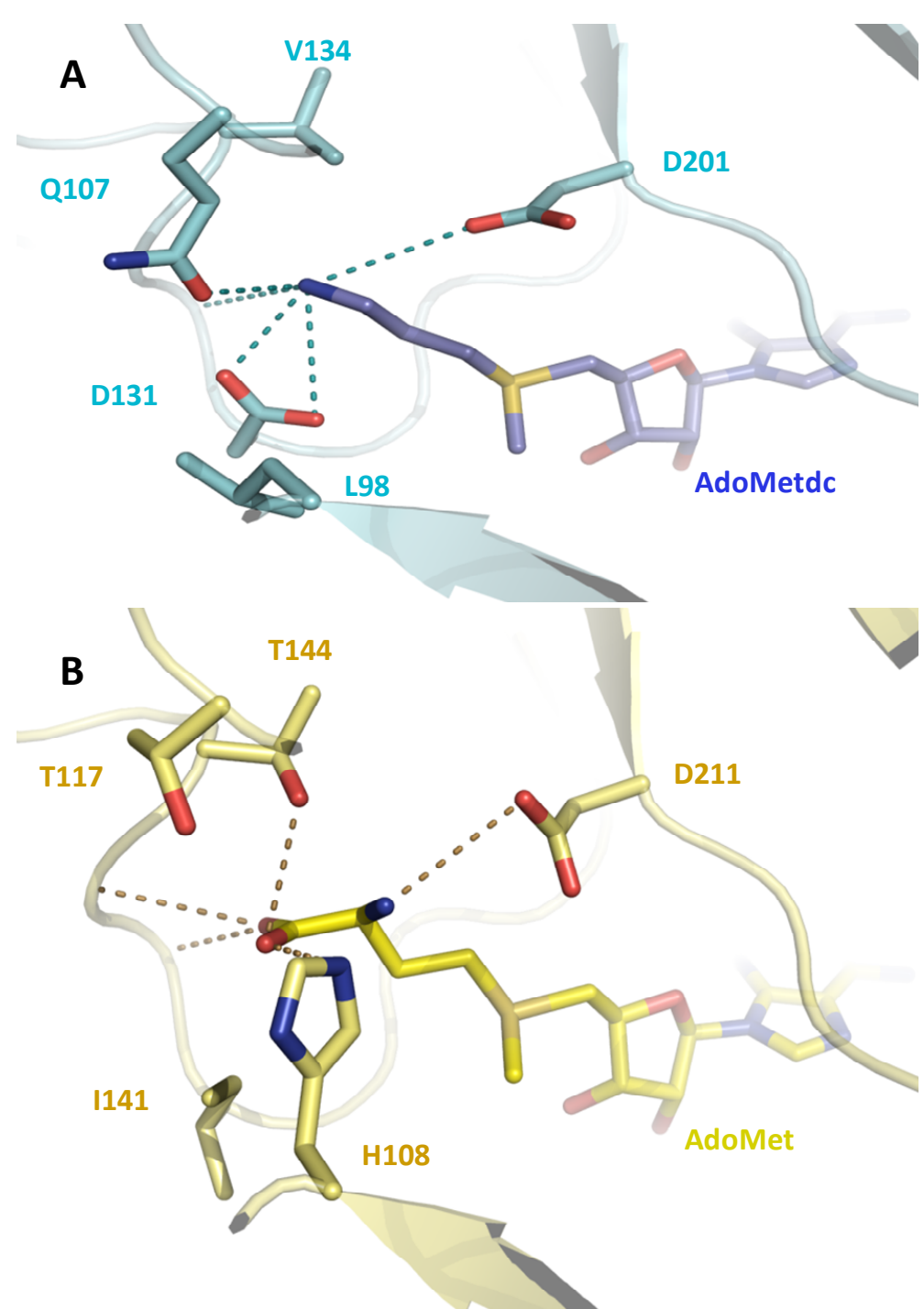

Figura 34. Comparación del centro activo de la SPD1 de $A$. thaliana modelizada con el AdoMetdc (A) y la PMT de Nicotiana tabacum con el AdoMet (B) (Figura cedida por Eugenio Gómez Minguet). 

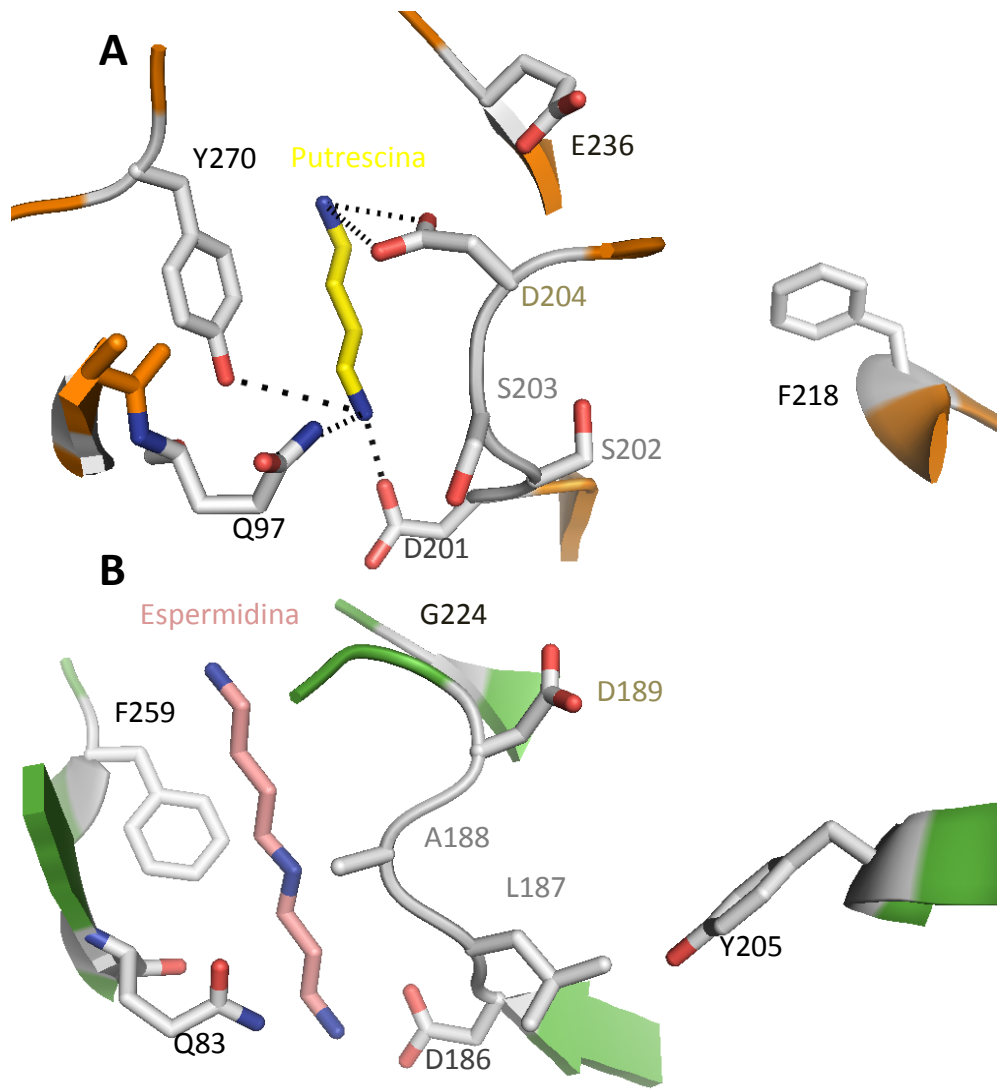

Figura 35. Comparación del centro activo de la SPD1 de $A$. thaliana modelizada con la putrescina (A) y ACL5 de $A$. thaliana con la espermidina (B).

Una vez analizados los centros activos de los enzimas, decidimos realizar las mutagénesis dirigidas indicadas en la tabla 5, para intentar conferir actividad espermidina sintasa a AtACL5, y para intentar conferir actividad putrescina-Nmetil transferasa a la $A t$ SPD1.

Comenzamos construyendo las versiones mutantes de AtACL5, de las cuales $\mathrm{ACL}_{\mathrm{L} 187 \mathrm{~S}}+\mathrm{A} 188 \mathrm{~S}$ y ACL5 $5_{\mathrm{G} 224 \mathrm{E}}$, generaron versiones insolubles y por lo tanto, hubo que descartarlas. Mientras tanto, las versiones ACL5 $5_{\mathrm{D} 189 \mathrm{E}}$ y ACL5 $5_{\mathrm{Y} 205 \mathrm{~F}}$, sí dieron lugar a proteínas solubles pero que carecían de cualquier tipo de actividad espermidina sintasa y que además habían perdido por completo su actividad nativa. El hecho de que cualquier cambio que realicemos provoque 
una pérdida total de la actividad enzimática nos indica que, probablemente, los aminoácidos mutagenizados son esenciales para el correcto funcionamiento del enzima, y que su modificación aislada no debe ser suficiente para cambiar la actividad.

Con respecto a las mutagénesis de SPD1 para convertirla en una putrescina-Nmetil transferasa sabíamos que, cambios puntuales en uno o dos aminoácidos eran incapaces de modificar la actividad (Biastoff et al. 2009a), por lo que construimos el tetramutante SPD1 $1_{\mathrm{L} 98 \mathrm{H}}+\mathrm{Q} 107 \mathrm{~T}+\mathrm{D} 131 \mathrm{I}+\mathrm{V} 134 \mathrm{~T}$, que no presentó ningún tipo de actividad putrescina-N-metil transferasa y, que además, perdió su actividad nativa como espermidina sintasa; por lo que razonablemente podemos concluir que la especificidad de sustrato no reside exclusivamente en los aminoácidos del centro activo.

Tabla 5. Nombres de las proteínas mutantes y aminoácidos mutagenizados, para convertir AtACL5 en una SPDS, y AtSPDS en una PMT.

\begin{tabular}{|c|c|c|c|}
\hline Nombre & AtACL5 & AtSPD1 & $\begin{array}{c}\text { Mutagénesis sobre } \\
\text { AtACL5 }\end{array}$ \\
\hline$A C L 5 L_{L 187 S}+A 188 S$ & L187, A188 & S202, S203 & L187, A188 $\rightarrow$ S187, S188 \\
\hline$A C L 5_{D 189 E}$ & D189 & D204 & $\mathrm{D} 189 \rightarrow \mathrm{E} 189$ \\
\hline ACL5Y205F & Y205 & F218 & Y205 $\rightarrow$ F205 \\
\hline $\mathrm{ACL}_{\mathrm{G} 224 \mathrm{E}}$ & G224 & E236 & G224 $\rightarrow E 224$ \\
\hline Nombre & AtSPD1 & DsPMT & $\begin{array}{c}\text { Mutagénesis sobre } \\
\text { AtSPD1 }\end{array}$ \\
\hline SPD1 ${ }_{L 98 H}$ & L98 & $\mathrm{H} 108$ & $\mathrm{~L} 98 \rightarrow \mathrm{H} 98$ \\
\hline SPD1 $107 T$ & Q107 & T117 & $\mathrm{Q} 107 \rightarrow \mathrm{T} 107$ \\
\hline SPD1D1311 & D131 & 1141 & $D 131 \rightarrow \mid 131$ \\
\hline $\mathrm{SPD}_{\mathrm{V} 134 \mathrm{~T}}$ & V134 & T144 & $\mathrm{V} 134 \rightarrow \mathrm{T} 134$ \\
\hline
\end{tabular}



DISCUSIÓN 

Desde que comenzó la aplicación de aproximaciones de genética molecular al estudio de la función de las poliaminas en plantas, dos ideas fundamentales han ido consolidándose: 1) no todas las poliaminas cumplen funciones equivalentes a pesar de su similitud estructural, y 2) la ruta de biosíntesis de poliaminas se encuentra sujeta a una tasa elevada de evolución y selección. Esta Tesis ha contribuido experimentalmente a ilustrar ambos conceptos de la siguiente manera:

- hemos podido confirmar la función de ACL5 como una termoespermina sintasa in vivo, incluso cuantificando los niveles normales de termoespermina en distintos tejidos y condiciones de crecimiento de Arabidopsis.

- hemos identificado una pequeña familia de factores de transcripción de la clase bHLH (los genes $A J A X$ ), como mediadores más probables para la regulación por ACL5 de la diferenciación del xilema.

- hemos determinado los parámetros cinéticos de varias aminopropil transferasas de A. thaliana y confirmado experimentalmente, la importancia de ciertos residuos del centro activo para la funcionalidad de la espermidina sintasa.

Todos estos hallazgos dan pie a interpretaciones de distinto signo y a la propuesta de lo que consideramos es el modelo molecular más probable para la función de la termoespermina en el desarrollo de A. thaliana, como se discute a continuación.

\section{ACL5, AJAX y desarrollo vascular: ¿una ruta única o dos vías paralelas?}

Al iniciar esta Tesis, nada hacía sospechar que la termoespermina, un metabolito presente en bacterias termófilas y otros procariotas (Oshima 1979; Hosoya et al. 2004), también estuviese presente en las plantas. La atribución inicial de una actividad espermina sintasa, y no termoespermina sintasa, a ACL5 (Hanzawa et al. 2000) justificaba la propuesta de que la espermina 
controlaba la formación del xilema evitando la muerte prematura de las células durante el proceso de diferenciación (Muñiz et al. 2008). La confirmación de que ACL5 presenta actividad termoespermina sintasa permite refinar el modelo inicial, pero no proporciona por sí misma un mecanismo molecular que explique cómo se ejerce el control de la muerte celular.

La metodología que hemos empleado en esta Tesis para diseccionar este mecanismo ha sido la búsqueda de supresores extragénicos, una aproximación que ya ha demostrado su utilidad en la resolución de las vías de señalización hormonal de plantas (McCourt 1999). Aunque el éxito de este abordaje puede medirse por el elevado número de supresores encontrados, la cuestión fundamental es dilucidar la relevancia fisiológica de estos nuevos mutantes; es decir, discriminar si el mecanismo de supresión se debe a:

- la alteración de una función controlada por ACL5 (en ese caso los genes supresores serían mediadores de la acción de ACL5).

- la compensación de la ausencia de ACL5 mediante la activación de una ruta paralela (en ese caso los genes supresores identificarían una vía alternativa para el control de la muerte celular durante la diferenciación del xilema)

- la compensación de la falta de ACL5 mediante una mutación neomórfica en algún elemento no relacionado con la función fisiológica de ACL5 (en ese caso la supresión se podría considerar como un artefacto).

Aunque nuestros resultados no resuelven inequívocamente la relación entre $A C L 5$ y $A J A X$, sí que proporciona evidencia a favor de un modelo en el que los genes AJAX actúan como mediadores de ACL5 en el control de la diferenciación del xilema:

- la supresión de acl5 por parte de los supresores ajax afecta a todas las características observadas del fenotipo del mutante, lo cual sería muy difícil de explicar con dos rutas de señalización paralelas no solapantes. 
- las mutaciones de los genes $A J A X$, en un fondo genético silvestre para ACL5 no presentan ningún fenotipo aparente (datos no mostrados), por lo que no parece haber un efecto aditivo más propio de dos rutas independientes.

- los patrones de expresión de ACL5 y AJAX solapan en la región de los haces vasculares atendiendo a los datos publicados (Figura 36), lo cual refuerza la idea de que actúan coordinadamente sobre los mismos tipos celulares.

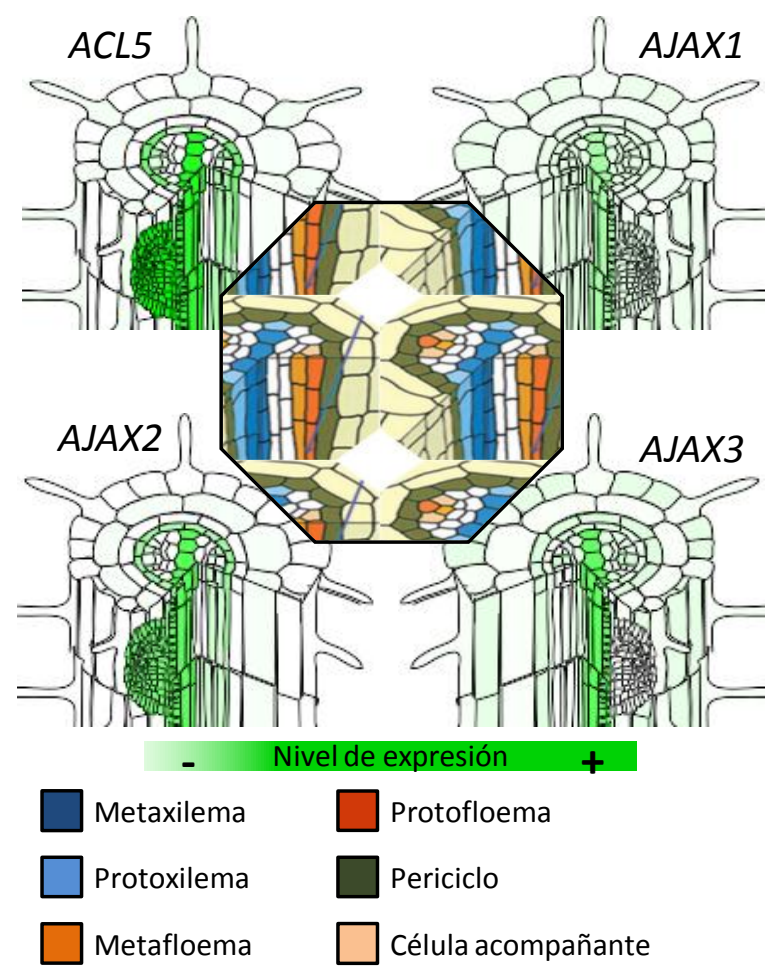

Figura 36. Patrones de expresión en la raíz de ACL5, AJAX1, AJAX2 y $A J A X 3$, según la herramienta "Deconvolved Root Expression Map Visualizer" (Cartwright et al. 2009). En la parte central se muestra un esquema de la estructura de los haces vasculares de la raíz.

- Las mutaciones en la uORF de, al menos, AJAX1 suprimen el fenotipo enano de acl5, pero no el de otros mutantes enanos afectados en 
diversas rutas de señalización hormonal como axr2, gail o dim (Imai et al. 2006).

Para consolidar el modelo en el que los genes $A J A X$ son mediadores de la señal de $A C L 5$, sería necesaria alguna evidencia experimental adicional. Por ejemplo, que un mutante nulo para los tres genes $A J A X$ fenocopie a acl5; o determinar el mecanismo bioquímico por el que la termoespermina regula la traducción de $A J A X$; o que la expresión de los genes AJAX, bajo el control del promotor de $A C L 5$ sea capaz de revertir el fenotipo mutante de acl5.

\section{Las poliaminas y el control traduccional de $A J A X$.}

El descubrimiento de que las mutaciones supresoras encontradas afectan al control traduccional de los factores de transcripción AJAX es especialmente interesante, porque sugiere que dicho control podría representar el nexo de unión entre ACL5 y los AJAX.

El control traduccional de una ORF principal por parte de su 5'-UTR, y más concretamente, por alguna pequeña uORF allí contenida, es una de las formas más eficientes de regulación de la expresión génica (Morris y Geballe 2000; Hernandez-Sanchez et al. 2003). El estudio de estos procesos ha permitido identificar varios mecanismos a través de los cuales se ejerce dicho control. Por ejemplo:

- en la 5'-UTR, el mRNA puede presentar una estructura secundaria que dificulte el avance del ribosoma hacia el codón de inicio (Wang y Wessler 2001).

- aunque el AUG de la uORF no se encuentre en un contexto adecuado, algunos ribosomas, por el mecanismo de escaneo permeable, inician la traducción en este primer AUG, rebasando el AUG de la ORF principal, y generando un proteína diferente (Souciet et al. 1999).

- en caso de que se inicie la traducción de una uORF y ésta no sobrepase al AUG de la ORF principal, el ribosoma podrá acabar de traducir la uORF y después realizar un proceso de reiniciado para traducir la ORF 
principal. La eficacia de este proceso de reiniciado depende del tamaño/tiempo de traducción de la propia uORF (Kozak 2001), del tamaño de fragmento intercistrónico (Abastado et al. 1991) y de otros factores.

- la traducción de la uORF genera un pequeño péptido que actúa en cis, bloqueando al ribosoma, dificultando la traducción de la ORF principal (Law et al. 2001).

Los resultados de nuestros ensayos de transcripción-traducción in vitro muestran inequívocamente que la región 5'-UTR de los genes AJAX controla la traducción de la ORF principal. Con los datos que disponemos no se puede descartar completamente, que este control se ejerza mediante la modificación de la estructura secundaria de la región 5'-UTR, aunque nos parece más probable que la regulación implique a un pequeño péptido codificado por una de las uORFs allí contenidas. Los argumentos que hacen inclinarnos por dicho modelo son varios:

1) Todas las mutaciones encontradas suponen un cambio de aminoácido o la introducción de un codón de parada prematura, en la secuencia del pequeño péptido codificado por la uORF. Es decir, no hemos encontrado en ningún caso mutaciones silenciosas respecto al péptido que alterasen la estructura secundaria.

2) Los péptidos codificados por la uORF afectada en cada gen $A J A X$ presentan un alto grado de conservación de secuencia en su extremo Cterminal, precisamente donde se localizan las mutaciones de cambio de aminoácido.

3) La existencia de mutaciones supresoras de acl5 en el gen que codifica la proteína ribosomal RPL10A (Imai et al. 2008), que es diana de diversos inhibidores del ribosoma (Xia et al. 2005), relaciona la función ribosomal con la regulación de $A J A X$ y permite imaginar que dicha proteína del ribosoma podría ser la diana natural del pequeño péptido codificado en la 5'-UTR de los genes AJAX. 
Un modelo muy atractivo que se intuye a partir de los resultados de nuestro trabajo es que la termoespermina, o la propia proteína ACL5, regulen la traducción de los factores de transcripción AJAX interfiriendo con la actividad del pequeño péptido. Mecanismos similares de regulación en una ruta de señalización se han descrito, por ejemplo, para la sacarosa y ATB2 (Wiese et al. 2004; Rahmani et al. 2009), y para la espermidina/espermina y SAMDC (Raney et al. 2000; Hanfrey et al. 2005).

Existen antecedentes que conectan las poliaminas con el control traduccional. El primero de ellos es el mecanismo de autorregulación de la biosíntesis de poliaminas, exclusivo de mamíferos, ejercido a través de la regulación postraduccional de la ornitina descarboxilasa (ODC) por parte de una proteína llamada antizima (OAZ) (Hayashi et al. 1996) que secuestra la ODC y la transporta a la maquinaria de degradación del proteosoma 26S. El control traduccional de la OAZ es realizado por las propias poliaminas puesto que $O A Z$ está compuesto por dos ORFs parcialmente solapadas, siendo la que está aguas abajo la que contiene la actividad funcional aunque, para poder ser traducida, debe producirse previamente la traducción de la situada aguas arriba, seguido de un cambio de la pauta de lectura +1 , que es mediado por altos niveles de poliaminas (Ivanov y Atkins 2007).

El segundo caso es un ejemplo muy similar al de nuestro modelo: el control traduccional de la $S A M D C$ en plantas (Franceschetti et al. 2001), por parte de dos uORFs, en función de los niveles de poliaminas. En la 5'-UTR de la $S A M D C$ existen dos uORFs parcialmente solapantes, de las cuales la segunda, situada aguas abajo, inhibe la traducción de la ORF principal a través de su péptido, mientras la primera, situada aguas arriba, impide la traducción de la segunda al solapar su secuencia con la de la segunda (Figura 37). A niveles bajos de poliaminas se traduce la primera uORF y por lo tanto se salta la segunda, mientras que a niveles altos se traduce la segunda uORF que inhibe la traducción de la ORF principal (Ivanov et al. 2010). 


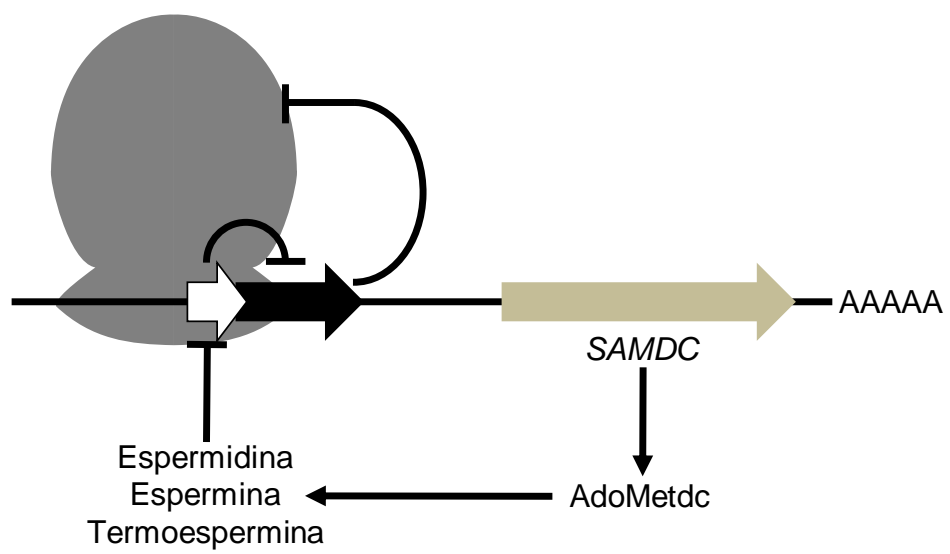

Figura 37. Modelo de traducción de la SAMDC. La flecha gris representa el fragmento de mRNA que contiene la pauta de lectura abierta del $S A M D C$, la flecha negra representa el primer péptido que inhibe la traducción de $S A M D C$, la flecha blanca representa el segundo péptido que inhibe la acción del primero.

Por tanto, el modelo de trabajo sobre el que realizar el trabajo futuro del laboratorio se representa en la Figura 38. Se basa en que el péptido codificado por uORF inhibe en cis la traducción de la ORF principal de $A J A X$, siendo la diana de este péptido, el componente ribosomal RPL10. La termoespermina sintetizada por ACL5 elimina esta inhibición, ya sea interaccionando con RPL10 y/o el péptido, o generando un cambio de la pauta de lectura +1 , que evite la síntesis del péptido. Nuestros intentos por encontrar variaciones en la traducción in vitro de la ORF principal de AJAX2 tras la adición de termoespermina no nos han proporcionado pruebas al respecto, bien porque este efecto esté enmascarado por otros efectos "tóxicos" derivados de la concentración utilizada; bien porque la síntesis de termoespermina deba producirse in situ, asociada a la traducción; bien porque la modificación de la actividad del pequeño péptido o la protección de RPL10A requieran una modificación enzimática implicando a la termoespermina, pero dicha enzima no está presente en nuestro sistema experimental de traducción in vitro; o bien porque no exista dicho vínculo entre ACL5 y los AJAX. También existe la posibilidad de que sea la proteína ACL5, y no el producto de su actividad enzimática, la que interfiera con la traducción de los $A J A X$. Se trataría entonces de una proteína multifuncional; en este sentido se han documentado casos de “moonlighting" para enzimas (Gancedo y Flores 2008), pero en este momento 
no existe ningún indicio que lo apoye, más allá de que la complementación que se puede conseguir del fenotipo acl5, mediante la adición de termoespermina, es muy leve (Kakehi et al. 2008).

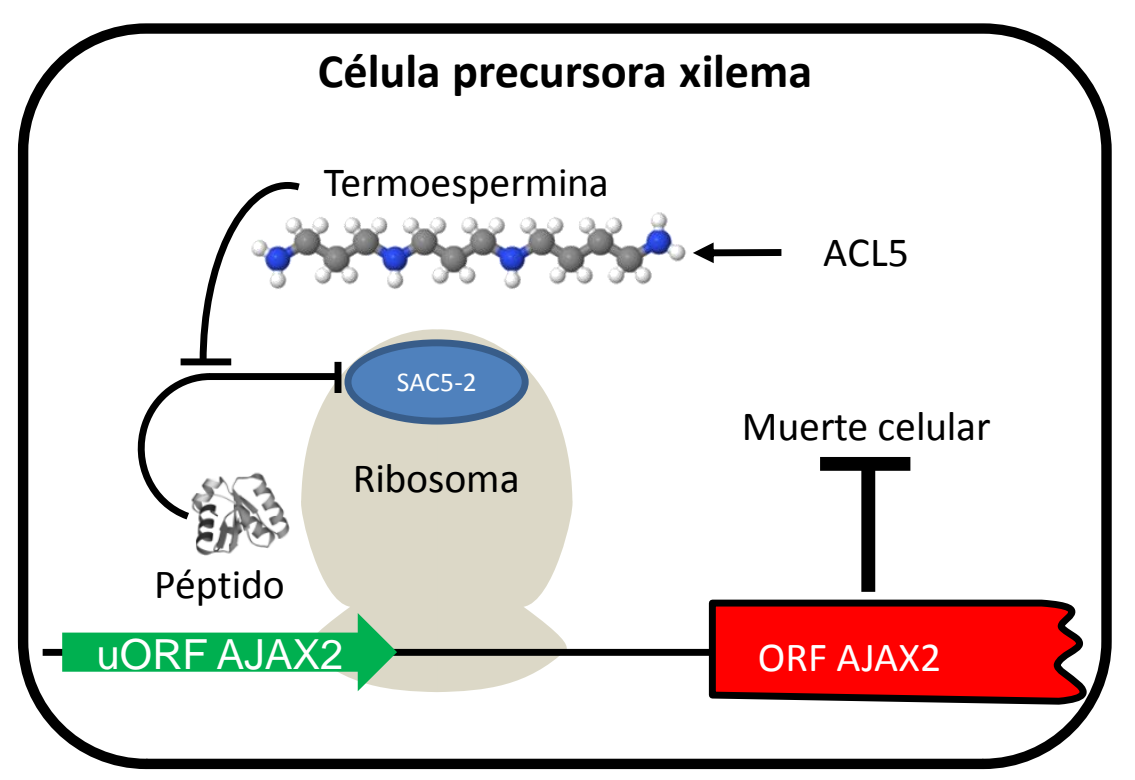

Figura 38. Modelo de traducción de AJAX2 en las células precursoras del xilema donde se exnresa ACL5.

Por último, el modelo contempla que los genes $A J A X$ codificarían factores de transcripción que regularían genes implicados en la muerte celular durante la diferenciación del xilema, algo que nuestros análisis transcriptómicos apoyan parcialmente. En términos mecanísticos, es importante hacer notar que las proteínas AJAX parecen carecer del dominio básico característico de los factores de transcripción bHLH (Toledo-Ortiz et al. 2003). Esto sugiere que las proteínas AJAX serían reguladores transcripcionales incapaces de unirse al DNA directamente, y requerirían la interacción con otros factores de transcripción. En A. thaliana se ha descrito al menos un caso en el que una proteína HLH (HFR1) regula la transcripción a través de la formación de heterodímeros con otros factores de transcripción de la familia bHLH (Hornitschek et al. 2009). Por supuesto, la identificación de interactores de las proteínas AJAX permitiría sustentar experimentalmente esta hipótesis. 
En este modelo, las dianas reguladas por los genes $A J A X$ determinarían la muerte celular de las células del metaxilema y el correcto desarrollo de los haces vasculares. Así pues, la termoespermina jugaría un papel de retardante de la muerte de estas células del metaxilema, permitiendo que se completase el proceso de diferenciación y formación del mismo. En un mutante acl5, la ausencia de termoespermina, provoca la muerte prematura del metaxilema impidiendo su correcto desarrollo. En un doble mutante acl5 ajx, la deficiencia en termoespermina sería compensada por la inexistencia o la modificación del péptido, que ya no podría inhibir la traducción de $A J A X$.

\section{Los genes $A J A X$ y el origen del xilema}

El xilema es un tejido conductor, que surgió por las nuevas necesidades que tenían los organismos fotosintéticos y acuáticos que comenzaron a colonizar el medio terrestre. Estas plantas terrestres primigenias debieron conciliar dos efectos biofísicos opuestos; por un lado, el beneficio de aumentar la superficie del organismo dedicada a la captación de $\mathrm{CO}_{2}$ y luz para el proceso fotosintético $\mathrm{y}$, por otro, el perjuicio que representa el aumento de la ratio área:volumen en pérdidas de agua. Fueron tres innovaciones vitales las que resolvieron este conflicto: el desarrollo de estomas, la generación de cutículas y el desarrollo de un nuevo tejido capaz de transportar el agua desde el suelo hacia las partes aéreas (Raven 1993). Este tejido, el xilema, está formado por un nuevo tipo celular, las traqueidas, cuyo desarrollo está caracterizado por la formación de una pared celular secundaria, la lignificación de la misma y, finalmente, un proceso de muerte celular programada.

¿Cómo fueron estas plantas primigenias capaces de colonizar el medio terrestre y generar este nuevo tejido? Para encontrar una respuesta podemos analizar algunos de estos procesos de desarrollo como la síntesis de lignina. La capacidad de sintetizar lignina ya estaba presente en las algas aunque con funciones de protección contra ataques microbianos y daño por luz ultravioleta (Martone et al. 2009), por lo que puede decirse que estas primeras plantas pudieron readaptar una función ya existente a una nueva función. ¿Pudo ocurrir algo parecido con la termoespermina? La biosíntesis de termoespermina debe de ser relativamente importante para las plantas, puesto que se ha conservado 
desde que la adquirieron por transferencia horizontal a partir de los procariotas (Minguet et al. 2008); esta conservación podría justificarse por su importante papel en el desarrollo del xilema, tal como se ha puesto de manifiesto en este trabajo; sin embargo, existen plantas no vasculares, como el musgo Physcomitrella patens o el alga Chlamydomonas reinhardtii, que parecen tener en su genoma una copia de una termoespermina sintasa, lo que sugiere que la termoespermina debería jugar otro papel en las plantas primigenias y que fue reclutada en el momento de la aparición de los tejidos vasculares para desempeñar una nueva función.

Con respecto al proceso de muerte celular programada de las traqueidas en $A$. thaliana, se cree que ésta puede ser controlada por los genes VND6 (Ohashi-Ito et al. 2010) y VND7 (Ohashi-Ito y Fukuda 2010), el cual regula positivamente algunos enzimas hidrolíticos como XCP1, XCP2 y XSP1 (Ohashi-Ito y Fukuda 2010; Yamaguchi et al. 2010), de modo indirecto a través de un elemento cis de $11 \mathrm{pb}$, la secuencia TERE, presente en sus promotores (Pyo et al. 2007). El promotor de ACL5 posee una pseudocaja TERE, que difiere en un solo nucleótido de la secuencia consenso, por lo que quizás también podría ser una diana de estos genes, que controlarían el proceso de muerte celular programada a través de ACL5 y de los AJAX, además de inducir los enzimas hidrolíticos ya citados.

¿Qué ocurrió a nivel evolutivo con los genes AJAX? ¿También fueron reclutados como ACL5 para una nueva función, o pudieron originarse de novo coincidiendo con la aparición del xilema? Parte de la respuesta podría encontrarse en nuestro estudio sobre la conservación de los $A J A X$ en el reino vegetal, basado en las 731 secuencias recopiladas a partir de las bases de datos de genomas vegetales, comprendiendo desde las plantas superiores como $A$. thaliana o arroz, hasta algas unicelulares como C. reinhardtii, pasando por musgos como P. patens.

Asimismo, teniendo en cuenta que los $A J A X$ son los únicos miembros de la familia de bHLHs que tienen una uORF, decidimos también buscar secuencias teóricas de uORFs que codificasen péptidos similares a los de los AJAX. Así encontramos que existían 12 secuencias uORFs de este tipo, en otras 9 plantas 
superiores (Medicago truncatula, arroz, manzano, caña de azúcar, algodón, pomelo, vid, Adiantum capillus-veneris y Welwitschia mirabilis) (Hayden y Jorgensen 2007). De estas 12 uORFs, 6 de ellas, las de M. truncatula, arroz y vid, están situadas aguas arriba de un bHLH, mientras que las otras 6 resultaron ser secuencias truncadas, sin información sobre las ORFs contiguas.

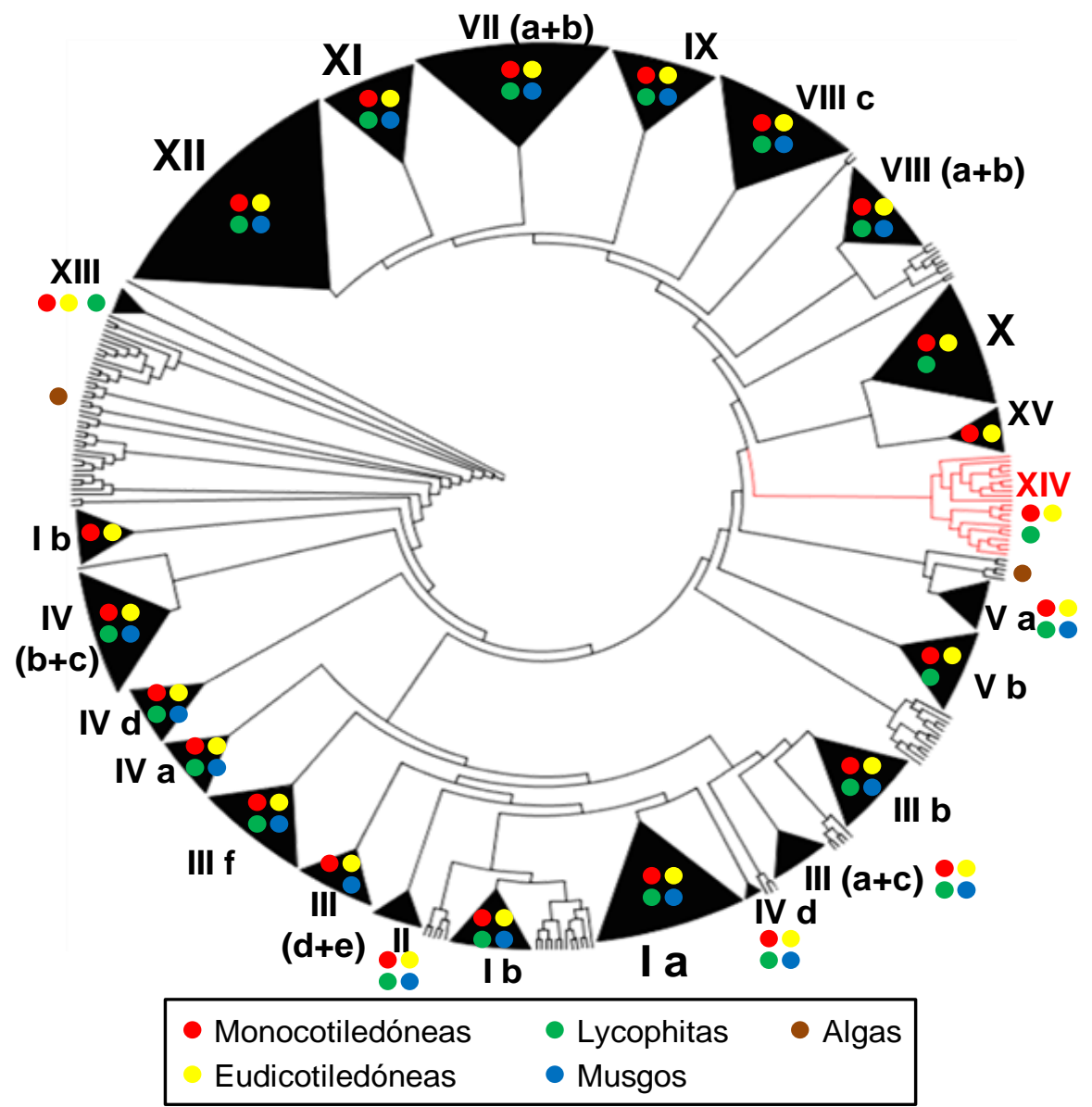

Figura 39. Arbol filogenético de las proteínas bHLH de plantas. Los grupos en los que se dividen los bHLH están basados en (Pires y Dolan 2009). Los triángulos negros representan todas las secuencias de cada grupo condensadas, la amplitud de cada triángulo es proporcional al número de secuencias del grupo. Todos los grupos se muestran condensados excepto el grupo XIV donde se incluyen los genes AJAX (en color rojo); el resto de líneas no condensadas (en negro) representan las secuencias huérfanas que no pertenecen a ningún grupo. El código de colores representa la taxonomía de las secuencias incluidas en cada grupo. 
Con estas 731 secuencias realizamos un árbol filogenético (Figura 39), en el cual las secuencias de los 4 genes AJAX de Arabidopsis junto con otras 17, entre las que se encuentran las 6 de Medicago, arroz y vid ya citadas, quedaban incluidas dentro del subgrupo XIV. Este subgrupo contiene 21 secuencias pertenecientes a 10 especies distintas (Figura 40), siendo todas ellas de plantas superiores o licofitas, pero en ningún caso musgos o algas. De estas 21 secuencias, sabíamos que 10 de ellas tenían una estructura genómica de tipo AJAX, una uORF aguas arriba de un bHLH. Al revisar la secuencia genómica de las 11 restantes encontramos que todas ellas tenían esta misma estructura y que además, todos los péptidos codificados por estas uORFs presentan un alto grado de similitud (Figura 41), especialmente en la región C-terminal, que es donde se concentran las mutaciones de cambio de aminoácido de los alelos supresores de $A J A X$.

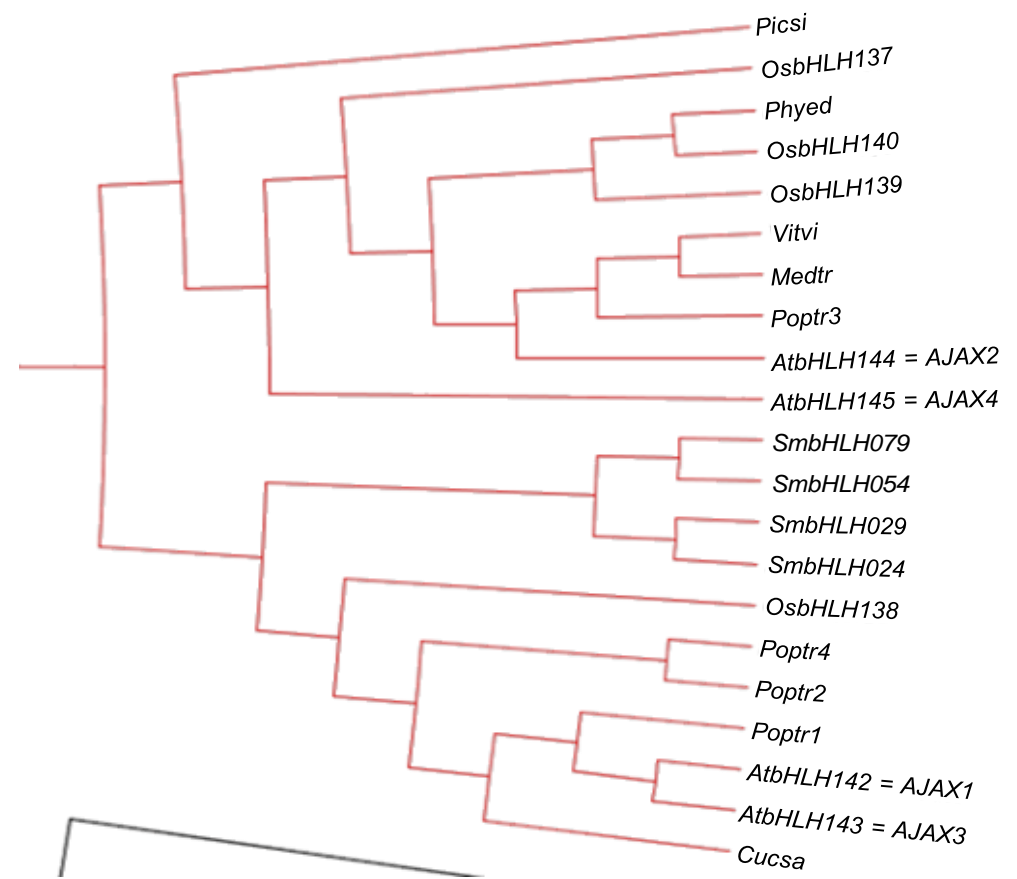

Figura 40. Detalle del subgrupo XIV de la figura anterior. Las abreviaturas quieren decir: Picsi - Picea sitchensis, Os - Oryza sativa, Phyed - Phyllostachys edulis, Vitvi - Vitis vinifera, Medtr - Medicago truncatula, Poptr - Populus trichocarpa, At Arabidopsis thaliana, Sm - Selaginella moellendorffii, Cucsa - Cucumis sativa. 
Así pues, los genes $A J A X$ están conservados exclusivamente entre las plantas vasculares (incluyendo a la más primitiva, Selaginella moellendorfii), y siempre presentan una uORF también conservada en sus 5'-UTR respectivas.

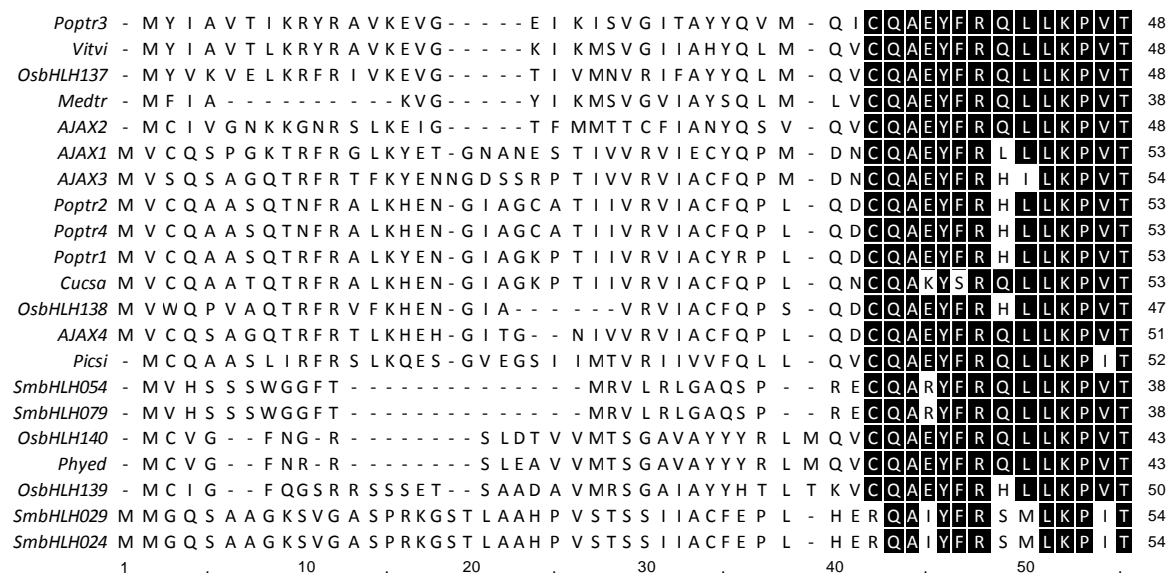

Figura 41. Alineamiento de los aminoácidos de los péptidos codificados por las uORFs situadas aguas arriba de los genes bHLH del subgrupo XIV. En negro se marcan los aminoácidos completa o mayoritariamente conservados en el extremo C-terminal.

Hay pues dos hechos que parecen apoyar la teoría de que los genes $A J A X$ se originaron de forma coincidente con el de la regulación de la formación del xilema por ACL5:

- el hecho de que no aparezcan homólogos de AJAX en plantas no vasculares (Figura 42), especialmente en $P$. patens, un musgo con el genoma completamente secuenciado y que posee $98 \mathrm{bHLH}$, un número del mismo orden de magnitud que A. thaliana o arroz.

- la gran mayoría de las subfamilias en que se dividen los bHLH en el reino vegetal tienen miembros entre los diversos tipos de plantas, mientras que el grupo XIV es exclusivo de plantas vasculares 


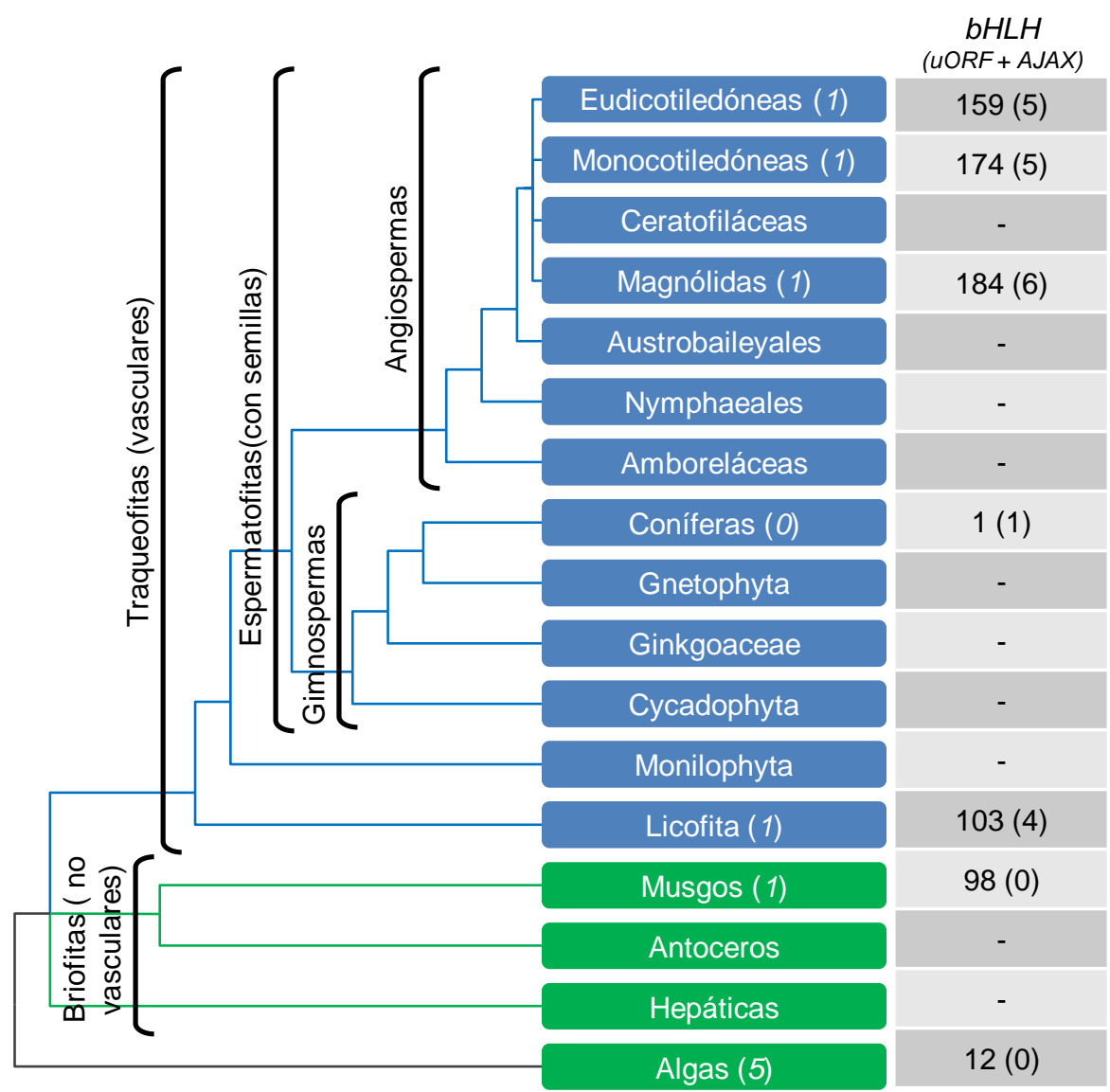

Figura 42. Esquema evolutivo del reino vegetal, indicando el número de genes $b H L H$ y $A J A X$. Al lado de cada clado, se indica en cursiva, el número de especies con su genoma secuenciado que hemos utilizado en la búsqueda. En la columna de los genes $b H L H$ se indica cuántos de ellos hemos encontrado y, entre paréntesis, cuántos de ellos se parecen a un gen AJAX y además tienen una uORF en su $5^{\prime}$ UTR.

\section{Mecanismos bioquímicos de las aminopropil transferasas}

La familia de las aminopropil transferasas (SPDS, SPMS y tSPMS) y la de las putrescina-N-metil transferasas (PMT) constituyen un grupo de enzimas con un alto grado de similitud entre ellas, tanto a nivel de secuencia como de estructura. Este alto grado de parecido en enzimas con funciones divergentes, 
nos pareció un modelo adecuado para reproducir aquellos cambios hipotéticos que han sufrido durante la evolución y comprobar experimentalmente su efecto.

Así pues, era necesaria la determinación de las constantes cinéticas de las enzimas analizadas, como testigo de los cambios en las actividades. Este resultado significó una cierta sorpresa, ya que los parámetros de $\mathrm{K}_{\mathrm{M}}$ observados en nuestras proteínas purificadas presentaron, en algunos casos, valores relativamente alejados de los obtenidos para las mismas enzimas de otros organismos. Además de las posibles explicaciones avanzadas en los resultados de esta Tesis, en el apartado de "Características cinéticas de SPDS, tSPMS y PMT" (Página 73), también habría que considerar que en las reacciones de biosíntesis de poliaminas, además de la propia poliamina, se genera un producto secundario, el 5'-metiltioadenosina (MTA), que es la molécula resultante de eliminación del grupo aminopropilo del AdoMetdc. En condiciones fisiológicas, este MTA es degradado por MTA quinasas (Sauter et al. 2004), pero en condiciones in vitro se acumula y actúa como un inhibidor tanto de las SPDS (Dufe et al. 2005) como de las SPMS (Ikeguchi et al. 2006), por lo que puede afectar a nuestras determinaciones de las constantes cinéticas.

Una base importante de nuestros estudios relacionando la estructura y la función es la asunción de que las aminopropil transferasas y las putrescina-N-metil transferasas, son proteínas de naturaleza modular, es decir, que diferentes partes de las proteínas se encargan de funciones diferentes. De hecho, la espermina sintasa de Homo sapiens se puede dividir en diversos módulos, de los cuales el $\mathrm{N}$-terminal es muy parecido al de una S-adenosilmetionina descarboxilasa, mientras que el C-terminal, es muy similar al de las espermidina sintasas, con la diferencia de poseer un espacio mayor para el anclaje de sustratos, lo cual le permite acomodar una triamina como sustrato y generar una tetraamina como producto (Wu et al. 2008).

Esta visión modular parece confirmarse cuando comparamos las actividades SPDS y PMT en D. stramonium: proteínas en las que la zona de unión a la putrescina parece encontrarse en la región C-terminal, mientras que la región de reconocimiento de AdoMetdc o del AdoMet respectivamente, se encuentra en la región N-terminal. De acuerdo con esta observación, las actividades enzimáticas 
de las proteínas quiméricas, realizadas entre la SPD1 y la PMT de $D$. stramonium, quedan definidas en este caso por la especificidad para reconocer el AdoMetdc o del AdoMet, que determina la región N-terminal (Figura 37) (Biastoff et al. 2009). De manera análoga, cuando se comparan las actividades ACL5 y SPMS, la región C-terminal reconoce siempre la espermidina como sustrato, pero con orientaciones opuestas, siendo ésta la razón por la que cada enzima produce específicamente una de las dos tetraaminas posibles.

Sin embargo, los resultados de nuestras mutagénesis dirigidas sobre los residuos diferenciales entre SPDS y PMT no han servido para confirmar el modelo hipotético de evolución de la función, aunque tampoco los desmienten. El hecho de que la mutación de cada aminoácido del centro activo afecte fundamentalmente a la funcionalidad completa de la enzima ya ha sido observado en anteriores ocasiones para residuos similares y distintos de los seleccionados en base a nuestro análisis informático. Por ejemplo:

- Las mutaciones D201A, D201N, D276N y E353Q en la SPMS de humanos reducen drásticamente su actividad enzimática (Wu et al. 2008).

- Las mutaciones G56S, V132G y I150T, en la SPMS de humanos, reducen los niveles de espermina y son la causa del síndrome de Synder-Robinson (de Alencastro et al. 2008; Becerra-Solano et al. 2009).

- Las versiones mutantes de Y76F, D101I, D170A y D173A en $T$. maritima, presentan valores las $\mathrm{K}_{\mathrm{M}}$ entre 12 y 100 veces superiores a las versiones silvestres (Wu et al. 2007).

- El intento de convertir la PMT de D. stramonium en una SPDS, mediante las mutaciones T117Q, I136V y I141D, resultó, en el mejor de los casos, en el mantenimiento de la mitad de la actividad PMT, sin la aparición de ninguna actividad SPDS (Teuber et al. 2007).

- Diferentes combinaciones de mutaciones (L70H, R73N, D74G, E75G, C76F, A77P, Q79T, D103I, G105F, R108F) generando mutantes simples, dobles, triples... hasta un decamutante, en el cual se intentaba 
convertir la SPDS de D. stramonium en una PMT, no presentaron en ningún caso esta nueva actividad (Biastoff et al. 2009).

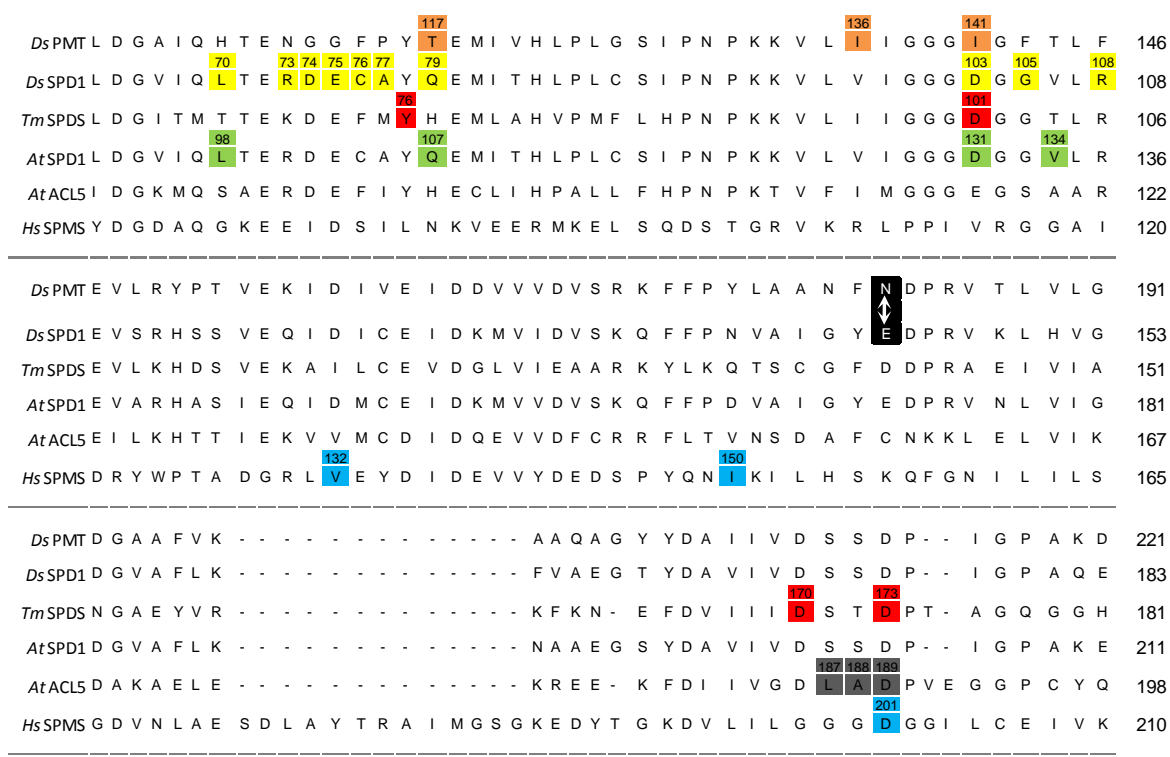

Figura 43. Alineamiento parcial en el cual se marcan en color los diferentes aminoácidos mutagenizados en diversas aminopropil transferasas y putrescina$\mathrm{N}$-metil transferasas. En naranja los de la PMT de D. stramonium (DsPMT), en amarillo los de la SPDS de D. stramonium (DsSPD1), en rojo los de la SPDS de T. maritima (TmSPDS), en verde y gris los realizados en esta Tesis sobre la SPDS y la tSPMS de $A$. thaliana respectivamente (AtSPD1 y AtACL5) y en azul los de la SPMS de humanos (HsSPMS), excepto tres de ellos (G56S, D276N y E353Q). En negro se indica el aminoácido de conexión para realizar las versiones quiméricas DsPMT y DsSPD1.

Así pues queda claro que la interconversión, que se consigue mediante proteínas quiméricas, no es tan fácil de obtener a través de las mutaciones puntuales. Serán necesarios estudios estructurales más detallados del centro activo de las aminopropil transferasas y de las putrescina-N-metil transferasas para 
determinar cuántos y cuáles son los aminoácidos que debemos cambiar para conseguir la interconversión. Y habrá que tener en cuenta el "camino" seguido por la evolución. Es decir, es probable que aunque los cambios predichos por nuestros análisis sean los responsables últimos de la diferencia en actividades, también sean necesarios cambios "preparativos" en otros lugares fuera del centro activo que permitan la fijación de los nuevos cambios sin causar efectos deletéreos en la actividad. 


CONCLUSIONES 

Si recordamos los objetivos que nos habíamos planteado al iniciar este trabajo, estos eran: intentar comprender cuáles son los mecanismos moleculares de control de la termoespermina sobre el desarrollo del xilema, y encontrar qué diferencias estructurales confieren especificidad a las aminopropil transferasas.

Con respecto a los objetivos planteados, podríamos decir que las conclusiones de esta Tesis son:

1. El papel de ACL5 es impedir la muerte prematura durante la diferenciación del xilema. El mecanismo más probable es la promoción de la traducción de los genes $A J A X$, que codifican factores de transcripción bHLH.

2. La discriminación de sustratos por parte de las aminopropil transferasas y putrescina-N-metil transferasas no se explica únicamente por diferencias en los centros activos.

Además, durante el desarrollo de este trabajo hemos llegado también a las siguientes conclusiones adicionales:

3. La termoespermina presente en Arabidopsis thaliana se sintetiza a través de la actividad ACL5.

4. El origen evolutivo del mecanismo regulatorio de los genes $A J A X$ sobre el desarrollo del xilema coincide con la aparición de la vasculatura en las plantas. 

MATERIALES Y MÉTODOS 



\section{Características y manejo del material biológico}

\subsection{Material vegetal}

En esta Tesis se ha usado como sistema experimental la planta Arabidopsis thaliana, más concretamente sus ecotipos Col-0, La-er, La-0 y diversos mutantes cuyos fondos genéticos eran Col-0 y La-er.

El cultivo de las plantas de A. thaliana se realizó habitualmente en el invernadero y en cámaras de cultivo con un rango de temperatura $21-23^{\circ} \mathrm{C}$, humedad relativa entre $50-80 \%$, un fotoperíodo de día largo ( 16 horas de luz y 8 horas de oscuridad) y se iluminaron mediante tubos fluorescentes que proporcionan luz blanca con una intensidad de $120 \mathrm{mmol} / \mathrm{m}^{2} \mathrm{~s}$. El sustrato de cultivo consistió en una mezcla de turba:perlita:vermiculita (2:1:1), que más adelante llamamos "tierra". Las plantas se regaron con una mezcla nutritiva, según fue descrito por Hoagland (Hoagland 1920).

Cuando el cultivo de las plantas se realizó in vitro, se utilizó un medio MS (Murashige y Skoog 1962) manteniendo las mismas condiciones de luz, fotoperíodo, temperatura y humedad, descritas previamente.

\subsubsection{Esterilizado y preparación de las semillas}

Se utilizaron dos protocolos para la siembra:

a) Para la siembra directa en tierra, las semillas eran sumergidas en un tubo con una solución de agarosa $0,05 \%$ y se agitaba para repartir homogéneamente las semillas. Posteriormente se vernalizaban, dándoles un tratamiento de 3 días en oscuridad a $4^{\circ} \mathrm{C}$.

b) Si las semillas se sembraban in vitro, eran esterilizadas y posteriormente se depositaban en placas petri con el medio de cultivo MS. Una vez cerradas las placas con cinta porosa, se vernalizaban con un tratamiento en oscuridad de 3 días a $4^{\circ} \mathrm{C}$. Para esterilizar las semillas se emplearon 2 protocolos descritos a continuación : 
b.1) Esterilizado por tratamiento en atmósfera de cloro: se coloca en un tubo "eppendorf" un volumen equivalente a $100 \mu \mathrm{l}$ de semillas y se deja abierto dentro de una campana de gases en la cual, hay un vaso de precipitados con $100 \mathrm{ml}$ de lejía; se añaden $3 \mathrm{ml}$ de ácido clorhídrico a la solución de lejía y se cierra la campana. Se dejan las semillas durante 5 horas y posteriormente se siembran.

b.2) Esterilizado por etanol: se coloca en un tubo "eppendorf" un volumen equivalente a $100 \mu \mathrm{l}$ de semillas, se añaden $200 \mu \mathrm{l}$ de etanol 70\% + 0,05\% Tritón X-100 y se lavan las semillas con esta solución durante 3 minutos; se retira lo anterior, se añaden $200 \mu \mathrm{l}$ de etanol $96 \%$ y se lavan las semillas durante 1 minuto; se recogen y se dejan secar en un papel estéril.

\subsubsection{Mutagénesis de semillas de Arabidopsis thaliana}

Se recogieron 20000 semillas del mutante acl5-4 de A. thaliana, se embebieron mediante agitación en $45 \mathrm{ml}$ de una solución $25 \mathrm{mM} \mathrm{Na}_{2} \mathrm{HPO}_{4} \mathrm{pH} 7+$ Tween $200,005 \%$. Pasadas 4 horas se añadieron $90 \mu \mathrm{l}$ del agente mutagénico etilmetilsulfonato (EMS); se dejaron durante 15 horas en agitación, transcurrido este tiempo se realizaron 10 lavados con agua destilada para eliminar los restos de EMS.

\subsubsection{Transformación de Arabidopsis thaliana}

Se siguió el protocolo de transformación de Clough y Bent modificado (Clough y Bent 1998). Se cultivaron las plantas hasta que empezaban a desarrollar los tallos florales; en ese momento se sumergieron los tallos durante un minuto, en una suspensión de Agrobacterium tumefaciens cepa C58 proveniente de un cultivo saturado. Este medio de suspensión está compuesto por sacarosa 1,5\% $(\mathrm{p} / \mathrm{v})+$ silwett $0,02 \%(\mathrm{v} / \mathrm{v})$. Las plantas se escurrieron para eliminar el medio de suspensión y se dejaron durante $24 \mathrm{~h}$ en oscuridad; posteriormente se restauraron las condiciones de cultivo normales hasta obtener semillas.

Para seleccionar líneas T1 transformadas con el vector pFP101 (Bensmihen et al. 2004) se colocaron las semillas transformadas bajo la lupa con luz 
ultravioleta, puesto que el vector de transformación lleva como marcador la proteína GFP regulada por un promotor específico de semillas, por lo que las semillas transformadas emiten fluorescencia verde.

\subsubsection{Maceración y cuantificación de elementos del xilema}

Se recolectaron hipocotilos de plantas de 2 meses. Se incubaron a $95^{\circ} \mathrm{C}$ durante 4 horas en una solución de ácido acético $50 \%+\mathrm{H}_{2} \mathrm{O}_{2} 3 \%$; posteriormente se realizaron 2 lavados con agua destilada y se neutralizó con $\mathrm{Na}_{2} \mathrm{CO}_{3}$ sólido. Se disgregó el hipocotilo mediante la agitación con un vórtex. Las células disgregadas se tiñeron con una solución de calcoflúor $0,01 \%(\mathrm{p} / \mathrm{v})$, se visualizaron bajo un microscopio óptico Zeiss Axioplan II y se fotografiaron con una cámara digital adjunta al microscopio. Por cada línea se analizaron 3 hipocotilos, con unas 100 células por hipocotilo.

\subsubsection{Microscopía}

Se recolectaron tallos basales de plantas de 6 semanas; se fijaron durante toda una noche en una solución etanol 50\% + ácido acético 5\% + formaldehído 4\%. Posteriormente se deshidrataron los tejidos con una serie de pases en etanol de concentración creciente $(70 \%$ etanol toda una noche, $80 \%$ etanol durante 3 horas, $90 \%$ etanol durante 3 horas, $95 \%$ etanol durante 1 hora, $100 \%$ etanol durante una noche); tras las deshidrataciones se embebieron en resina LR White (London REsin Company) durante 2 días, haciendo un cambio de resina tras el primer día. Por último se dejaron en LR White durante una noche a $60^{\circ} \mathrm{C}$.

De las muestras incluidas en resina se obtuvieron secciones de 8-10 $\mu \mathrm{m}$ con un microtomo rotatorio (MicromHM330). Las secciones se tiñeron con una solución de azul de toluidina $0,1 \%(\mathrm{p} / \mathrm{v})$.

\subsection{Cepas bacterianas}

Se utilizaron tres tipos de cepas:

- Cepas de E. coli como vehículo de almacenamiento y producción de diversos vectores, como por ejemplo TOP10, XL1Blue o DH5 $\alpha$. 
- Cepas de E. coli para producir proteínas recombinantes de A. thaliana que posteriormente son purificadas, como por ejemplo RIL o BL21.

- Cepa C58 de A. tumefaciens para transformar plantas.

Los cultivos de E. coli y el de A. tumefaciens se realizaron en medio LB (extracto de levadura $0,5 \% \mathrm{p} / \mathrm{v}+$ triptona $1 \% \mathrm{p} / \mathrm{v}+\mathrm{NaCl} 1 \% \mathrm{p} / \mathrm{v}$ ) suplementado con el antibiótico correspondiente a cada construcción. Si el cultivo se realizaba en medio sólido se añadía agarosa $1,5 \% \mathrm{p} / \mathrm{v}$. Los cultivos de $E$. coli se incubaron a $37^{\circ} \mathrm{C}$ y los de $A$. tumefaciens a $28^{\circ} \mathrm{C}$, ambos durante una noche. En caso de poder seleccionarse las colonias transformantes por su color blanco/azul se añadían al medio $40 \mu \mathrm{l}$ de IPTG $(100 \mathrm{mM})$ y $40 \mu \mathrm{lde}$ X-Gal $(40 \mathrm{mg} / \mathrm{ml})$ por placa.

\subsubsection{Transformación de bacterias}

Se emplearon dos métodos de transformación de bacterias, según los siguientes protocolos:

- Por choque térmico: se toma una alícuota de células quimiocompetentes, se mantiene a $4^{\circ} \mathrm{C}$ en hielo, se añade el DNA con el que se quiere transformar (al menos $50 \mu \mathrm{g}$ en caso de que se trate de una ligación) y se deja durante $30 \mathrm{~min}$ en el hielo. Después se realiza el choque térmico $\left(1 \mathrm{~min}\right.$ a $42^{\circ} \mathrm{C}$ para $E$. coli y $5 \mathrm{~min}$ a $37^{\circ} \mathrm{C}$ para $A$. tumefaciens). Nada más realizado el choque se añaden $500 \mu$ fríos de medio LB y se incuba durante $1 \mathrm{~h}$ a $37^{\circ} \mathrm{C}$ (E.coli) o $3 \mathrm{~h}$ a $28^{\circ} \mathrm{C}(A$. tumefaciens). Tras este tiempo de incubación se vierten los $500 \mu 1$ en una placa de LB sólido con los antibióticos adecuados.

- Por electroporación: se toma una alícuota de células electrocompetentes, se mantiene a $4^{\circ} \mathrm{C}$ en hielo, se añade el DNA y se coloca toda la mezcla en una cubeta de electroporación seca y fría. Se le da un pulso eléctrico de $1500 \mathrm{~V}$, se añaden inmediatamente $500 \mu 1 \mathrm{de}$ LB frío y se incuba durante $1 \mathrm{~h}$ a $37^{\circ} \mathrm{C}$ (E.coli) o $3 \mathrm{~h} \mathrm{a} 28^{\circ} \mathrm{C}(A$. tumefaciens). Tras este tiempo de incubación se vierten los $500 \mu \mathrm{l}$ en una placa de LB sólido con los antibióticos adecuados. 


\section{Técnicas de bioquímica}

\subsection{Extracción, identificación y cuantificación de poliaminas por GC-MS}

Se realizó la extracción, identificación y cuantificación de poliaminas según el método desarrollado en cooperación con el Servicio de Metabolómica del IBMCP (Rambla et al. 2010).

Las muestras de tejido fresco de $A$. thaliana se trituraron con nitrógeno líquido y se conservaron a $-80^{\circ} \mathrm{C}$ hasta el momento de su empleo. A la muestra congelada se le añadieron 4 volúmenes $(4 \mu \mathrm{l} / \mathrm{mg}$ de peso fresco) de ácido perclórico 0,2 N y 1 volumen de 1,6-diamina-hexano como patrón interno $(152,5 \mu \mathrm{g} / \mathrm{ml})$. Se homogeneizaron las muestras mediante vórtex; se centrifugaron a $13000 \mathrm{rpm}$ durante 5 minutos a $4^{\circ} \mathrm{C}$; se recuperaron los sobrenadantes y se conservaron a $-20^{\circ} \mathrm{C}$ hasta el momento de su uso.

Para purificar las poliaminas de la muestra mediante una extracción par iónico, se tomó el sobrenadante de la centrífuga, se llevó su pH a un rango de 7,0-7,4 con $\mathrm{KOH}$ 0,1 M; se ajustó a un volumen total de $4 \mathrm{ml}$ adicionando agua miliQ y se añadió $1 \mathrm{ml}$ de tampón fosfato potásico $0,2 \mathrm{M} \mathrm{pH} 7,4$. Se mezcló mediante vórtex con $5 \mathrm{ml}$ de una solución de cloroformo + BEHPA 0,1 M; se separaron las fases centrifugando a $3500 \mathrm{~g}$ durante 5 minutos y se recogieron $4 \mathrm{ml}$ de la fase orgánica. Esta fase se mezcló mediante vórtex con $4 \mathrm{ml}$ de $\mathrm{HCl} \mathrm{0,1} \mathrm{M;} \mathrm{se}$ volvieron a separar las fases centrifugando a $3500 \mathrm{~g}$ durante 5 minutos y se recogieron $3 \mathrm{ml}$ de la fase acuosa. De estos $3 \mathrm{ml}$, se secó $1 \mathrm{ml}$ en un bloque térmico a $70^{\circ} \mathrm{C}$ bajo una corriente de $\mathrm{N}_{2}$.

Para derivatizar la muestra, se resuspendió el residuo seco en $200 \mu 1$ de acetonitrilo, y posteriormente se mezcló mediante vórtex con $200 \mu 1$ de HFBA. Se incubó esta mezcla a $80^{\circ} \mathrm{C}$ durante 1 hora, se dejó enfriar y se añadieron 500 $\mu \mathrm{l}$ de metanol. La muestra se secó a temperatura ambiente bajo una corriente de $\mathrm{N}_{2}$. Se resuspendió el residuo seco con $1 \mathrm{ml}$ de tampón fosfato potásico $0,5 \mathrm{M}$ $\mathrm{pH} 7.0$, que fue mezclado mediante vórtex con $3 \mathrm{ml}$ de diclorometano. Se recogió la fase orgánica y se secó a temperatura ambiente bajo una corriente de 
$\mathrm{N}_{2}$. Se resuspendió el residuo en $100 \mu \mathrm{l}$ de acetato de etilo, y la suspensión se trasvasó al inserto de un vial de inyección de GC.

Para la separación cromatográfica por GC, se inyectaron $2 \mu \mathrm{l}$ del derivado heptafluorado en una columna BPX35 30m x 0,32 $\mathrm{mm}$ x 0,25 $\mu \mathrm{m}$, usando como gas portador helio a $2 \mathrm{ml} / \mathrm{min}$ y aplicando una rampa de temperatura $85-280^{\circ} \mathrm{C}$, a $15^{\circ} \mathrm{C} / \mathrm{min}$. El liner del inyector estaba a una temperatura de $250^{\circ} \mathrm{C}$. Para la detección en el MS, se tomaron 6,25 espectros/s, en un rango de masa/carga de 35 a 900, y con una energía de ionización de $70 \mathrm{eV}$. Los iones seleccionados para la cuantificación fueron, 226 para la putrescina y el 1,6-diamina-hexano, y $226+254$ para la espermidina, la espermina y la termoespermina; todas las cantidades fueron corregidas en función del patrón interno.

\subsection{Extracción, identificación y cuantificación de poliaminas por HPLC}

Se realizó la extracción, identificación y cuantificación de poliaminas utilizando un procedimiento descrito previamente (Carbonell y Navarro 1989).

La homogenización de la muestra, extracción con acido perclórico, adición del patrón interno y centrifugación son idénticas a las realizadas para el GC-MS

Para la reacción de dansilación se pipetearon $100 \mu 1$ del sobrenadante en un vial de vidrio de color topacio, se mezclaron con $200 \mu \mathrm{lde} \mathrm{Na}_{2} \mathrm{CO}_{3}$ en solución saturada y con $400 \mu \mathrm{l}$ de cloruro de dansilo (10 $\mathrm{mg} / \mathrm{ml}$ en acetona). Se incubó la mezcla a $60^{\circ} \mathrm{C}$ durante una hora en oscuridad, posteriormente se añadió $100 \mu \mathrm{l}$ de prolina $\left(100 \mathrm{mg} / \mathrm{ml}\right.$ en agua miliQ) y se dejó durante 30 minutos a $60^{\circ} \mathrm{C}$ en oscuridad. Se añadió $1 \mathrm{ml}$ de tolueno y tras agitación mediante vórtex, se esperó a que se separaran las 2 fases, recogiéndose la fase orgánica en otro vial de vidrio de color topacio. Esta fase orgánica se secó en corriente de $\mathrm{N}_{2}$ a $37^{\circ} \mathrm{C}$. Una vez secadas las muestras se mantuvieron a $-20^{\circ} \mathrm{C}$ hasta que fueron resuspendidas en $100 \mu \mathrm{l}$ de acetonitrilo. Previamente a su inyección en el HPLC las muestras se filtraron en un filtro MIllex-HV de 0,45 $\mu \mathrm{m}$ (Millipore). 
En el análisis de HPLC se usó una columna de reparto en fase inversa de Hypersil ODS C18, 200 × 4'6 mm, $5 \mu \mathrm{m}$ de partícula (Tracer Analítica, Teknokroma) equilibrada con acetronitrilo:agua al $60 \% \mathrm{v} / \mathrm{v}$. Se inyectaron 30 $\mu \mathrm{l}$ de cada muestra. Los derivados dansilados se separaron en un gradiente de acetonitrilo:agua $60 \%-40 \%$ hasta $90 \%-10 \% \mathrm{v} / \mathrm{v}$ en 30 minutos, con un flujo de $1,5 \mathrm{ml} / \mathrm{min}$. La columna se mantuvo a $37^{\circ} \mathrm{C}$ durante todo el análisis. Para la detección se utilizó un fluorímetro 420 Waters con filtros de excitación y emisión de 365 y $425 \mathrm{~nm}$, respectivamente. La cuantificación se realizó utilizando el 1,6-diamina-hexano como patrón interno.

\subsection{Purificación de proteínas}

\subsubsection{Inducción de proteínas}

Se dejó creciendo durante toda una noche un preinóculo de la cepa de E.coli con la construcción a purificar. Este preinóculo saturado se usó como inóculo para un cultivo de volumen 100 veces mayor, que fue inducido con un tratamiento 1 $\mathrm{mM}$ de IPTG cuando su OD a $600 \mathrm{~nm}$ alcanzó un valor de 0,5-0,6. Una vez inducido se dejó crecer durante tres horas, se centrifugó durante 30 min a 12000 rpm, se descartó el sobrenadante y se conservó el precipitado a $-20^{\circ} \mathrm{C}$.

\subsubsection{Purificación de proteínas}

Para la purificación de las proteínas en estado nativo por columnas de níquel se empleó el sistema Ni-NTA Fast Start Kit (Qiagen), siguiendo las instrucciones del fabricante.

\subsection{Ensayos enzimáticos}

Según cada enzima los ensayos enzimáticos fueron:

- Para el cálculo la $\mathrm{k}_{\mathrm{M}}{ }^{\text {Put }}$ de la SPD1, realizamos 7 reacciones, cada una de ellas en un volumen total de $250 \mu 1$, con un contenido $100 \mathrm{mM}$ de tampón fosfato potásico $\mathrm{pH}$ 7,4, $2 \mathrm{mM}$ de AdoMetdc, $10 \mathrm{mg} / \mathrm{ml} \mathrm{de}$ proteína purificada y una concentración variable de putrescina (entre 
$0,25-50 \mathrm{mM}$ ). Recogimos cuatro muestras de $50 \mu \mathrm{l}$ a intervalos de 15 minutos. Cada muestra fue derivatizada y analizada mediante HPLC.

- Para el cálculo la $\mathrm{k}_{\mathrm{M}}{ }^{\text {AdoMetdc }}$ de la SPD1, usamos las mismas condiciones que para la $\mathrm{k}_{\mathrm{M}}{ }^{\text {Put }}$, modificando el $2 \mathrm{mM}$ de AdoMetdc por una $5 \mathrm{mM}$ de putrescina, y las concentraciones variables de putrescina $(0,25-50$ $\mathrm{mM}$ ) por concentraciones variables de AdoMetdc (0,05 - $2 \mathrm{mM})$.

Las muestras fueron recogidas y procesadas de modo similar al caso anterior.

- Para el cálculo la $\mathrm{k}_{\mathrm{M}}^{\text {Spd }}$ de la ACL5, usamos las mismas condiciones que para la $\mathrm{k}_{\mathrm{M}}{ }^{\text {Put }}$ de la SPD1, modificando el $\mathrm{pH}$ del tampón de 7,4 a 7, y las concentraciones variables de putrescina por concentraciones variables de espermidina. Las muestras fueron recogidas y procesadas de modo similar al caso anterior.

- Para comprobar la actividad PMT, realizamos una reacción con un volumen total de $250 \mu 1$, con un contenido $100 \mathrm{mM}$ de tampón HEPES pH 8, $1 \mathrm{mM}$ de AdoMet, $5 \mathrm{mM}$ de putrescina y $10 \mathrm{mg} / \mathrm{ml}$ de proteína purificada. Recogimos cuatro muestras de $50 \mu 1$ a intervalos de 15 minutos. Cada muestra fue derivatizada y analizada mediante HPLC. 


\section{Técnicas de biología molecular}

\subsection{Extracción de ácidos nucleicos}

\subsubsection{Extracción de RNA}

Las extracciones de mRNA total se realizaron partiendo de unos $100 \mathrm{mg}$ de tejido, utilizando el sistema RNAeasy (QIAGEN) según las indicaciones del fabricante. En caso de usar las muestras para realizar qRT-PCR, se eliminó el DNA genómico con un tratamiento con DNAsa (DNase digestión, QIAGEN) según las instrucciones del fabricante. La concentración del RNA se determinó mediante un espectrofotómetro Nanodrop (Thermo Scientific). Una vez purificados los RNAs fueron almacenados a $-80^{\circ} \mathrm{C}$ hasta su utilización.

\subsubsection{Extracción de DNA genómico}

Las extracciones de DNA genómico para su posterior uso como molde para PCR se realizaron según el método descrito por Edwards (Edwards et al. 1991). Se cortó un disco de $1 \mathrm{~cm}$ de diámetro por cada muestra, y se trituró en $\mathrm{N}_{2}$ líquido. Se añadieron $400 \mu \mathrm{l}$ del tampón de extracción $(200 \mathrm{mM}$ Tris- $\mathrm{HCl} \mathrm{pH}$ $7,5+250 \mathrm{mM} \mathrm{NaCl}+25 \mathrm{mM}$ EDTA $+0,5 \%$ SDS p/v) se mezclaron mediante vórtex y se centrifugaron 1 minuto a $13000 \mathrm{rpm}$; se tomaron $300 \mu \mathrm{l}$ del sobrenadante y se añadieron $300 \mu \mathrm{l}$ de isopropanol; se mezclaron mediante vórtex y se dejaron 2 minutos a temperatura ambiente para que precipitaran; se centrifugó 5 min a 13000 rpm, se eliminó todo el sobrenadante y se dejó secar al aire. El precipitado se resuspendió en $50 \mu 1$ de agua destilada y se almacenó a $20^{\circ} \mathrm{C}$ hasta su utilización.

\subsubsection{Extracción de DNA plasmídico}

La extracción de DNA plasmídico se realizó a partir de $1,5 \mathrm{ml}$ de cultivo saturado, con el sistema Plasmid Mini Kit I (E.Z.N.A.), siguiendo las indicaciones del fabricante. 


\subsection{Generación de construcciones en vectores plasmídicos}

\subsubsection{Reacción en cadena de la polimerasa (PCR)}

Realizamos las PCRs en tubos de $0,2 \mathrm{ml}$ con un termociclador TC-152 (Techne). El volumen final era $50 \mu \mathrm{l}$, con una concentración final de $1 \mathrm{x}$ del tampón de reacción, $0,2 \mu \mathrm{M}$ de cada oligonucleótido, $0,2 \mathrm{mM}$ de nucleótidos y 1 unidad de la polimerasa (Biotools). Los programas de amplificación constan de $30-40$ ciclos con $30 \mathrm{~s}$ a $94^{\circ} \mathrm{C}, 30 \mathrm{~s}$ a $50-60^{\circ} \mathrm{C}$ (según la $\mathrm{T}_{\mathrm{m}}$ de los oligonucleótidos) y un tiempo variable (según el tamaño de producto a amplificar $1 \mathrm{~min} / \mathrm{Kb}$ ) a $72^{\circ} \mathrm{C}$. Los productos amplificados por PCR se analizaron en geles de agarosa al $1 \%$ teñidos con bromuro de etidio.

\subsubsection{Digestiones}

Las digestiones se realizaron utilizando el tampón indicado por el fabricante de cada enzima, y con un número de unidades de enzima calculadas a partir de la siguiente fórmula:

$$
\mathrm{N}^{\circ} \text { unidades }=\frac{\mathrm{kb} \text { DNA referencia }}{\mathrm{kb} \text { DNA diana }} \times \frac{\mathrm{n}^{\mathrm{o}} \text { cortes DNA diana }}{\mathrm{n}^{\mathrm{o}} \text { cortes DNA referencia }} \times \mu \mathrm{g} \text { DNA diana }
$$

\subsubsection{Purificación de bandas de DNA separadas en geles de agarosa}

El DNA contenido en las bandas de agarosa se purificó con el sistema de extracción de bandas QIAquick Gel Extraction Kit (QIAGEN). Para bandas de tamaño superior a $5 \mathrm{~Kb}$ se usó el QIAEX II Gel Extraction Kit (QIAGEN).

\subsubsection{Ligaciones}

Las reacciones de ligación se realizaron con una proporción molar entre inserto y plásmido de 5:1. Para cada reacción se emplearon unos 50-200 ng de plásmido linearizado; mientras que para calcular la cantidad de inserto se aplicó la siguiente fórmula: 


$$
\frac{\mu \mathrm{l} \text { inserto }}{\mu \mathrm{l} \text { vector }}=5 \times \frac{\mathrm{ng} / \mu \mathrm{l} \text { vector } \times \text { tamaño inserto }(\mathrm{kb})}{\mathrm{ng} / \mu \mathrm{l} \text { inserto } \times \text { tamaño vector }(\mathrm{kb})}
$$

Cada reacción contenía tampón de ligación 1x (Roche) y 1 unidad de ligasa T4.

\subsubsection{Mutagénesis dirigidas}

Para cada mutagénesis se diseñaron dos oligonucleótidos complementarios y parcialmente solapantes que incorporaban la mutación a introducir; se realizaba una PCR con estos dos oligonucleótidos con un tiempo de extensión en función del tamaño del plásmido a mutagenizar. El producto de la PCR fue digerido con Dpn I para eliminar las copias de plásmido original no mutagenizado. Este producto de digestión fue utilizado, para transformar por choque térmico células competentes de E.coli.

\subsection{Construcciones generadas}

\subsubsection{Sobre-expresión de $A J A X$ en el mutante $a c l 5$}

Los fragmentos de las secuencias codificantes principales de $A J A X 1,2$ y 3 fueron amplificados por PCR (Tabla 6). Los productos de PCR fueron digeridos con Bam HI y Sal I, al igual que el plásmido pFP101 (Bensmihen et al. 2004) y posteriormente purificados de una banda aislada de un gel de agarosa y ligados.

Tabla 6. Oligonucleótidos para clonar los AJAXs en el pFP101

\begin{tabular}{|c|c|c|c|}
\hline Oligonucleótido & Gen & Secuencia (5'a 3') & $\begin{array}{c}\text { Enzima de } \\
\text { restricción }\end{array}$ \\
\cline { 1 - 3 } FVS249 & AJAX1 & CCGGATCCCTGCTAAGAGCATGCCTCTGGA & \multirow{2}{*}{ BamH I } \\
\cline { 1 - 3 } FVS245 & AJAX2 & CCGGATCCACGTTTGCACGGGTTTTCTGAT & \\
\cline { 1 - 3 } FVS251 & AJAX3 & CCGGATCCCAAGAGCATGCCTCTTGATACCA & \multirow{2}{*}{ Sal I } \\
\cline { 1 - 3 } FVS250 & AJAX1 & CCGTCGACTTTCACGCCTTATCTGTCTGCA & \\
\cline { 1 - 3 } FVS246 & AJAX2 & CCGTCGACATCGGTAGCATTCAAGATTGGT & \\
\hline FVS252 & AJAX3 & CCGTCGACAGGGGTTGTAGGTTTTTCACCA & \\
\hline
\end{tabular}




\subsubsection{Transcripción in vitro de $A J A X 2$}

Se amplificó por PCR (tabla 7) un fragmento de $1868 \mathrm{pb}$, que corresponde al cDNA completo de $A J A X 2$, de las que, $756 \mathrm{pb}$ corresponden a la secuencia codificante principal de $A J A X 2$ y $1112 \mathrm{pb}$ que corresponden a la 5'-UTR del mismo gen, incluida la uORF. Se digirieron tanto este fragmento como el vector pSP64 (Promega) con Pst I y Xbal I, se purificaron y se ligaron. Al no conseguir transcribir in vitro esta construcción, la digerimos con Hind III para eliminar gran parte de la 5'-UTR y religamos el vector en el cual sólo transcribíamos la ORF principal.

Después amplificamos por PCR (Tabla 7) la uORF, y lo subclonamos en un vector pCR2.1 (Invitrogen), para luego clonarlo en el vector que contenía la ORF de $A J A X 2$, mediante un corte con Hind III y ligación para generar una construcción para transcribir $A J A X 2$ bajo el control del uORF.

Tabla 7. Oligonucleótidos para clonar los AJAX2 en el pSP64

\begin{tabular}{|c|c|l|c|}
\hline Oligonucleótido & Gen & \multicolumn{1}{|c|}{ Secuencia (5'a 3') } & $\begin{array}{c}\text { Enzima de } \\
\text { restricción }\end{array}$ \\
\hline FVS265 & $\begin{array}{c}\text { C-DNA } \\
\text { AJAX2 }\end{array}$ & GGCTGCAGGCTGAATTTGATTTTTC & Pst I \\
\hline FVS266 & $\begin{array}{c}\text { c-DNA } \\
\text { AJAX2 }\end{array}$ & CCTCTAGAGGTATAAGCGTGACTTTTC & Xba I \\
\hline FVS272 & $\begin{array}{c}u O R F \\
\text { AJAX2 }\end{array}$ & TTCCTTTCAGGTGTTGTTTCCGGAATTCGG & - \\
\hline FVS226 & $\begin{array}{c}u \text { OORF } \\
\text { AJAX2 }\end{array}$ & TTCTACTACCGATTTGTCGCCT & - \\
\hline
\end{tabular}

Por último, generamos las versiones mutantes de la uORF, realizando mutagénesis dirigida sobre el vector de transcripción de $A J A X 2$ controlado por la uORF (Tabla 8).

Tabla 8. Oligonucleótidos de mutagénesis de pSP64 + uORF + AJAX2.

\begin{tabular}{|c|l|c|}
\hline Oligonucleótido & \multicolumn{1}{|c|}{ Secuencia (5'a 3') } & \multirow{2}{*}{ Mutación generada } \\
\cline { 1 - 2 } FVS309 & CAGTTGTTTAAGCCTGTAACGTAGA & \multirow{2}{*}{ L44 $\rightarrow$ F44 (ajx2-31) } \\
\cline { 1 - 2 } FVS282 & GCTTAAACAACTGTCTGAAATATTCAG & \\
\cline { 1 - 2 } FVS283 & GGAAACTGATCATTGAAGGAAATAG & \multirow{2}{*}{ G11 STOP (ajx2-48) } \\
\cline { 1 - 2 } FVS284 & ATGATCAGTTTCCCTTCTTGTTTC & \\
\hline
\end{tabular}




\subsubsection{Purificación de proteínas}

En la purificación de proteínas se utilizó el vector pET28b (Novagen) para realizar una fusión traduccional de nuestra proteína de interés a un epítopo de seis histidinas en el extremo $\mathrm{C}$ terminal. Amplificamos por PCR las CDS completas (excepto el triplete del codón de parada) de ACL5 y SPD1, mediante los oligos mostrados en la tabla 9, digerimos estos productos de PCR y el vector con los enzimas de restricción indicados en la tabla 9, ligamos y transformamos con células competentes de E.coli. Una vez comprobado que la construcción era correcta, se extrajo el plásmido y se retransformó en una cepa de E.coli adecuada para la producción de proteínas como BL21.

Tabla 9. Oligonucleótidos para clonar ACL5 y SPD1 en el pET28b

\begin{tabular}{|c|c|l|c|}
\hline Oligonucleótido & Gen & Secuencia (5'a $\mathbf{3}^{\prime}$ ) & $\begin{array}{c}\text { Enzima de } \\
\text { restricción }\end{array}$ \\
\hline FVS006 & ACL5 & CCCCATGGGTGAAGCCGTAGAGGTCATGT & Nco I \\
\hline FVS019 & ACL5 & ATGTGCTCGAGAATATGCCGGTACGCCACA & Xho I \\
\hline FVS027 & SPD1 & GCGGAATTCATGGACGCTAAAGAAACCTCT & Eco RI \\
\hline FVS026 & SPD1 & CGTGCTCGAGATTGGCTTTTGACTCAATGAC & Xho I \\
\hline
\end{tabular}

La purificación de la $D S P M T$ se realizó a partir de una construcción con la CDS de la $P M T$ en el vector pET21d, cedido amablemente por la Dra. Birgit Dräge.

Para generar las versiones mutantes $A C L 5$ y SPD1, realizamos mutagénesis dirigida sobre las construcciones generadas previamente (Tabla 10a y 10b).

Tabla 10a. Oligonucleótidos de mutagénesis de pET28b + ACL5

\begin{tabular}{|c|l|c|}
\hline Oligonucleótido & \multicolumn{1}{|c|}{ Secuencia (5'a $\mathbf{3}^{\prime}$ ) } & Mutación generada \\
\cline { 1 - 2 } FVS105 & GGGAGATTCATCTGATCCAGTGG & \multirow{2}{*}{ L187 A188 $\rightarrow$} \\
\cline { 1 - 2 } FVS106 & CTGGATCAGATGAATCTCCCACTATG & \multirow{2}{*}{ D189 $\rightarrow$ E189 } \\
\cline { 1 - 2 } FVS039 & TAGCTGAGCCCGTGGAAGGTGGACCTTGTTATC & \multirow{2}{*}{ Y205 $\rightarrow$ F205 } \\
\cline { 1 - 2 } FVS040 & CTTCCACGGGCTCAGCTAAATCTCCCACTATG & \multirow{2}{*}{ G224 $\rightarrow$ E224 } \\
\cline { 1 - 2 } FVS103 & AATCCTTCTTCCAAAACATTCTC & \\
\cline { 1 - 2 } FVS104 & ATGTTTTGGAAGAAGGATTTGG & \multicolumn{1}{|c}{} \\
\cline { 1 - 2 } FVS101 & CCAGGCTGAACCAGCAGGAATATTC &
\end{tabular}


Tabla 10b. Oligonucleótidos de mutagénesis de pET28b + SPD1

\begin{tabular}{|c|c|c|}
\hline Oligonucleótido & Secuencia (5'a $\left.3^{\prime}\right)$ & Mutación generada \\
\hline FVS301 & GTAATCCAACATACGGAGAGAGATG & \multirow{2}{*}{$\mathrm{L} 98 \rightarrow \mathrm{H} 98$} \\
\hline FVS302 & TCTCTCCGTATGTTGGATTACTCC & \\
\hline FVS299 & TGTGCTTATACGGAAATGATCACTC & \multirow{2}{*}{ Q107 $\rightarrow$ T107 } \\
\hline FVS300 & TCATTTCCGTATAAGCACATTCATC & \\
\hline FVS261 & GAGGAGGAATTGGAGGTGTCCTGC & \multirow{2}{*}{$\mathrm{D} 131 \rightarrow \mathrm{I} 131$} \\
\hline FVS262 & GАСАССТССААТTССТССТССААТG & \\
\hline FVS297 & TGGAGGTACCCTGCGGGAAGTTG & \multirow{2}{*}{$\mathrm{V} 134 \rightarrow \mathrm{T} 134$} \\
\hline FVS298 & CCGCAGGGTACCTCCAATTCCTC & \\
\hline
\end{tabular}

\subsection{Genotipados}

\subsubsection{Genotipado de la deleción del mutante $a c l 5-4$}

Para comprobar el genotipo de una planta problema se realizaba una PCR con 3 oligonucleótidos; dos de ellos, FVS013 y EGM044, son flanqueantes a la deleción; mientras que el tercero, FVS017, es un oligonucleótido interno que hibrida dentro de ella. En caso de ser una planta acl5-4, los oligonucleótidos flanqueantes amplificaban un producto de $548 \mathrm{pb}$; pero si la planta era silvestre el producto era de $376 \mathrm{pb}$.

Tabla 11. Oligonucleótidos para genotipar la deleción del ac/5-4. acl5acl5mutante

\begin{tabular}{|c|l|}
\hline Oligonucleótido & \multicolumn{1}{|c|}{ Secuencia (5'a $\mathbf{3}^{\prime}$ ) } \\
\hline FVS013 & GTCGAGAGGGGACTGACAAGTGTACA \\
\hline FVS017 & CTCCCACCCAAAATCTCAGTCCTTGT \\
\hline EGM044 & GCAAATGATGGCACATGTGCTGTGTAAG \\
\hline
\end{tabular}

\subsubsection{Genotipado de mutantes de inserción de T-DNA}

Los mutantes por inserción de T-DNA utilizados en este trabajo provinieron de dos colecciones; 4 líneas de la colección conocida como líneas SALK (Alonso 
et al. 2003) y una línea de la colección conocida como Gene Trap del Cold Spring Harbor (Sundaresan et al. 1995). Las líneas empleadas fueron:

- SALK_147291. Con inserción en la 5'-UTR de AJAX2.

- SALK_095875. Con inserción en la 5'-UTR de AJAX2.

- SALK_107954. Con inserción en la 5'-UTR de $A J A X 1$.

- SALK_02930. Con inserción en la 3'-UTR de AJAX1.

- ET12122.Ds5.08.28.2003.jx25.459. Con inserción en la 5'-UTR de AJAX3.

Para el genotipado de una planta problema, se realizaron dos PCRs. En la primera de ellas se utilizaron dos oligonucleótidos flanqueantes al punto de inserción de T-DNA; en la segunda, se utilizaron un oligonucleótido flanqueante (Tabla 12) y otro que hibrida exclusivamente dentro de la inserción (el oligonucleótido EGMLB1 para las líneas del SALK y el oligonucleótido FVS303 para la línea del Cold Spring Harbor). Según se obtuvo un producto de PCR en la primera, en la segunda o en ambas; teníamos una planta silvestre, heterocigota u homocigota para la inserción, respectivamente. En todos los genotipados, se llevó en paralelo una muestra de una planta silvestre Col-0 como control positivo.

Tabla 12. Oligonucleótidos flanqueantes para genotipar las inserciones de TDNA.

\begin{tabular}{|c|l|c|}
\hline Oligonucleótido & \multicolumn{1}{|c|}{ Secuencia (5'a $\mathbf{3}^{\prime}$ ) } & Gen \\
\hline FVS195 & CTTACATTGGTACCTTGTGGAAGC & AJAX2 \\
\hline FVS227 & TTGTTGCCACTCACCTCTTTAGA & AJAX1 \\
\hline FVS228 & CCCGTTGCCTCTTATCCAGA & AJAX1 \\
\hline FVS239 & GAGCATCGATCTCATTTGGATCT & AJAX2 \\
\hline FVS244 & CATTGTTTGTCGCTGTGCTCTCT & AJAX3 \\
\hline FVS296 & CCCTCGCTCTGCATCCATAG & AJAX3 \\
\hline
\end{tabular}

Tabla 13. Oligonucleótidos internos a la inserción de T-DNA..

\begin{tabular}{|c|l|c|}
\hline Oligonucleótido & \multicolumn{1}{|c|}{ Secuencia (5'a 3') } & Inserción \\
\hline FVS303 & CCGTCCCGCAAGTTAAATATG & Cold Spring Harbor \\
\hline EGMLB1 & CAAACCAGCGTGGACCGCTTGCTGCA & SALK \\
\hline
\end{tabular}




\subsection{Cartografiado de las líneas ajx1-4, ajx2-10 y ajx2-31}

Para localizar en el genoma de $A$. thaliana, la posición física de las mutaciones de las 3 líneas, cruzamos cada una de las líneas, que se encuentran en fondo La$e r$, con una planta acl5-5 en fondo Col-0. En la F2 seleccionamos 50 plantas de fenotipo enano acl5, de las que se enviaron muestras congeladas al Servicio de Cartografía Génica de la Universidad Miguel Hernández. En esta primera fase se analizaron estos 50 individuos mediante un análisis de ligamiento con 32 microsatélites polimórficos entre Col-0 y La-er, distribuidos por los 5 cromosomas de A. thaliana. De los resultados de este cartografiado de "baja resolución", se concluyó que:

- las mutaciones de las líneas ajx2-10 y ajx2-31 están localizadas en una región de unas 3 megabases situada en el cromosoma 1, delimitada por los marcadores AthZFPG y SNP10026. Como ambas mutaciones se encuentran en la misma región, supusimos que son alélicas y únicamente continuamos con el mapeo de la línea ajx2-31.

- la mutación de ajx1-4 está en una región de unas 4,5 megabases situada en el cromosoma 5, entre los marcadores MUA2 y K8K14.

Para continuar delimitando la posición, enviamos muestras de otros 600 individuos enanos de la F2, al Servicio de Cartografía Génica de la Universidad Miguel Hernández. Con estas muestras se realizó un cartografiado de "alta resolución" a través del análisis de otros microsatélites, incluidos dentro de la región delimitada previamente para cada línea. De los resultados se concluyó que:

- la mutación de la línea ajxl-4 está situada en una región de $136 \mathrm{~Kb}$ que incluye 3 BAC parcialmente solapantes comprendidos entre los marcadores Cer455797 (con 1 individuo recombinante para este marcador de la población inicial de 650) y Cer458067 (con 1 individuo recombinante para este marcador de la población inicial de 650).

- la mutación de la línea ajx2-31 está situada en una región de $222 \mathrm{~Kb}$ que incluye $4 \mathrm{BAC}$ parcialmente solapantes comprendidos entre los marcadores Cer479911 (con 7 individuos recombinantes para este 
marcador de la población inicial de 650) y Cer479988 (con 1 individuo recombinante para este marcador de la población inicial de 650).

Desde el Servicio de Cartografía Génica nos reenviaron estos individuos recombinantes, en los que analizamos más marcadores, CAPs y dCAPs. Con este trabajo redujimos los intervalos a:

- en la línea ajx1-4, un tamaño de $81 \mathrm{~Kb}$ comprendidos entre los marcadores Cer458067 y Cer440084; con 22 genes dentro del intervalo.

- en la línea ajx2-31, un tamaño de $93 \mathrm{~Kb}$ comprendidos entre los marcadores Cer480732 y Cer479895; con 21 genes dentro del intervalo.

Para terminar de localizar las mutaciones pasamos a amplificar por PCR los genes internos de cada intervalo usando como molde el DNA genómico de cada línea supresora. Estos productos de PCR se purificaron por fenolización seguida de una precipitación, y fueron secuenciados por el Servicio de Secuenciación del IBMCP. En la línea ajx1-4 secuenciamos 3 genes antes de encontrar la mutación en el gen At5g64340, mientras que en ajx2-31 secuenciamos 12 genes antes de encontrar la mutación en el gen At1g29950.

Tabla 14. Oligonucleótidos para genotipar microsatélites utilizados en el mapeo de ajx1-4

\begin{tabular}{|c|c|c|c|c|}
\hline \multirow{2}{*}{ Marcador } & \multirow{2}{*}{ Oligonucleótido } & \multirow{2}{*}{ Secuencia (5'a $\left.3^{\prime}\right)$} & \multicolumn{2}{|c|}{ Tamaño amplificado } \\
\hline & & & Col & La-er \\
\hline \multirow{2}{*}{ Cer455797 } & $455797-1$ & GAACCTGTAACATTTCAACTAAG & \multirow{2}{*}{$244 \mathrm{pb}$} & \multirow{2}{*}{$270 \mathrm{pb}$} \\
\hline & $455797-2$ & TGTCTCATCCAGGTCATGGAC & & \\
\hline \multirow{2}{*}{ Cer458067 } & $458067-1$ & AGAATTTCTCCATCTCTCCGC & \multirow{2}{*}{$288 \mathrm{pb}$} & \multirow{2}{*}{$305 \mathrm{pb}$} \\
\hline & $458067-2$ & ATTCACAGTGTCCCCAAAAGTC & & \\
\hline
\end{tabular}

Tabla 15. Oligonucleótidos para genotipar CAPS utilizados en el mapeo de aj×1-4

\begin{tabular}{|c|c|l|c|}
\hline Marcador & Oligonucleótido & \multicolumn{1}{|c|}{ Secuencia (5'a 3') } & $\begin{array}{c}\text { Enzima de } \\
\text { restricción }\end{array}$ \\
\hline \multirow{2}{*}{ Cer437611 } & FVS182 & CACGACGCAGAAATTATGGGA & \multirow{2}{*}{ Acc I } \\
\cline { 2 - 3 } & FVS183 & ATTTTGTCACGAATAATTTGCGTT & \multirow{2}{*}{ Nsp I } \\
\hline \multirow{2}{*}{ Cer440074 } & FVS186 & CAATGGAATCTACTAGATACGGGGA & \multirow{2}{*}{} \\
\cline { 2 - 3 } & FVS187 & AACGACATTTGGTGTGTGGATACA & \\
\hline
\end{tabular}




\begin{tabular}{|l|l|l|c|}
\hline \multirow{2}{*}{ Cer440109 } & FVS190 & CGGTTCCTTTCTCTTCTTTGGT & \multirow{2}{*}{ Taq I } \\
\cline { 2 - 3 } & FVS191 & CGAGCTCTTAAAATCGTCTCCG & \\
\hline Cer440084 & FVS193 & TCAGGGAGGATACTGTCGCTGT & Taq I \\
\hline
\end{tabular}

Tabla 16. Oligonucleótidos para amplificar y secuenciar el gen At5g64340 en el mapeo de ajx1-4. Los oligonucleótidos del resto de genes secuenciados se muestran en el CD de anexos.

\begin{tabular}{|c|c|l|}
\hline Gen & Oligonucleótido & \multicolumn{1}{c|}{ Secuencia (5'a 3') } \\
\hline \multirow{4}{*}{ At5g64340 } & FVS218 & GTTCCATAATTCTGAGAGACTACTCCC \\
\cline { 2 - 3 } & FVS219 & GCCAAATCCAAGTTCTGGTTAGT \\
\cline { 2 - 3 } & FVS220 & GATAAATTCGCCGTTCTCCATC \\
\cline { 2 - 3 } & FVS221 & CAATACGAATTCCCATTCTCTGTG \\
\cline { 2 - 3 } & FVS227 & CGCAGTGAGTTCCTCTCTCTCAT \\
\cline { 2 - 3 } & FVS228 & GCTCTAATCGTACCGTATTCATGG \\
\hline
\end{tabular}

Tabla 17. Oligonucleótidos para genotipar microsatélites utilizados en el mapeo de ajx2-31

\begin{tabular}{|l|c|l|c|c|}
\hline \multirow{2}{*}{ Marcador } & \multirow{2}{*}{ Oligonucleótido } & \multicolumn{2}{|c|}{ Secuencia (5'a 3') } & \multicolumn{2}{|c|}{ Tamaño amplificado } \\
\cline { 3 - 4 } & & & Col & La-er \\
\hline \multirow{2}{*}{ Cer479911 } & $479911-1$ & CAAAATAGAACCAACACCGTAAA & \multirow{2}{*}{$227 \mathrm{pb}$} & \multirow{2}{*}{$221 \mathrm{pb}$} \\
\cline { 2 - 3 } & $479911-2$ & ATTCACTTTCCAATAGATCACTC & & \\
\hline \multirow{2}{*}{ Cer479988 } & $479988-1$ & CAACGGCTCACACTTTCCCTT & \multirow{2}{*}{$222 \mathrm{pb}$} & \multirow{2}{*}{$227 \mathrm{pb}$} \\
\cline { 2 - 3 } & $479988-2$ & CTGTAAAGATGGACACACTATG & & \\
\hline
\end{tabular}

Tabla 18. Oligonucleótidos para genotipar dCAPS utilizados en el mapeo de ajx2-31

\begin{tabular}{|c|c|c|c|}
\hline Marcador & Oligonucleótido & Secuencia (5’a 3') & $\begin{array}{l}\text { Enzima de } \\
\text { restricción }\end{array}$ \\
\hline \multirow{2}{*}{ Cer481348 } & FVS062 & AGCCACTATGTGGAGGTACATCGA & \multirow{2}{*}{ Cla I } \\
\hline & FVS063 & ATATATTCCCACAGCCAATAGAAC & \\
\hline \multirow{2}{*}{ Cer480732 } & FVS064 & CAGTTTGCTCTGGCTTGAAATAGT & \multirow{2}{*}{ Mae III } \\
\hline & FVS065 & TGTCTGAACAAGACGAATAGGGTC & \\
\hline \multirow{2}{*}{ Cer480737 } & FVS060 & AAGCAGCTCCTATCAGGAGAATGAT & \multirow{2}{*}{$\mathrm{Bcll}$} \\
\hline & FVS061 & GCGAAGAACTTCTTAGTTTCCGTG & \\
\hline \multirow{2}{*}{ Cer479897 } & FVS089 & ATGCGACTTTAAGTTATTCCTCA & \multirow{2}{*}{ Dde I } \\
\hline & FVS090 & AAACTCTAAATATATAGAACTAGACCG & \\
\hline
\end{tabular}




\begin{tabular}{|l|l|l|l|}
\hline \multirow{2}{*}{ Cer479895 } & FVS082 & TTGGACCAAAGCCCCATGAAGGC & \multirow{2}{*}{ Hae III } \\
\cline { 2 - 3 } & FVS083 & CGCCGTCGGCAACGAACTATACA & \\
\hline
\end{tabular}

Tabla 19. Oligonucleótidos para amplificar y secuenciar el gen At1g29950 en el mapeo de ajx2-31. Los oligonucleótidos del resto de genes secuenciados se muestran en el CD de anexos.

\begin{tabular}{|c|c|c|}
\hline Gen & Oligonucleótido & \multicolumn{1}{c|}{ Secuencia (5'a 3') } \\
\hline \multirow{3}{*}{ At1g29950 } & FVS195 & CTTACATTGGTACCTTGTGGAAGC \\
\cline { 2 - 3 } & FVS196 & CTCTGGTGGAAACTCGTGATATCT \\
\cline { 2 - 3 } & FVS197 & CCTGCCAACAAAAGGAAGTGAG \\
\hline
\end{tabular}

\subsection{Secuenciación de los alelos supresores de $\boldsymbol{A J A} X 1$, AJAX2, AJAX3 y AJAX4}

Para secuenciar las uORFs de los 4 genes bHLH candidatos a suprimir la mutación de $a c l 5$, realizamos PCR de cada una de las uORFs, en cada uno de los genes $A J A X$, usando como molde el DNA genómico de las 40 líneas supresoras que obtuvimos en la búsqueda de supresores. Estos productos de PCR fueron purificados por fenolización seguida de una precipitación y posteriormente secuenciados por el servicio de secuenciación del IBMCP. Los oligonucleótidos empleados para amplificar las uORFs fueron:

Tabla 20. Oligonucleótidos para amplificar y secuenciar las uORFs de los genes AJAX1, 2, 3 y 4

\begin{tabular}{|c|c|l|}
\hline Gen & Oligonucleótido & Secuencia (5'a 3') \\
\hline $\begin{array}{c}\text { At5g64340 } \\
\text { AJAX1 }\end{array}$ & FVS218 & GCTGATGAGATTCTTCCTTCGACT \\
\cline { 2 - 3 } & FVS228 & CCCGTTGCCTCTTATCCAGA \\
\hline $\begin{array}{c}\text { At5g09460 } \\
\text { AJAX3 }\end{array}$ & FVS230 & TGCTGTTTGGTATCAAGAGGCA \\
\cline { 2 - 3 } $\begin{array}{c}\text { At1g29950 } \\
\text { AJAX2 }\end{array}$ & FVS244 & CATTGTTTGTCGCTGTGCTCTCT \\
\cline { 2 - 3 } & FVS231 & TTATCAGATGATTGCTGAATTTGAT \\
\hline $\begin{array}{c}\text { At5g50010 } \\
\text { AJAX4 }\end{array}$ & FVS232 & TTCCGTTAGCTGAATTTGTTTACA \\
\cline { 2 - 3 } & FVS233 & ACGATCTTGTCCCATCCAACA \\
\hline
\end{tabular}




\subsection{Análisis de expresión de genes}

\subsubsection{Obtención de cDNA}

A partir de $1 \mu \mathrm{g}$ de RNA total, se produjo cDNA, usando el sistema SuperScript II First-Strand cDNA Synthesis System (Invitrogen), según las indicaciones del fabricante.

\subsubsection{Análisis qRT-PCR}

Los oligonucleótidos utilizados para estas reacciones se diseñaron con el programa Primer Express 2.0 (Tabla 21). Las reacciones de PCR cuantitativa se realizaron en un volumen de $20 \mu \mathrm{l}$, empleando $10 \mu \mathrm{l}$ de SYBR $^{\circledR}$ Green PCR Master Mix (Applied Biosystems), $1 \mu \mathrm{l}$ de c-DNA y $1 \mu \mathrm{l}$ de cada oligo $5 \mu \mathrm{M}$. Por cada muestra se realizaron tres PCRs idénticas, utilizando un termociclador 7000 Real-Time PCR System o un 7500 Real-Time PCR System. Los valores de expresión génica se calcularon mediante la cuantificación de la fluorescencia en un punto de la fase exponencial asociado a un número de ciclos $\left(\mathrm{C}_{\mathrm{t}}\right)$. A partir de este $C_{t}$ se calculó la expresión relativa de cada gen respecto a una muestra control, siendo previamente normalizados todos los valores en función del gen constitutivo EIF $\alpha 1$.

Tabla 21. Oligonucleótidos de qRT-PCR.

\begin{tabular}{|c|c|l|}
\hline \multirow{2}{*}{ Gen } & Oligonucleótido & \multicolumn{1}{c|}{ Secuencia (5'a $\mathbf{3}^{\prime}$ ) } \\
\hline \multirow{2}{*}{ AJAX1 1} & EGM qAJAX1 01F & GGATAATTGCCAGGCTGAGTACTT \\
\cline { 2 - 3 } & EGM qAJAX1 01R & GAACGAAAAACAATCACAGATTGAA \\
\hline \multirow{2}{*}{ AJAX2 } & qPCR-AJAX2-F & GATGAAGTGGGTGACAGAAATATG \\
\cline { 2 - 3 } & qPCR-SSS31-R & GCACATGGTGGGAACAAAGC \\
\hline \multirow{2}{*}{ AJAX3 } & FVS295 & GGGAGAGCAGACTCGTTTGTTAC \\
\cline { 2 - 3 } & FVS296 & CCCTCGCTCTGCATCCATAG \\
\hline \multirow{2}{*}{ EIF $\alpha 1$} & EF-1 $\alpha \mathrm{F}$ & CCCAGGCTGATTGTGCTGT \\
\cline { 2 - 3 } & EF-1 $\alpha \mathrm{R}$ & GGGTAGTGGCATCCATCTTGTT \\
\hline
\end{tabular}




\subsection{Transcripción-traducción in vitro}

Se digirieron $10 \mu \mathrm{g}$ de plásmido pSP64 con la construcción correspondiente, con el enzima de restricción EcoRI; esta digestión que linealizaba el plásmido fue purificada por fenolización y precipitación. La reacción de transcripción se realizó en $20 \mu \mathrm{l}$ totales con $3 \mu \mathrm{g}$ de plásmido linealizado, 20 unidades de SP6 RNA polimerasa (Roche), 20 unidades de inhibidor de RNAsa (Roche), $2 \mu 1$ de buffer 10x y ATP, GTP, CTP y UTP a $0,5 \mathrm{mM}$, se incubó 2 horas a $37^{\circ} \mathrm{C}$; pasado este tiempo se trató con 20 unidades de DNAsa I (Roche) 30 min a $37^{\mathrm{a}} \mathrm{C}$, $\mathrm{y}$ finalmente se purificó por fenolización y precipitación.

La traducción in vitro se realizó en $20 \mu \mathrm{l}$ totales con $12 \mu \mathrm{g}$ de RNA como molde, $12 \mu \mathrm{l}$ de Wheat Germ Extract Plus (Promega) y $0,5 \mu \mathrm{l}$ de Fluorotect $^{\mathrm{TM}}$ Green Lys tRNA (Promega); la reacción fue incubada durante 2 horas a $25^{\circ} \mathrm{C}$. El resultado de la reacción fue separado en un gel SDS-PAGE al 12\% de acrilamida. El gel fue escaneado en un Typhoon TRIO (Amersham Biosciences) con un filtro de excitación de $488 \mathrm{~nm}$ y uno de emisión de $520 \mathrm{~nm}$ de longitud de onda.

\subsection{Análisis de expresión génica mediante micromatrices}

\subsubsection{Extracción de RNA total}

Se sembraron semillas de los genotipos indicados, acl5-5, Col-0, acl5-5 + 35S::AJAX2, en placas de MS y MS + 0,1 mM termoespermina. Se recolectaron las plántulas a las 2 semanas y se pulverizaron con $\mathrm{N}_{2}$ líquido. El RNA total se extrajo usando el sistema RNeasy Plant Minikit (QIAGEN) según las instrucciones del fabricante. La cantidad de RNA fue cuantificada mediante un espectrofotómetro Nanodrop.

\subsubsection{Amplificación de RNA}

Se amplificó el RNA extraído mediante el sistema MessageAmp ${ }^{\mathrm{TM}}$ aRNA Kit (Ambion). Para ello a partir de un $1 \mu \mathrm{g}$ de RNA total, sintetizamos c-DNA de 
doble cadena usando el oligonucleótido T7-Oligo-dT como cebador, siguiendo las instrucciones del fabricante. Este cDNA fue purificado usando el sistema DNA Clear (Ambion) siguiendo las instrucciones del fabricante y fue usado como molde para generar nuevo aRNA, con una mezcla de ribonucleótidos con aminoalil-UTP, mediante el MessageAmp ${ }^{\text {TM }}$ aRNA Kit (Ambion). Este aRNA fue purificado con el sistema Mega Clear (Ambion) según las instrucciones del fabricante y fue cuantificado mediante el espectrofotómetro Nanodrop.

\subsubsection{Marcaje fluorescente del RNA amplificado}

Se tomaron $10 \mu \mathrm{g}$ de aRNA para cada muestra, y fueron marcados con Cy3 y Cy5 (Amersham/GE Healthcare). Cada vial de fluoróforo fue resuspendido en $15 \mu \mathrm{l}$ de DMSO, de los cuales se usaron $5 \mu 1$ por marcaje. Se secaron los $10 \mu \mathrm{g}$ de aRNA mediante "speed-vacuum" y fueron resuspendidos en $2 \mu \mathrm{lde} \mathrm{Na}_{2} \mathrm{CO}_{3}$ $1 \mathrm{M}$; se añadieron los $5 \mu 1$ del fluoróforo correspondiente y $13 \mu \mathrm{l}$ de agua miliQ. Se dejó incubar la reacción a temperatura ambiente, durante una hora en oscuridad. Se detuvo la reacción añadiendo $35 \mu \mathrm{l}$ de acetato sódico pH 5,2 100 mM. Los aRNAs de las muestras Col-0, acl5-5 + 35S::AJAX2, y acl5-5 + 0,1 $\mathrm{mM}$ termoespermina se marcaron con Cy3 y las muestras de acl5-5 se marcaron con Cy5. Todos estos Cy dye-aRNA fueron purificados mediante el sistema Mega Clear (Ambion). El rendimiento del marcaje (pM de fluoróforo/ $\mu 1$ ) fue determinado mediante el espectrofotómetro Nanodrop.

\subsubsection{Hibridación de Cy-dy-aRNA con las micromatrices}

Se emplearon micromatrices de DNA de oligonucleótidos largos del conjunto del A. thaliana Genome Oligo Set Versión 3.0, generadas en la Universidad de Arizona (http://ag.arizona.edu/microarray). Para cada una de las tres comparaciones se realizaron tres réplicas biológicas.

Se preparó el cristal, entrecruzando su DNA mediante un tratamiento de $65 \mathrm{~mJ}$ de luz ultravioleta en un horno de entrecruzamiento UV Stratalinker 1800. Tras este paso, se prehibridó el cristal durante $30 \mathrm{~min}$ a $42^{\circ} \mathrm{C}$ con la solución de prehibridación (3x SSC $+001 \%(\mathrm{p} / \mathrm{v}) \mathrm{SDS}+0,016 \%(\mathrm{p} / \mathrm{v}) \mathrm{BSA})$. Posteriormente se hicieron dos lavados al cristal con agua miliQ y uno con isopropanol. Se secó 
el cristal por centrifugación a 2000 rpm durante un minuto, y se dejó en la cámara de hibridación.

Paralelamente se preparó la sonda mezclando $300 \mathrm{pM}$ de cada uno de los dos Cy dye-aRNA, se secaron mediante "speed-vacuum", se resuspendieron en $5 \mu 1$ de agua miliQ, y se le añadieron $1 \mu \mathrm{g}$ de tRNA de levadura (Ambion), $1 \mu \mathrm{g}$ de polyA (roche), y $1 \mu 1$ de tampón de fragmentación (Ambion), hasta un total de $10 \mu 1$. Se incubó a $70^{\circ} \mathrm{C}$ durante $15 \mathrm{~min}$ para conseguir la fragmentación de la sonda, tras los cuales se interrumpió la reacción añadiendo $1 \mu 1$ de tampón de parada (Ambion) y dejándola en hielo. Posteriormente se colocó la sonda en un baño hirviendo durante $5 \mathrm{~min}$. Se dejó enfriar y se añadió $55 \mu \mathrm{l}$ de solución de hibridación (formamida desionizada 62,5\%(v/v) + 6,66x SSC + SDS $0,55 \%(\mathrm{p} / \mathrm{v})+5,55 \mathrm{x}$ de solución Dendhardt's). La sonda ya preparada se colocó sobre el cristal y se tapó con un cubre LifterSlip (Eries Scientific Company).

Se dejó el cristal con la sonda encerrado en la cámara de hibridación, incubando a $37^{\circ} \mathrm{C}$ durante $16 \mathrm{~h}$.

\subsubsection{Lavado de las micromatrices}

Trascurridas las $16 \mathrm{~h}$, se quitó el cubre y se realizaron los siguientes lavados a la micromatriz:

- Un lavado con $2 x \mathrm{SSC}+0,1 \%$ (p/v) SDS a $30^{\circ} \mathrm{C}$ durante $5 \mathrm{~min}$.

- Un lavado con $0,2 \mathrm{x} \mathrm{SSC}+0,1 \%(\mathrm{p} / \mathrm{v}) \mathrm{SDS}$ a $30^{\circ} \mathrm{C}$ durante $5 \mathrm{~min}$.

- Seis lavados con 0,1x SSC a temperatura ambiente durante $2 \mathrm{~min}$.

- Un lavado con 0,01x SSC a temperatura ambiente durante $2 \mathrm{~min}$.

Se secó el cristal mediante centrifugación de 1 min a 2000 rpm.

\subsubsection{Escaneo y análisis de las micromatrices}

El escaneado se realizó en un escáner Genepix 4000B (Axon Instruments), usando la aplicación informática Genepix 4.0. Las imágenes se escanearon a 635 y $532 \mathrm{~nm}$, ajustado la ganancia de los fotomultiplicadores de modo que el número de pocillos saturados fuese inferior al $0,1 \% \mathrm{y}$ que el cociente entre el 
sumatorio de las señales totales para cada fluoróforo, tuviese un valor entorno a 1 .

El análisis de las imágenes se realizó utilizando la aplicación informática Genepix 6.0 (Axon Instruments) y para el análisis estadístico se utilizó el programa Acuity 4.0 (Axon Instruments). Para el análisis de enriquecimiento de categorías se usó la aplicación Classification SuperViewer Tool w/ Bootstrap (http://bar.utoronto.ca/).

\section{Análisis filogenético y estructural}

\subsection{Rastreo y análisis de secuencias}

Todas las secuencias de $A$. thaliana empleadas en los diversos alineamientos se obtuvieron de la base de datos del TAIR (www.arabidopsis.org). En el caso del estudio evolutivo de los genes $A J A X$ y sus uORFs, utilizamos las secuencias $A J A X 1, A J A X 2$ y $A J A X 3$ para realizar una búsqueda mediante BLAST en las bases de datos del NCBI (www.ncbi.nlm.nih.gov) y PHYTOZOME (www.phytozome.net). Además, también obtuvimos más secuencias aprovechando los datos suplementarios de diversos artículos científicos (Toledo-Ortiz et al. 2003; Hayden y Jorgensen 2007; Pires y Dolan 2009).

Para los análisis filogenéticos, el alineamiento de las secuencias se generó utilizando el programa CLUSTALX utilizando los parámetros definidos por defecto (Thompson et al. 1997); excepto para la figura 33 en la cual se empleó el programa MUSCLE (Edgar 2004) utilizando los parámetros por defecto, este último alineamiento fue analizado utilizando el programa PhyMLv3.0 (Guindon y Gascuel 2003) utilizando el modelo de sustitución aminoacídica WAG y los parámetros por defecto.

La representación de los alineamientos obtenidos se realizó con el programa CLUSTALX, mientras que para los árboles filogenéticos empleamos el programa FIGTREE (http://tree.bio.ed.ac.uk/software/figtree/). 


\subsection{Análisis estructural}

La estructura tridimensional de la PMT de Nicotiana tabacum fue generada con el servidor MODWEB (http://salilab.org/modweb) (Pieper et al. 2004). La PMT modelada y la estructura de la SPDS de $A$. thaliana (código PDB 1XJ5) se superpusieron utilizando el programa LSQKAB del paquete CCP4 (CCP4 1994). La molécula de AdoMet en el centro activo de la PMT fue generada utilizando como molde la molécula del AdoMetdc de la estructura de la SPDS. Para mejorar la modelización del complejo AdoMet-PMT se aplicó dinámicas de ángulos de torsión y minimización de energía con el programa CNS (Brunger et al. 1998).

Para evaluar los sitios de unión de las poliaminas en las proteínas SPDS, SPMS $\mathrm{y}$ tSPMS, se superpusieron las estructuras de la tSPMS de Thermus thermophilus (código PDB 1UIR), la de la SPDS de Thermotoga marítima (código PDB 1INL) y la SPDS de A. thaliana, utilizando el programa LSQKAB. El análisis de las interacciones de las poliaminas en los diferentes centros activos se realizó con el paquete CCP4. Para la representación estructural de esta comparación se utilizaron la estructura de la SDPS de $A$. thaliana y la estructura de ACL5 de A. thaliana, predicha por el programa PHYRE (Kelley y Sternberg 2009) y extraída de la página web EPLANT (http://bar.utoronto.ca/eplant/).

La representación gráfica de todos los modelos se llevó a cabo con el programa PyMOL (www.pymol.org). 

BIBLIOGRAFÍA 

Abastado, J. P., Miller, P. F., Jackson, B. M. and Hinnebusch, A. G. (1991). "Suppression of ribosomal reinitiation at upstream open reading frames in amino acid-starved cells forms the basis for GCN4 translational control." Mol Cell Biol 11(1): 486-96.

Alcázar, R., Cuevas, J. C., Patron, M., Altabella, T. and Tiburcio, A. F. (2006a). "Abscisic acid modulates polyamine metabolism under water stress in Arabidopsis thaliana." Physiologia Plantarum 128(3): 448-55.

Alcázar, R., Garcia-Martinez, J. L., Cuevas, J. C., Tiburcio, A. F. and Altabella, T. (2005). "Overexpression of ADC2 in Arabidopsis induces dwarfism and late-flowering through GA deficiency." Plant J 43(3): 425-36.

Alcázar, R., Marco, F., Cuevas, J. C., Patron, M., Ferrando, A., Carrasco, P., Tiburcio, A. F. and Altabella, T. (2006b). "Involvement of polyamines in plant response to abiotic stress." Biotechnol Lett 28(23): 1867-76.

Alonso, J. M., Stepanova, A. N., Leisse, T. J., Kim, C. J., Chen, H., Shinn, P., Stevenson, D. K., Zimmerman, J., Barajas, P., Cheuk, R., Gadrinab, C., Heller, C., Jeske, A., Koesema, E., Meyers, C. C., Parker, H., Prednis, L., Ansari, Y., Choy, N., Deen, H., Geralt, M., Hazari, N., Hom, E., Karnes, M., Mulholland, C., Ndubaku, R., Schmidt, I., Guzman, P., Aguilar-Henonin, L., Schmid, M., Weigel, D., Carter, D. E., Marchand, T., Risseeuw, E., Brogden, D., Zeko, A., Crosby, W. L., Berry, C. C. and Ecker, J. R. (2003). "Genome-wide insertional mutagenesis of Arabidopsis thaliana." Science 301(5633): 653-7.

Amarantos, I., Zarkadis, I. K. and Kalpaxis, D. L. (2002). "The identification of spermine binding sites in 16S rRNA allows interpretation of the spermine effect on ribosomal 30S subunit functions." Nucleic Acids Res 30(13): 2832-43.

Applewhite, P. B., Kaur-Sawhney, R. and Galston, A. W. (2000). "A role for spermidine in the bolting and flowering of Arabidopsis." Physiologia Plantarum 108(3): 314-20.

Bachrach, U. (2004). "Polyamines and cancer: minireview article." Amino Acids 26(4): 307-9.

Bachrach U, H. Y. (1989). Propylamine transfer reactions in thermophilic archaebacteria: enzymological aspects and comparative biochemistry. The Physiology of Polyamines, CRC Press. Volume II.

Becerra-Solano, L. E., Butler, J., Castaneda-Cisneros, G., McCloskey, D. E., Wang, X., Pegg, A. E., Schwartz, C. E., Sanchez-Corona, J. and Garcia-Ortiz, J. E. (2009). "A missense mutation, p.V132G, in the X-linked spermine synthase gene (SMS) causes Snyder-Robinson syndrome." Am J Med Genet A 149A(3): 328-35.

Ben-Hayyim, G., Damon, J. P., Martin-Tanguy, J. and Tepfer, D. (1994). "Changing root system architecture through inhibition of putrescine and feruloyl putrescine accumulation." FEBS Lett 342(2): 145-8. 
Bensmihen, S., To, A., Lambert, G., Kroj, T., Giraudat, J. and Parcy, F. (2004). "Analysis of an activated ABI5 allele using a new selection method for transgenic Arabidopsis seeds." FEBS Lett 561(1-3): 127-31.

Biastoff, S., Brandt, W. and Drager, B. (2009a). "Putrescine Nmethyltransferase-the start for alkaloids." Phytochemistry 70(15-16): 1708-18.

Biastoff, S., Reinhardt, N., Reva, V., Brandt, W. and Drager, B. (2009b). "Evolution of putrescine N-methyltransferase from spermidine synthase demanded alterations in substrate binding." FEBS Lett 583(20): 336774.

Biastoff, S., Teuber, M., Zhou, Z. S. and Drager, B. (2006). "Colorimetric activity measurement of a recombinant putrescine Nmethyltransferase from Datura stramonium." Planta Med 72(12): 1136-41.

Bitonti, A. J., Kelly, S. E. and McCann, P. P. (1984). "Characterization of spermidine synthase from Trypanosoma brucei brucei." Mol Biochem Parasitol 13(1): 21-8.

Bowman, W. H., Tabor, C. W. and Tabor, H. (1973). "Spermidine biosynthesis. Purification and properties of propylamine transferase from Escherichia coli." J Biol Chem 248(7): 2480-6.

Brunger, A. T., Adams, P. D., Clore, G. M., DeLano, W. L., Gros, P., Grosse-Kunstleve, R. W., Jiang, J. S., Kuszewski, J., Nilges, M., Pannu, N. S., Read, R. J., Rice, L. M., Simonson, T. and Warren, G. L. (1998). "Crystallography \& NMR system: A new software suite for macromolecular structure determination." Acta Crystallogr D Biol Crystallogr 54(Pt 5): 905-21.

Cacciapuoti, G., Porcelli, M., Moretti, M. A., Sorrentino, F., Concilio, L., Zappia, V., Liu, Z. J., Tempel, W., Schubot, F., Rose, J. P., Wang, B. C., Brereton, P. S., Jenney, F. E. and Adams, M. W. (2007). "The first agmatine/cadaverine aminopropyl transferase: biochemical and structural characterization of an enzyme involved in polyamine biosynthesis in the hyperthermophilic archaeon Pyrococcus furiosus." J Bacteriol 189(16): 605767.

Carbonell, J. and Blazquez, M. A. (2009). "Regulatory Mechanisms of Polyamine Biosynthesis in Plants." Genes \& Genomics 31(2): 107-18.

Carbonell, J. and Navarro, J. L. (1989). "Correlation of spermine levels with ovary senescence and with fruit set and development inPisum sativum L." Planta 178(4): 482-87.

Cartwright, D. A., Brady, S. M., Orlando, D. A., Sturmfels, B. and Benfey, P. N. (2009). "Reconstructing spatiotemporal gene expression data from partial observations." Bioinformatics 25(19): 2581-7.

CCP4 (1994). "The CCP4 suite: programs for protein crystallography." Acta Crystallogr D Biol Crystallogr 50(Pt 5): 760-3.

Clay, N. K. and Nelson, T. (2005). "Arabidopsis thickvein mutation affects vein thickness and organ vascularization, and resides in a provascular 
cell-specific spermine synthase involved in vein definition and in polar auxin transport." Plant Physiol 138(2): 767-77.

Clough, S. J. and Bent, A. F. (1998). "Floral dip: a simplified method for Agrobacterium-mediated transformation of Arabidopsis thaliana." Plant $J$ 16(6): 735-43.

Childs, A. C., Mehta, D. J. and Gerner, E. W. (2003). "Polyaminedependent gene expression." Cell Mol Life Sci 60(7): 1394-406.

Dalla Via, L., Di Noto, V. and Toninello, A. (1999). "Binding of spermidine and putrescine to energized liver mitochondria." Arch Biochem Biophys 365(2): 231-8.

David-Assael, O., Saul, H., Saul, V., Mizrachy-Dagri, T., Berezin, I., Brook, E. and Shaul, O. (2005). "Expression of AtMHX, an Arabidopsis vacuolar metal transporter, is repressed by the $5^{\prime}$ untranslated region of its gene." J Exp Bot 56(413): 1039-47.

de Alencastro, G., McCloskey, D. E., Kliemann, S. E., Maranduba, C. M., Pegg, A. E., Wang, X., Bertola, D. R., Schwartz, C. E., Passos-Bueno, M. R. and Sertie, A. L. (2008). "New SMS mutation leads to a striking reduction in spermine synthase protein function and a severe form of SnyderRobinson X-linked recessive mental retardation syndrome." J Med Genet 45(8): 539-43.

Douglas, S. J., Chuck, G., Dengler, R. E., Pelecanda, L. and Riggs, C. D. (2002). "KNAT1 and ERECTA regulate inflorescence architecture in Arabidopsis." Plant Cell 14(3): 547-58.

Dufe, V. T., Luersen, K., Eschbach, M. L., Haider, N., Karlberg, T., Walter, R. D. and Al-Karadaghi, S. (2005). "Cloning, expression, characterisation and three-dimensional structure determination of Caenorhabditis elegans spermidine synthase." FEBS Lett 579(27): 6037-43.

Dufe, V. T., Qiu, W., Muller, I. B., Hui, R., Walter, R. D. and AlKaradaghi, S. (2007). "Crystal structure of Plasmodium falciparum spermidine synthase in complex with the substrate decarboxylated S-adenosylmethionine and the potent inhibitors 4MCHA and AdoDATO." J Mol Biol 373(1): 167-77.

Edgar, R. C. (2004). "MUSCLE: multiple sequence alignment with high accuracy and high throughput." Nucleic Acids Res 32(5): 1792-7.

Edwards, K., Johnstone, C. and Thompson, C. (1991). "A simple and rapid method for the preparation of plant genomic DNA for PCR analysis." Nucleic Acids Res 19(6): 1349.

Esau, K. (1977). Anatomy of seed plants $2^{\circ}$ Edition E. J. W. Sons.

Fernandes, J. O. and Ferreira, M. A. (2000). "Combined ion-pair extraction and gas chromatography-mass spectrometry for the simultaneous determination of diamines, polyamines and aromatic amines in Port wine and grape juice." J Chromatogr A 886(1-2): 183-95. 
Flores, H. E. and Galston, A. W. (1982). "Analysis of Polyamines in Higher Plants by High Performance Liquid Chromatography." Plant Physiol 69(3): 701-06.

Franceschetti, M., Hanfrey, C., Scaramagli, S., Torrigiani, P., Bagni, N., Burtin, D. and Michael, A. J. (2001). "Characterization of monocot and dicot plant S-adenosyl-1-methionine decarboxylase gene families including identification in the mRNA of a highly conserved pair of upstream overlapping open reading frames." Biochem J 353(Pt 2): 403-9.

Galston, A. W. (1983). "Polyamines as modulators of plant development." Bioscience 33(6): 382-88.

Galston, A. W. and Sawhney, R. K. (1990). "Polyamines in plant physiology." Plant Physiol 94(2): 406-10.

Gancedo, C. and Flores, C. L. (2008). "Moonlighting proteins in yeasts." Microbiol Mol Biol Rev 72(1): 197-210, table of contents.

Ge, C., Cui, X., Wang, Y., Hu, Y., Fu, Z., Zhang, D., Cheng, Z. and Li, J. (2006). "BUD2, encoding an S-adenosylmethionine decarboxylase, is required for Arabidopsis growth and development." Cell Res 16(5): 446-56.

Geuns, J. M., Smets, R., Struyf, T., Prinsen, E., Valcke, R. and Van Onckelen, H. (2001). "Apical dominance in Pssu-ipt-transformed tobacco." Phytochemistry 58(6): 911-21.

Godiard, L., Sauviac, L., Torii, K. U., Grenon, O., Mangin, B., Grimsley, N. H. and Marco, Y. (2003). "ERECTA, an LRR receptor-like kinase protein controlling development pleiotropically affects resistance to bacterial wilt." Plant J 36(3): 353-65.

Grant, J. J. and Loake, G. J. (2000). "Role of reactive oxygen intermediates and cognate redox signaling in disease resistance." Plant Physiol 124(1): 21-9.

Graser, G. and Hartmann, T. (2000). "Biosynthesis of spermidine, a direct precursor of pyrrolizidine alkaloids in root cultures of Senecio vulgaris L." Planta 211(2): 239-45.

Greene, E. A., Codomo, C. A., Taylor, N. E., Henikoff, J. G., Till, B. J., Reynolds, S. H., Enns, L. C., Burtner, C., Johnson, J. E., Odden, A. R., Comai, L. and Henikoff, S. (2003). "Spectrum of chemically induced mutations from a large-scale reverse-genetic screen in Arabidopsis." Genetics 164(2): 731-40.

Guindon, S. and Gascuel, O. (2003). "A simple, fast, and accurate algorithm to estimate large phylogenies by maximum likelihood." Syst Biol 52(5): 696-704.

Haider, N., Eschbach, M. L., Dias Sde, S., Gilberger, T. W., Walter, R. D. and Luersen, K. (2005). "The spermidine synthase of the malaria parasite Plasmodium falciparum: molecular and biochemical characterisation of the polyamine synthesis enzyme." Mol Biochem Parasitol 142(2): 224-36. 
Hamana, K., Niitsu, M., Samejima, K. and Matsuzaki, S. (1992). "N4Methylthermospermine in leguminous seeds." Phytochemistry 31(4): 1410-12.

Hamana, K., Niitsu, M. and Samejina, K. (1998). "Unusual polyamines in aquatic plants: the occurrence of homospermidine, norspermidine, thermospermine, norspermine, aminopropylhomospermidine, bis(aminopropyl)ethanediamine, and methylspermidine." Canadian Journal of Botany 76(1): 130-33.

Hamasaki-Katagiri, N., Katagiri, Y., Tabor, C. W. and Tabor, H. (1998). "Spermine is not essential for growth of Saccharomyces cerevisiae: identification of the SPE4 gene (spermine synthase) and characterization of a spe4 deletion mutant." Gene 210(2): 195-201.

Hamasaki-Katagiri, N., Tabor, C. W. and Tabor, H. (1997). "Spermidine biosynthesis in Saccharomyces cerevisae: polyamine requirement of a null mutant of the SPE3 gene (spermidine synthase)." Gene 187(1): 35-43.

Hanfrey, C., Elliott, K. A., Franceschetti, M., Mayer, M. J., Illingworth, C. and Michael, A. J. (2005). "A dual upstream open reading frame-based autoregulatory circuit controlling polyamine-responsive translation." J Biol Chem 280(47): 39229-37.

Hanfrey, C., Franceschetti, M., Mayer, M. J., Illingworth, C. and Michael, A. J. (2002). "Abrogation of upstream open reading frame-mediated translational control of a plant S-adenosylmethionine decarboxylase results in polyamine disruption and growth perturbations." J Biol Chem 277(46): 44131-9.

Hanfrey, C., Sommer, S., Mayer, M. J., Burtin, D. and Michael, A. J. (2001). "Arabidopsis polyamine biosynthesis: absence of ornithine decarboxylase and the mechanism of arginine decarboxylase activity." Plant $J$ 27(6): 551-60.

Hanzawa, Y., Imai, A., Michael, A. J., Komeda, Y. and Takahashi, T. (2002). "Characterization of the spermidine synthase-related gene family in Arabidopsis thaliana." FEBS Lett 527(1-3): 176-80.

Hanzawa, Y., Takahashi, T. and Komeda, Y. (1997). "ACL5: an Arabidopsis gene required for internodal elongation after flowering." Plant $J$ 12(4): 863-74.

Hanzawa, Y., Takahashi, T., Michael, A. J., Burtin, D., Long, D., Pineiro, M., Coupland, G. and Komeda, Y. (2000). "ACAULIS5, an Arabidopsis gene required for stem elongation, encodes a spermine synthase." Embo J 19(16): 4248-56.

Hashimoto, T., Tamaki, K., Suzuki, K. and Yamada, Y. (1998). "Molecular cloning of plant spermidine synthases." Plant Cell Physiol 39(1): 73-9.

Havelange, A., Lejeune, P., Bernier, G., Kaur-Sawhney, R. and Galston, A. W. (1996). "Putrescine export from leaves in relation to floral transition in Sinapis alba." Physiologia Plantarum 96(1): 59-65. 
Hayashi, S., Murakami, Y. and Matsufuji, S. (1996). "Ornithine decarboxylase antizyme: a novel type of regulatory protein." Trends Biochem Sci 21(1): 27-30.

Hayden, C. A. and Jorgensen, R. A. (2007). "Identification of novel conserved peptide uORF homology groups in Arabidopsis and rice reveals ancient eukaryotic origin of select groups and preferential association with transcription factor-encoding genes." BMC Biol 5: 32.

Hernandez-Sanchez, C., Mansilla, A., de la Rosa, E. J., Pollerberg, G. E., Martinez-Salas, E. and de Pablo, F. (2003). "Upstream AUGs in embryonic proinsulin mRNA control its low translation level." Embo $J$ 22(20): 5582-92.

Hibi, N., Fujita, T., Hatano, M., Hashimoto, T. and Yamada, Y. (1992). "Putrescine N-Methyltransferase in Cultured Roots of Hyoscyamus albus: nButylamine as a Potent Inhibitor of the Transferase both in Vitro and in Vivo." Plant Physiol 100(2): 826-35.

Hoagland (1920). "Optimum nutrient solutions for plants." Science 52(1354): 562-64.

Hornitschek, P., Lorrain, S., Zoete, V., Michielin, O. and Fankhauser, C. (2009). "Inhibition of the shade avoidance response by formation of nonDNA binding bHLH heterodimers." Embo J 28(24): 3893-902.

Hosoya, R., Hamana, K., Niitsu, M. and Itoh, T. (2004). "Polyamine analysis for chemotaxonomy of thermophilic eubacteria: Polyamine distribution profiles within the orders Aquificales, Thermotogales, Thermodesulfobacteriales, Thermales, Thermoanaerobacteriales, Clostridiales and Bacillales." J Gen Appl Microbiol 50(5): 271-87.

Igarashi, K. and Kashiwagi, K. (2000). "Polyamines: mysterious modulators of cellular functions." Biochem Biophys Res Commun 271(3): 55964.

Ikeguchi, Y., Bewley, M. C. and Pegg, A. E. (2006). "Aminopropyltransferases: function, structure and genetics." J Biochem 139(1): $1-9$.

Imai, A., Hanzawa, Y., Komura, M., Yamamoto, K. T., Komeda, Y. and Takahashi, T. (2006). "The dwarf phenotype of the Arabidopsis acl5 mutant is suppressed by a mutation in an upstream ORF of a bHLH gene." Development 133(18): 3575-85.

Imai, A., Komura, M., Kawano, E., Kuwashiro, Y. and Takahashi, T. (2008). "A semi-dominant mutation in a ribosomal protein L10 gene suppresses the dwarf phenotype of the acl5 mutant in Arabidopsis thaliana." Plant $J$.

Imai, A., Matsuyama, T., Hanzawa, Y., Akiyama, T., Tamaoki, M., Saji, H., Shirano, Y., Kato, T., Hayashi, H., Shibata, D., Tabata, S., Komeda, Y. and Takahashi, T. (2004). "Spermidine synthase genes are essential for survival of Arabidopsis." Plant Physiol 135(3): 1565-73. 
Ivanov, I. P. and Atkins, J. F. (2007). "Ribosomal frameshifting in decoding antizyme mRNAs from yeast and protists to humans: close to 300 cases reveal remarkable diversity despite underlying conservation." Nucleic Acids Res 35(6): 1842-58.

Ivanov, I. P., Atkins, J. F. and Michael, A. J. (2010). "A profusion of upstream open reading frame mechanisms in polyamine-responsive translational regulation." Nucleic Acids Res 38(2): 353-9.

Iwasaki, T. and Shibaoka, H. (1991). "Brassinosteroids Act as Regulators of Tracheary-Element Differentiation in Isolated Zinnia Mesophyll Cells." Plant Cell Physiol. 32(7): 1007-14.

Janowitz, T., Kneifel, H. and Piotrowski, M. (2003). "Identification and characterization of plant agmatine iminohydrolase, the last missing link in polyamine biosynthesis of plants." FEBS Lett 544(1-3): 258-61.

Jean, G. B., Pierre, S. M., Joseph, W., Fritz, G. and Philippe, L. U. X. (1988). "Fluorinated analogues of spermidine as substrates of spermine synthase." European Journal of Biochemistry 176(2): 237-42.

Kajander, E. O., Kauppinen, L. I., Pajula, R. L., Karkola, K. and Eloranta, T. O. (1989). "Purification and partial characterization of human polyamine synthases." Biochem J 259(3): 879-86.

Kakehi, J., Kuwashiro, Y., Niitsu, M. and Takahashi, T. (2008). "Thermospermine is required for stem elongation in Arabidopsis thaliana." Plant Cell Physiol 49(9): 1342-9.

Kelley, L. A. and Sternberg, M. J. (2009). "Protein structure prediction on the Web: a case study using the Phyre server." Nat Protoc 4(3): 363-71.

Knott, J. M., Romer, P. and Sumper, M. (2007). "Putative spermine synthases from Thalassiosira pseudonana and Arabidopsis thaliana synthesize thermospermine rather than spermine." FEBS Lett 581(16): 3081-6.

Korolev, S., Ikeguchi, Y., Skarina, T., Beasley, S., Arrowsmith, C., Edwards, A., Joachimiak, A., Pegg, A. E. and Savchenko, A. (2002). "The crystal structure of spermidine synthase with a multisubstrate adduct inhibitor." Nat Struct Biol 9(1): 27-31.

Kozak, M. (2001). "Constraints on reinitiation of translation in mammals." Nucleic Acids Res 29(24): 5226-32.

Kubo, M., Udagawa, M., Nishikubo, N., Horiguchi, G., Yamaguchi, M., Ito, J., Mimura, T., Fukuda, H. and Demura, T. (2005). "Transcription switches for protoxylem and metaxylem vessel formation." Genes Dev 19(16): 1855-60.

Kuehn, G. D., Rodriguez-Garay, B., Bagga, S. and Phillips, G. C. (1990). "Novel Occurrence of Uncommon Polyamines in Higher Plants." Plant Physiol 94(3): 855-57.

Kumar, A., Taylor, M., Altabella, T. and Tiburcio, A. F. (1997). "Recent advances in polyamine research." Trends in Plant Science 2(4): 124-30. 
Law, G. L., Raney, A., Heusner, C. and Morris, D. R. (2001). "Polyamine regulation of ribosome pausing at the upstream open reading frame of S-adenosylmethionine decarboxylase." J Biol Chem 276(41): 38036-43.

Long, D., Goodrich, J., Wilson, K., Sundberg, E., Martin, M., Puangsomlee, P. and Coupland, G. (1997). "Ds elements on all five Arabidopsis chromosomes and assessment of their utility for transposon tagging." Plant J 11(1): 145-8.

Lu, P. K., Tsai, J. Y., Chien, H. Y., Huang, H., Chu, C. H. and Sun, Y. J. (2007). "Crystal structure of Helicobacter pylori spermidine synthase: a Rossmann-like fold with a distinct active site." Proteins 67(3): 743-54.

Martin-Tanguy, J. (1997). "Conjugated polyamines and reproductive development: Biochemical, molecular and physiological approaches." Physiologia Plantarum 100(3): 675-88.

Martone, P. T., Estevez, J. M., Lu, F., Ruel, K., Denny, M. W., Somerville, C. and Ralph, J. (2009). "Discovery of lignin in seaweed reveals convergent evolution of cell-wall architecture." Curr Biol 19(2): 169-75.

Masle, J., Gilmore, S. R. and Farquhar, G. D. (2005). "The ERECTA gene regulates plant transpiration efficiency in Arabidopsis." Nature 436(7052): 866-70.

Matsufuji, S., Matsufuji, T., Miyazaki, Y., Murakami, Y., Atkins, J. F., Gesteland, R. F. and Hayashi, S. (1995). "Autoregulatory frameshifting in decoding mammalian ornithine decarboxylase antizyme." Cell 80(1): 51-60.

McCourt, P. (1999). "Genetic Analysis of Hormone Signaling." Annu Rev Plant Physiol Plant Mol Biol 50: 219-43.

Milioni, D., Sado, P. E., Stacey, N. J., Domingo, C., Roberts, K. and McCann, M. C. (2001). "Differential expression of cell-wall-related genes during the formation of tracheary elements in the Zinnia mesophyll cell system." Plant Mol Biol 47(1-2): 221-38.

Minguet, E. G., Vera-Sirera, F., Marina, A., Carbonell, J. and Blazquez, M. A. (2008). "Evolutionary diversification in polyamine biosynthesis." Mol Biol Evol 25(10): 2119-28.

Morris, D. R. and Geballe, A. P. (2000). "Upstream open reading frames as regulators of mRNA translation." Mol Cell Biol 20(23): 8635-42.

Muñiz, L., Minguet, E. G., Singh, S. K., Pesquet, E., Vera-Sirera, F., Moreau-Courtois, C. L., Carbonell, J., Blazquez, M. A. and Tuominen, H. (2008). "ACAULIS5 controls Arabidopsis xylem specification through the prevention of premature cell death." Development 135(15): 2573-82.

Murashige, T. and Skoog, F. (1962). "A Revised Medium for Rapid Growth and Bio Assays with Tobacco Tissue Cultures." Physiologia Plantarum 15(3): 473-97. 
Nishimura, T., Wada, T., Yamamoto, K. T. and Okada, K. (2005). "The Arabidopsis STV1 protein, responsible for translation reinitiation, is required for auxin-mediated gynoecium patterning." Plant Cell 17(11): 2940-53.

Ohashi-Ito, K. and Fukuda, H. (2010). "Transcriptional regulation of vascular cell fates." Curr Opin Plant Biol 13: 7.

Ohashi-Ito, K., Oda, Y. and Fukuda, H. (2010). "Arabidopsis VASCULAR-RELATED NAC-DOMAIN6 Directly Regulates the Genes That Govern Programmed Cell Death and Secondary Wall Formation during Xylem Differentiation." Plant Cell Epub ahead of print.

Ohnuma, M., Terui, Y., Tamakoshi, M., Mitome, H., Niitsu, M., Samejima, K., Kawashima, E. and Oshima, T. (2005). "N1aminopropylagmatine, a new polyamine produced as a key intermediate in polyamine biosynthesis of an extreme thermophile, Thermus thermophilus." $J$ Biol Chem 280(34): 30073-82.

Oshima, T. (1979). "A new polyamine, thermospermine, 1,12-diamino4,8-diazadodecane, from an extreme thermophile." J Biol Chem 254(18): 87202 .

Pajula, R. L. (1983). "Kinetic properties of spermine synthase from bovine brain." Biochem J 215(3): 669-76.

Pajula, R. L. and Raina, A. (1979). "Methylthioadenosine, a potent inhibitor of spermine synthase from bovine brain." FEBS Lett 99(2): 343-5.

Panicot, M., Minguet, E. G., Ferrando, A., Alcazar, R., Blazquez, M. A., Carbonell, J., Altabella, T., Koncz, C. and Tiburcio, A. F. (2002). "A polyamine metabolon involving aminopropyl transferase complexes in Arabidopsis." Plant Cell 14(10): 2539-51.

Park, M. H. (2006). "The post-translational synthesis of a polyaminederived amino acid, hypusine, in the eukaryotic translation initiation factor $5 \mathrm{~A}$ (eIF5A)." J Biochem 139(2): 161-9.

Paschalidis, K. A. and Roubelakis-Angelakis, K. A. (2005). "Sites and regulation of polyamine catabolism in the tobacco plant. Correlations with cell division/expansion, cell cycle progression, and vascular development." Plant Physiol 138(4): 2174-84.

Pegg, A. E., Shuttleworth, K. and Hibasami, H. (1981). "Specificity of mammalian spermidine synthase and spermine synthase." Biochem $J$ 197(2): 315-20.

Pieper, U., Eswar, N., Braberg, H., Madhusudhan, M. S., Davis, F. P., Stuart, A. C., Mirkovic, N., Rossi, A., Marti-Renom, M. A., Fiser, A., Webb, B., Greenblatt, D., Huang, C. C., Ferrin, T. E. and Sali, A. (2004). "MODBASE, a database of annotated comparative protein structure models, and associated resources." Nucleic Acids Res 32(Database issue): D217-22.

Piotrowski, M., Janowitz, T. and Kneifel, H. (2003). "Plant C-N hydrolases and the identification of a plant $\mathrm{N}$-carbamoylputrescine 
amidohydrolase involved in polyamine biosynthesis." J Biol Chem 278(3): 1708-12.

Pires, N. and Dolan, L. (2009). "Origin and diversification of basic-helixloop-helix proteins in plants." Mol Biol Evol 27(4): 862-74.

Pyo, H., Demura, T. and Fukuda, H. (2007). "TERE; a novel cis-element responsible for a coordinated expression of genes related to programmed cell death and secondary wall formation during differentiation of tracheary elements." Plant J 51(6): 955-65.

Rahmani, F., Hummel, M., Schuurmans, J., Wiese-Klinkenberg, A., Smeekens, S. and Hanson, J. (2009). "Sucrose control of translation mediated by an upstream open reading frame-encoded peptide." Plant Physiol 150(3): 1356-67.

Raina, A., Hyvonen, T., Eloranta, T., Voutilainen, M., Samejima, K. and Yamanoha, B. (1984). "Polyamine synthesis in mammalian tissues. Isolation and characterization of spermidine synthase from bovine brain." Biochem J 219(3): 991-1000.

Rambla, J. L., Vera-Sirera, F., Blazquez, M. A., Carbonell, J. and Granell, A. (2010). "Quantitation of biogenic tetraamines in Arabidopsis thaliana." Anal Biochem 397(2): 208-11.

Raney, A., Baron, A. C., Mize, G. J., Law, G. L. and Morris, D. R. (2000). "In vitro translation of the upstream open reading frame in the mammalian mRNA encoding S-adenosylmethionine decarboxylase." $J$ Biol Chem 275(32): 24444-50.

Raven, J. A. (1993). "The evolution of vascular plants in relation to quantitative functioning of dead water conducting cells and stomata." Biological Reviews 68(3): 337-63.

Rich, A., Nordheim, A. and Wang, A. H. (1984). "The chemistry and biology of left-handed Z-DNA." Annu Rev Biochem 53: 791-846.

Roberts, D. R., Dumbroff, E. B. and Thompson, J. E. (1986). "Exogenous polyamines alter membrane fluidity in bean leaves - a basis for potential misinterpretation of their true physiological role." Planta 167(3): 395401.

Rodriguez-Garay, B., Phillips, G. C. and Kuehn, G. D. (1989). "Detection of Norspermidine and Norspermine in Medicago sativa L. (Alfalfa)." Plant Physiol 89(2): 525-29.

Samejima, K. and Yamanoha, B. (1982). "Purification of spermidine synthase from rat ventral prostate by affinity chromatography on immobilized S-adenosyl(5')-3-thiopropylamine." Arch Biochem Biophys 216(1): 213-22.

Sauter, M., Cornell, K. A., Beszteri, S. and Rzewuski, G. (2004). "Functional analysis of methylthioribose kinase genes in plants." Plant Physiol 136(4): 4061-71. 
Schwab, R., Ossowski, S., Riester, M., Warthmann, N. and Weigel, D. (2006). "Highly specific gene silencing by artificial microRNAs in Arabidopsis." Plant Cell 18(5): 1121-33.

Seiler, N. and Raul, F. (2005). "Polyamines and apoptosis." J Cell Mol Med 9(3): 623-42.

Sindhu, R. K. and Cohen, S. S. (1984). "Propylamine Transferases in Chinese Cabbage Leaves." Plant Physiol 74(3): 645-49.

Souciet, G., Menand, B., Ovesna, J., Cosset, A., Dietrich, A. and Wintz, H. (1999). "Characterization of two bifunctional Arabdopsis thaliana genes coding for mitochondrial and cytosolic forms of valyl-tRNA synthetase and threonyl-tRNA synthetase by alternative use of two in-frame AUGs." Eur $J$ Biochem 266(3): 848-54.

Stenzel, O., Teuber, M. and Drager, B. (2006). "Putrescine Nmethyltransferase in Solanum tuberosum L., a calystegine-forming plant." Planta 223(2): 200-12.

Sundaresan, V., Springer, P., Volpe, T., Haward, S., Jones, J. D., Dean, C., Ma, H. and Martienssen, R. (1995). "Patterns of gene action in plant development revealed by enhancer trap and gene trap transposable elements." Genes Dev 9(14): 1797-810.

Takahashi, Y., Berberich, T., Miyazaki, A., Seo, S., Ohashi, Y. and Kusano, T. (2003). "Spermine signalling in tobacco: activation of mitogenactivated protein kinases by spermine is mediated through mitochondrial dysfunction." Plant J 36(6): 820-9.

Teuber, M., Azemi, M. E., Namjoyan, F., Meier, A. C., Wodak, A., Brandt, W. and Drager, B. (2007). "Putrescine N-methyltransferases--a structure-function analysis." Plant Mol Biol 63(6): 787-801.

Thomas, T. and Thomas, T. J. (2001). "Polyamines in cell growth and cell death: molecular mechanisms and therapeutic applications." Cell Mol Life Sci 58(2): 244-58.

Thomas, T. and Thomas, T. J. (2003). "Polyamine metabolism and cancer." J Cell Mol Med 7(2): 113-26.

Thompson, J. D., Gibson, T. J., Plewniak, F., Jeanmougin, F. and Higgins, D. G. (1997). "The CLUSTAL_X windows interface: flexible strategies for multiple sequence alignment aided by quality analysis tools." Nucleic Acids Res 25(24): 4876-82.

Tiburcio, A. F., Teresa, A., Antoni, B. and Carles, M. (1997). "Polyamine metabolism and its regulation." Physiologia Plantarum 100(3): 664-74.

Toledo-Ortiz, G., Huq, E. and Quail, P. H. (2003). "The Arabidopsis basic/helix-loop-helix transcription factor family." Plant Cell 15(8): 1749-70.

Torrigiani, P., Maria Maddalena, A., Gabriella, P., Barbara, M., Donatella, S.-F. and Nello, B. (1987). "Free and conjugated polyamines during 
de novo floral and vegetative bud formation in thin cell layers of tobacco." Physiologia Plantarum 70(3): 453-60.

Tsukaya, H., Naito, S., Redei, G. P. and Komeda, Y. (1993). "A new class of mutations in Arabidopsis thaliana, acaulis1, affecting the development of both inflorescences and leaves." Development 118(3): 751-64.

Turner, S., Gallois, P. and Brown, D. (2007). "Tracheary element differentiation." Annu Rev Plant Biol 58: 407-33.

van Zanten, M., Snoek, L. B., Proveniers, M. C. and Peeters, A. J. (2009). "The many functions of ERECTA." Trends Plant Sci.

Vila-Sanjurjo, A., Schuwirth, B. S., Hau, C. W. and Cate, J. H. (2004). "Structural basis for the control of translation initiation during stress." Nat Struct Mol Biol 11(11): 1054-9.

Walton, N. J., Peerless, A. C. J., Robins, R. J., Rhodes, M. J. C., Boswell, H. D. and Robins, D. J. (1994). "Purification and properties of putrescine N-methyltransferase from transformed roots of Datura stramonium L." Planta 193(1): 9-15.

Wallace, H. M., Fraser, A. V. and Hughes, A. (2003). "A perspective of polyamine metabolism." Biochem J 376(Pt 1): 1-14.

Wang, L. and Wessler, S. R. (2001). "Role of mRNA secondary structure in translational repression of the maize transcriptional activator $\operatorname{Lc}(1,2) . "$ Plant Physiol 125(3): 1380-7.

Wang, X., Ikeguchi, Y., McCloskey, D. E., Nelson, P. and Pegg, A. E. (2004). "Spermine synthesis is required for normal viability, growth, and fertility in the mouse." J Biol Chem 279(49): 51370-5.

Weiger, T. M., Langer, T. and Hermann, A. (1998). "External action of di- and polyamines on maxi calcium-activated potassium channels: an electrophysiological and molecular modeling study." Biophys $J$ 74(2 Pt 1): 72230 .

Wiese, A., Elzinga, N., Wobbes, B. and Smeekens, S. (2004). "A conserved upstream open reading frame mediates sucrose-induced repression of translation." Plant Cell 16(7): 1717-29.

Williams, K. (1997). "Interactions of polyamines with ion channels." Biochem J 325 ( Pt 2): 289-97.

Wu, H., Min, J., Ikeguchi, Y., Zeng, H., Dong, A., Loppnau, P., Pegg, A. E. and Plotnikov, A. N. (2007). "Structure and mechanism of spermidine synthases." Biochemistry 46(28): 8331-9.

Wu, H., Min, J., Zeng, H., McCloskey, D. E., Ikeguchi, Y., Loppnau, P., Michael, A. J., Pegg, A. E. and Plotnikov, A. N. (2008). "Crystal structure of human spermine synthase: implications of substrate binding and catalytic mechanism." J Biol Chem 283(23): 16135-46. 
Xia, X., Hou, F., Li, J. and Nie, H. (2005). "Ribosomal protein L10a, a bridge between trichosanthin and the ribosome." Biochem Biophys Res Commun 336(1): 281-6.

Yamaguchi, K., Takahashi, Y., Berberich, T., Imai, A., Miyazaki, A., Takahashi, T., Michael, A. and Kusano, T. (2006). "The polyamine spermine protects against high salt stress in Arabidopsis thaliana." FEBS Lett 580(30): 6783-8.

Yamaguchi, K., Takahashi, Y., Berberich, T., Imai, A., Takahashi, T., Michael, A. J. and Kusano, T. (2007). "A protective role for the polyamine spermine against drought stress in Arabidopsis." Biochem Biophys Res Commun 352(2): 486-90.

Yamaguchi, M., Goue, N., Igarashi, H., Ohtani, M., Nakano, Y., Mortimer, J. C., Nishikubo, N., Kubo, M., Katayama, Y., Kakegawa, K., Dupree, P. and Demura, T. (2010). "VASCULAR-RELATED NACDOMAIN6 and VASCULAR-RELATED NAC-DOMAIN7 effectively induce transdifferentiation into xylem vessel elements under control of an induction system." Plant Physiol 153(3): 906-14.

Yamakawa, H., Kamada, H., Satoh, M. and Ohashi, Y. (1998). "Spermine is a salicylate-independent endogenous inducer for both tobacco acidic pathogenesis-related proteins and resistance against tobacco mosaic virus infection." Plant Physiol 118(4): 1213-22.

Yamanoha, B. and Cohen, S. S. (1985). "S-Adenosylmethionine Decarboxylase and Spermidine Synthase from Chinese Cabbage." Plant Physiol 78(4): 784-90.

Yoon, S. O., Lee, Y. S., Lee, S. H. and Cho, Y. D. (2000). "Polyamine synthesis in plants: isolation and characterization of spermidine synthase from soybean (Glycine max) axes." Biochim Biophys Acta 1475(1): 17-26. 

ANEXOS 

Los anexos incluidos en el disco compacto que acompaña esta Tesis son los siguientes archivos:

- Anexo oligos.doc $\rightarrow$ Relación de oligonucleótidos empleados en la secuenciación de diversos genes, durante el cartografiado de ajxl-4 y ajx2-31.

- Anexo resumen resultados microarrays.xlsx $\rightarrow$ Listado de genes diferencialmente expresados de las micromatrices de esta Tesis.

- Anexo Secuencias Figura 20, 21, 33, 39, 41 y 43.txt $\rightarrow$ Relación de secuencias empleadas en la figuras 20,21,33, 39, 41 y 33 de esta Tesis, respectivamente.

- Anexo ACAULIS5 controls Arabidopsis xylem specification through the prevention of premature cell death, anexo Evolutionary Diversification in Polyamine Biosynthesis, anexo Quantitation of biogenic tetraamines in Arabidopsis thaliana $y$ anexo Role of polyamines in plant vascular development.pdf $\rightarrow$ Relación de las cuatro publicaciones en la que participa el autor de la Tesis y realizados durante la misma. 


